\title{
Necesidades de tecnología agropecuaria en el Centro Poblado de Accaso - Puno Perú
}

\author{
Needs for agriculture and livestock technology in the Accaso village in Puno Peru
}

\author{
${ }^{1}$ Fermin Chaiña Chura \\ ${ }^{2}$ Juan Inquilla Mamani
}

\begin{abstract}
La identificación de las necesidades de tecnología agropecuaria requiere de mayor atención institucional por parte del Ministerio de Agricultura y sus dependencias en la región, asegurando la participación de los pequeños productores a través de la coordinación interinstitucional como política del sector agrario. El objetivo de esta investigación fue analizar y comprender los requerimientos de innovaciones tecnológicas en agricultura y ganadería expresadas por los jefes de familia del Centro Poblado de Accaso, Pilcuyo, El Collao (Puno - Perú). Se utilizó la metodología cuantitativa a través de la técnica de la encuesta y como instrumento el cuestionario. Los resultados de este estudio muestra que los factores sociales sexo, edad del jefe de familia y composición familiar; así como las variables productivas tamaño de propiedad de la tierra e ingreso económico no tiene relación con las necesidades de tecnología. El nivel educativo es la variable que tiene relación con los requerimientos de innovaciones tecnológicas en el componente pecuario.
\end{abstract}

RESUMEN

Palabras clave: Agricultura, demanda tecnológica, ganadería, unidad familiar.

\section{ABSTRACT}

The identification of the needs for agriculture and livestock technology requires more attention by the institutional sector of the Ministry of Agriculture and its competent agencies in the region, which leaves out the participation of small producers due to the lack of inter-institutional coordination as a policy of the agricultural sector. The objective was to analyze and understand the requirements of technological innovations in agriculture and livestock expressed by the family heads of the Populated Center of Accaso, Pilcuyo, El Collao (Puno - Peru). The quantitative methodology was used through the survey technique and the questionnaire as an instrument. The results of this study show that social factors such as sex, family head's age and family composition; as well as productive variables such as land property size and economic income have no relation with the needs for technology. The educational level is the variable that is related to the requirements of technological innovations in the livestock component.

Keywords: Agriculture, technological demand, livestock, family unit. 


\section{INTRODUCCIÓN}

La sociedad contemporánea del sistema mundo trajo consigo el desarrollo tecnológico a nivel global. El cambio técnico cumple un papel importante en la forma en que ha evolucionado al introducir tecnologías (Medina y Posso, 2018) en la producción de alimentos en función al crecimiento de la población por lo que se atribuye directa o indirectamente a la actividad humana (Ahumada, Velásquez y Ahumada, 2018). Se observa que en algunas regiones el deterioro de los mantos acuíferos ha comenzado a afectar la producción (García, Guzmán y Fortis, 2006).

En la actualidad, la población mundial depende de la agricultura. Asimismo, se puede afirmar que el poder alimentario está en manos de aquellas naciones capaces de cultivar las plantas y criar animales en diferentes condiciones ecológicas. Es sabido que los países desarrollados realizan la mayor parte de la investigación agropecuaria, sin embargo, es necesario identificar en qué grado se practica en los países de América Latina y El Caribe (Arenas, Dovalina y Licea, 2004).

Referente a la generación de conocimientos tecnológicos en el agro; Damián, Ramírez, Parra, Paredes, Gil, López y Cruz (2007) consideran que la generación y transferencia de tecnología agrícola son esenciales para acrecentar el rendimiento del trabajo y la tierra. La investigación agrícola incluye cuatro fases: experimentación, validación, difusión y adopción.

Entonces, se evidencia que la situación problemática en la identificación de las necesidades de tecnología agropecuaria no es tomada en cuenta por estudios agrarios y en muchos casos por el sector institucional. Esto debido a que antes de la experimentación se desarrolla una fase de aprehensión de las necesidades de tecnología agropecuaria, a partir de pequeños productores agropecuarios.

El cambio del enfoque de transferencia de tecnología al sistema de capacitación y visitas fue una de las principales transformaciones. La nueva concepción está enfocada a la interacción entre agentes de extensión y grupos de productores (Guevara, 2017). La generación de tecnología en la propia comunidad es un factor importante en la transferencia y adopción del conocimiento; la estrategia incluye una acción participativa de todos los miembros de la familia (Sangerman, Rangel, Villaseñor, Navarro, Larqué, De la Olán y Torres, 2012).

Las economías familiares rurales del altiplano peruano no son ajenas a estos procesos de cambio global porque el problema de la identificación de las necesidades tecnológicas, como etapa inicial de procesos de investigación, no ha sido considerado por el sector institucional. Siendo esta fase muy importante en acciones de generación de tecnologías agropecuarias, debido a que todo proceso de innovación tecnológica, para el desarrollo del medio rural, debe iniciar con el conocimiento previo de las necesidades de los agricultores para el mejoramiento de su sistema de producción familiar. Insertada, hoy en día, en los procesos dinámicos de interrelación con lo urbano y lo global (Sánchez, 2017).

Los procesos de intervención del desarrollo rural dejan de lado la fase de identificación de la necesidad tecnológica porque no dinamizan la participación de los pequeños productores agropecuarios, quienes son los verdaderos interesados y conocedores de sus necesidades tecnológicas más urgentes. Se observó la ausencia de la coordinación del sector institucional y, en muchos casos, esto trajo el fracaso de los proyectos de desarrollo rural.

El propósito de esta investigación fue analizar y comprender los requerimientos de innovaciones tecnológicas expresados por los pequeños productores, para el fortalecimiento de sus capacidades en la gestión de su economía familiar. La hipótesis fue que los factores socioproductivos de la unidad familiar influyen de manera diferenciada en la identificación de las necesidades de tecnología agropecuaria.

\section{MATERIAL Y MÉTODOS}

El núcleo de investigación es el Centro Poblado de Accaso, ubicado en la zona del lago del distrito de Pilcuyo, provincia de El Collao de la Región Puno. Dedicado a actividades agropecuarias, con una temperatura media anual que oscila entre $2{ }^{\circ} \mathrm{C}$ a $15{ }^{\circ} \mathrm{C}$, con altitud de $3.812 \mathrm{msnm}$, con precipitación pluvial promedio anual de $853 \mathrm{~mm}$. El ámbito es plano con ligera inclinación hacia el Este, donde se encuentra el lago Titicaca. Sus pobladores desarrollan principalmente la agricultura y ganadería familiar. El estudio se desarrolló durante los años 2015-2016.

El tipo de investigación por su naturaleza fue aplicada, esto debido a que está relacionada con las prácticas agropecuarias de la unidad familiar. El nivel de investigación fue descriptivoexplicativo porque especifica propiedades, características y rasgos importantes (Hernández, Fernández y Baptista, 2010) de la necesidad de tecnología agropecuaria; por tanto, el método fue cuantitativo. Se desarrolló dentro de la dimensión social porque comprende y expresa los requerimientos de tecnología agropecuaria de los 
productores rurales. Se consideró como unidad de análisis al jefe de familia, y la unidad de observación fue la necesidad de tecnología agropecuaria.

La población estuvo constituida por los jefes de familia (dedicada a la actividad agropecuaria) del ámbito de estudio. Se determinó una muestra no probabilística de un total de 42 jefes de familia; en base a los siguientes criterios: a) ser productor agropecuario, b) con economía de subsistencia al producir para el consumo familiar y para el mercado, c) voluntad para participar y d) que brinde accesibilidad a la información requerida.

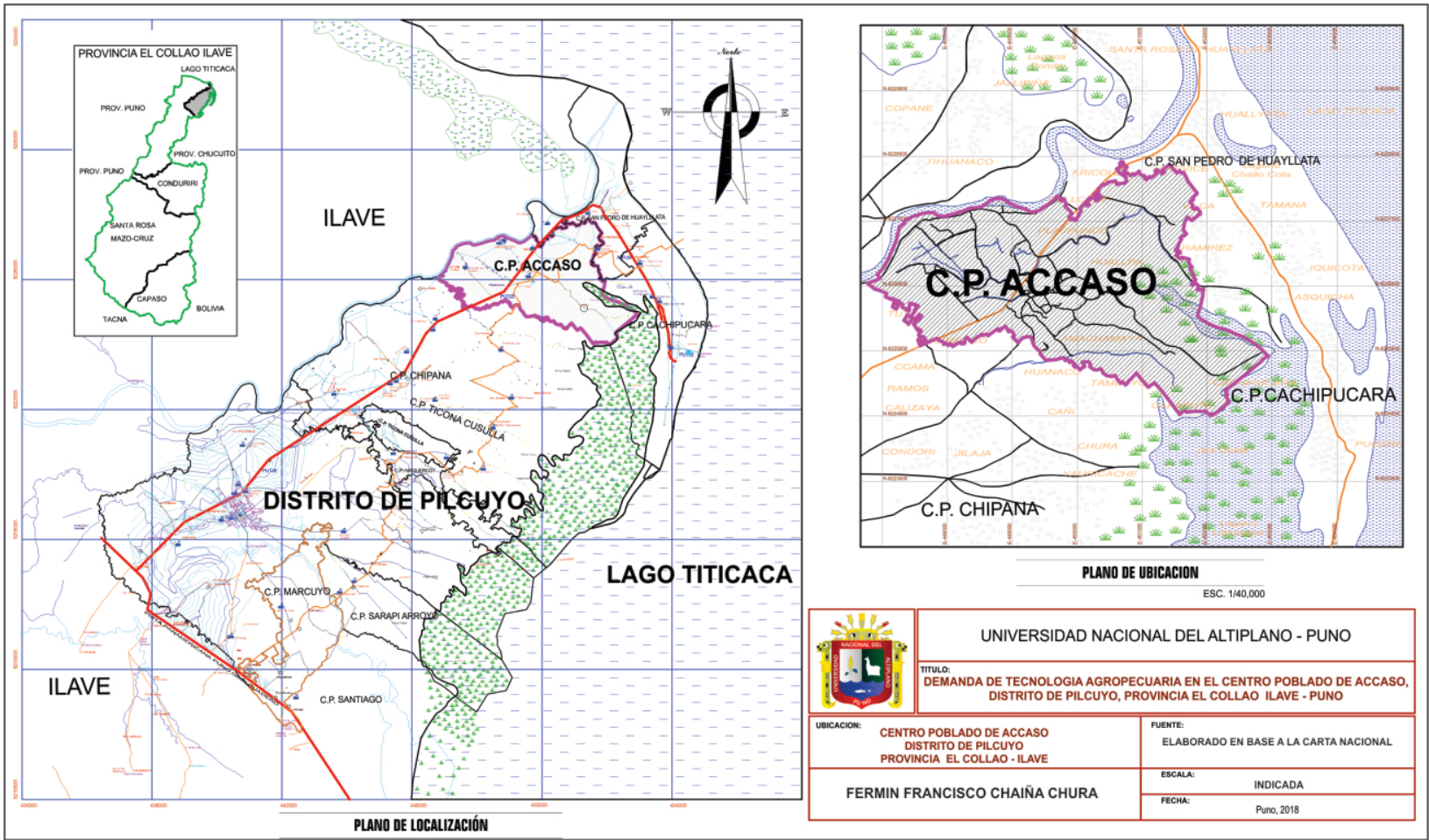

Figura 1. Ubicación del Centro Poblado de Accaso del distrito de Pilcuyo.

En el marco de la metodología cuantitativa se utilizó la técnica de la encuesta y como instrumento el cuestionario, a fin de conocer las necesidades tecnológicas agropecuarias. Se empleó la observación y la revisión de documentos de segunda fuente. Para la verificación de las hipótesis se utilizó la prueba estadística de chi-cuadrado $\left(\mathrm{X}^{2}\right)$ (Amaya, 2017).

\section{RESULTADOS Y DISCUSIÓN}

En esta parte, se expone los resultados de la influencia de los factores socio-productivos en la identificación de las necesidades de tecnología agropecuaria.
Los factores socio-productivos, en términos medios, presentan las siguientes características: son unidades familiares con 4 integrantes, la edad del jefe de familia es de 52 años, su nivel educativo es de 7 años de escolaridad, se dedican a la agricultura y la ganadería familiar, el ingreso económico es de S/ 156.79 al mes y la tenencia del recurso tierra por unidad familiar es de 1 hectárea.

1. Las variables edady sexo son independientes de la necesidad de tecnología agropecuaria familiar, que no tienen influencia con la variable en estudio. Los productores rurales, sean hombres o mujeres mayores de edad, pueden requerir o no información y capacitación en su unidad de producción familiar. 
Tabla 1. Características de los factores socio-productivos de 42 familias del Centro Poblado de Accaso

\begin{tabular}{|lccccc|}
$\begin{array}{l}\text { Medidas } \\
\text { estadísticas* }\end{array}$ & $\begin{array}{c}\text { Tamaño de } \\
\text { la familia }\end{array}$ & Edad & $\begin{array}{c}\text { Nivel } \\
\text { educativo }\end{array}$ & $\begin{array}{c}\text { Ingreso } \\
\text { mensual }\end{array}$ & $\begin{array}{c}\text { Tenencia de } \\
\text { tierra (ha) }\end{array}$ \\
\hline Media & 3.1 & 52.4 & 7.1 & 156.79 & 0.97 \\
Mediana & 3.0 & 55.0 & 6.0 & 85.00 & 0.76 \\
Moda & 2.0 & 52.0 & 13.0 & 0 & 1.00 \\
Desviación estándar & 1.6 & 14.4 & 4.8 & 222.33 & 0.93 \\
Mínimo & 1 & 21 & 1 & 0 & 0.03 \\
Máximo & 7 & 75 & 17 & 1000.00 & 4.50 \\
$\mathrm{X}^{2} \mathrm{c}$ nt** agrícola & 0.14 & 3.32 & 3.17 & 5.57 & 2.27 \\
$\mathrm{X}^{2} \mathrm{c}$ nt pecuaria & 1.19 & 5.96 & 8.69 & 3.11 & 1.9 \\
$\mathrm{X}^{2} \mathrm{t}, \quad \alpha=0.05 \%$ & 5.99 & 5.99 & 7.81 & 7.81 & 5.99 \\
\end{tabular}

Fuente: Elaborado en base a la información del cuestionario.

*: La variable sexo contiene: 22 hombres y 20 mujeres.

**: Necesidades de tecnología agrícola y pecuaria.

2. La variable tamaño de familia no tiene influencia en las necesidades tecnológicas. Los productores rurales, con una composición familiar diferenciada, pueden requerir o no innovaciones en la producción agropecuaria.

3. La variable nivel educativo no tiene influencia en la necesidad de tecnología para la actividad agrícola; pero, esta variable no es independiente de los requerimientos de tecnología para el desarrollo de la ganadería familiar. El nivel educativo tiene influencia en la necesidad de tecnología para desarrollar la actividad pecuaria. Los productores rurales con mayor nivel educativo requieren información, capacitación y nuevos conocimientos que refuercen las prácticas que desarrollan en la crianza; y con estas capacidades, fortalecer su eficiencia en la chacra familiar (Barreto et al., 2018).

4. La variable tamaño del predio es independiente de la necesidad de tecnología agropecuaria. El tamaño de la propiedad de la tierra no tiene influencia en las necesidades de tecnología. Los productores con diferente dimensión de predio pueden requerir o no información y capacitación para la producción agrícola y pecuaria.

5. La variable ingreso económico mensual no tiene influencia en los requerimientos de innovación tecnológica agropecuaria porque los productores rurales con diferentes niveles de ingreso pueden requerir o no información, capacitación y nuevos conocimientos en cultivos agrícolas y crianzas familiares.

En consecuencia, las variables sociales y productivas no tienen influencia en la necesidad de tecnología agropecuaria, a excepción del nivel educativo que sí tiene influencia en los requerimientos de tecnología en la ganadería familiar.

Los resultados permiten evidenciar que los pequeños productores requieren socialización de innovaciones tecnológicas de manera diversificada; sin embargo, no se encontró relación entre las variables en estudio y la necesidad de tecnología agropecuaria. Estas necesidades fueron analizadas cuantitativamente, donde se evidenció que las variables edad, sexo, el tamaño de la familia, tamaño del predio e ingreso mensual no tienen influencia en las necesidades de tecnologías en cultivos y crianzas; a excepción de la variable nivel educativo que sí tiene relación con la necesidad de tecnología agropecuaria, principalmente para el desarrollo de la ganadería familiar.

Entonces, se confirma que las características de las variables sociales y productivas tienen influencia diferenciada en la necesidad de tecnología agropecuaria en el Centro Poblado de Accaso.

De modo que, la discusión se da en tres niveles; primero se presentan las características de las necesidades de tecnología agropecuaria; luego la unidad familiar, tecnología y desarrollo; y finalmente sobre los sectores sociales y desarrollo tecnológico.

\section{Características de las necesidades de tecnología agropecuaria}

Actualmente, el mundo está acuciado por problemas demográficos, de provisión de 
alimentos y energía, de degradación ambiental y cambio climático, de pobreza y marginalidad, entre otros. Las predicciones sobre el futuro son inciertas por lo limitado de nuestro conocimiento (Andrade, 2011). La situación de escases de alimentos puede ser viabilizado por el desarrollo tecnológico en el agro y una educación no formal para productores rurales.

Al respecto, Martínez, Mavarez, Rojas y Carvallo (2008) consideran que la mayor práctica de responsabilidad social está referida a la transferencia de tecnología a través de asesorías a las comunidades en diversos ámbitos; a fin de establecer alianzas duraderas con el entorno, utilizar los medios de comunicación como verdaderos agentes de transformación social, realizar una sistematización de las acciones de responsabilidad social, entre otros.

La agricultura es el motor del crecimiento y desarrollo, y el uso de la tecnología es una variable útil para explicar el crecimiento o estancamiento de la agricultura en países desarrollados o en desarrollo, razón por la cual la productividad es un factor determinante para la creciente demanda de alimentos para la población mundial (Osorio, López, Gil, Ramírez, Gutiérrez, Crespo y Montero, 2012).

Por ejemplo, en Argentina, la generación de tecnología agropecuaria era responsabilidad casi enteramente del Instituto de Investigaciones Agropecuarias (INIA). Al igual que en los otros países de la región, se pretendía aumentar la oferta de alimentos básicos (consideraba insuficiente) mediante la generación e incorporación a la producción de variedades de alto rendimiento potencial, con un paquete tecnológico que permitiera expresar sus atributos de productividad (Portilla, 2000).

Hasta aquí se evidencia que, predominantemente el sector institucional descuida la fase más importante del proceso de generación de tecnología, que es la identificación de las necesidades tecnológicas, los requerimientos y urgencias del pequeño productor a partir de su pensamiento.

De modo que, las necesidades de tecnología agropecuaria presentan características importantes desde la expresión de los productores agrarios, constituyéndose como base para procesos de investigación o generación de tecnologías; y consecuentemente, para la divulgación, socialización de tecnologías y los procesos de adopción o adaptación en el sistema de producción familiar.
La identificación de las necesidades de tecnología agropecuaria considera como el actor principal al pequeño productor. Este es el verdadero interesado como conocedor de sus necesidades tecnológicas en el funcionamiento de su unidad familiar y, como tal, expresa la ayuda que requiere del sector institucional.

La expresión de estos problemas, a partir de los productores rurales, contribuirá al éxito de las acciones de extensión y capacitación que desarrolle el sector institucional. De lo contrario, si estas acciones son desarrolladas a partir de la mente de los profesionales y técnicos del sector institucional como el Ministerio de Agricultura, la municipalidad, entre otros, puede resultar ajeno a los intereses de los agricultores y conducir al fracaso de cualquier proceso de intervención. Las perspectivas de intervención que se aspiran no tendrían éxito; sus efectos e impactos generarían mayores problemas y nuestra ayuda resultaría siendo un factor que entorpecería el desarrollo de estas economías familiares.

Las acciones del sector institucional, que no consideren a los interesados, se enmarcan dentro de una concepción vertical e impositiva de los procesos de intervención porque no toman en cuenta al actor principal del proceso productivo. Por ello, se considera necesario trabajar dentro de una concepción horizontal de diálogo entre los productores y los equipos técnicos del sector institucional, para emprender acciones duraderas y que realmente contribuyan al incremento de la producción agropecuaria como elemento de sensibilidad para el desarrollo de capacidades personales y sociales de los pequeños productores rurales.

Por consiguiente, la clave del éxito de la función contemporánea del sector institucional, referida a la generación de tecnologías y socialización de nuevos conocimientos tecnológicos, es considerar al poblador rural (pequeño productor) a fin de que exprese sus necesidades de tecnología, como elemento previo, básico y fundamental en este quehacer. Solo así se logrará las perspectivas de desarrollo sostenible, el desarrollo de las capacidades humanas y el desarrollo humano tendiente al bienestar social generalizado.

Las necesidades de tecnología agropecuaria en el ámbito del Centro Poblado de Accaso, manifestadas por la población rural en temas que contribuyan a las principales actividades de la agricultura y la pequeña ganadería familiar, tienen la siguiente característica: 
Tabla 2. Necesidades de tecnología para la agricultura y ganadería familiar

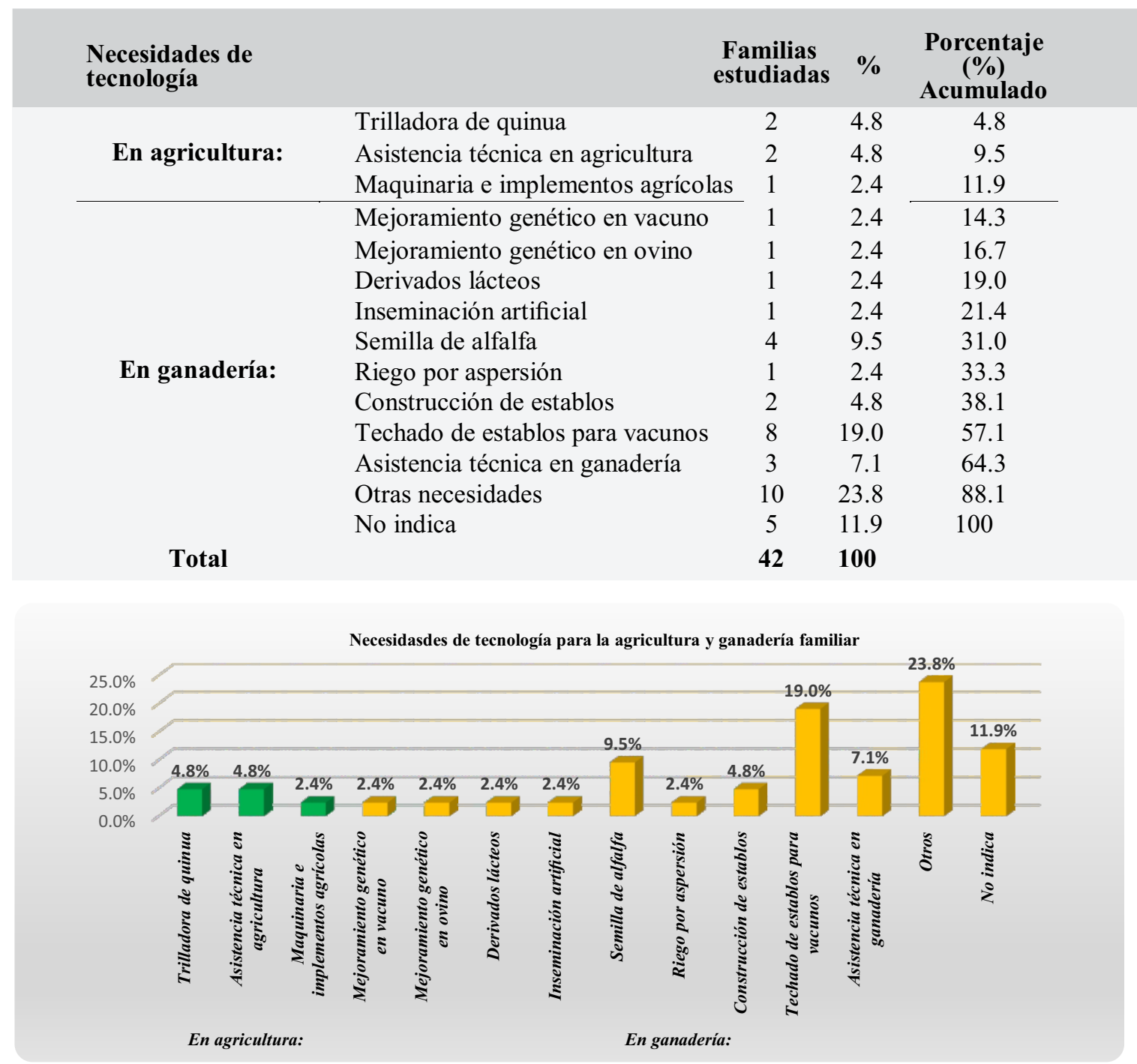

Figura 2. Necesidades de tecnología para agricultura y ganadería familiar.

Los requerimientos de tecnología para el fortalecimiento de la agricultura familiar están constituidos por las siguientes necesidades:

a) Asistencia técnica en agricultura familiar, referido al proceso productivo de los principales cultivos como la papa. Desde la preparación del suelo, variedades vegetales, densidad de siembra, abonamiento, laboreo, control de plagas y enfermedades, cosecha y poscosecha. Dicho tubérculo es base de muchas preparaciones en la mesa, además que sus derivados crean oportunidades de negocio y desarrollo para las zonas donde se cultiva (Buitrago y Peñuela, 2018).

b) Maquinarias agrícolas e implementos, importantes para diferentes procesos del componente agrícola.

c) Trilladora de quinua, entre otros.

Para atender estas necesidades se requiere condiciones económicas favorables, pese a enfrentarse a un problema de vigencia de la tecnología. Este requerimiento tecnológico, expresado en esta aspiración de maquinaria, en otros contextos, es obsoleta. Esto debido a que, en la actualidad, ya existe tecnología de ủltima generación para actividades agrícolas, claro que para otras realidades.

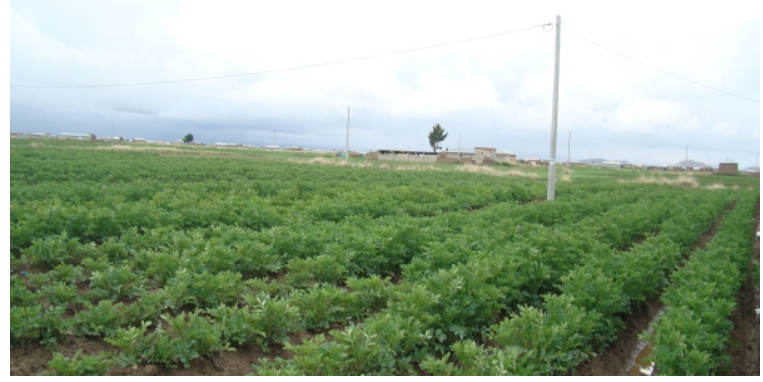

Figura 3. Agricultura familiar C.P. Accaso. 
Urcola (2013) considera que la desinversión en maquinaria agrícola parece ser el límite que lleva al productor rural, gradualmente, a pegar el salto tecnológico en equipos y empezar a ofrecer servicios para solventar la inversión o a abandonar sus máquinas viejas y convertirse en administradores de sus fincas, dejando paulatinamente el trabajo directo en las principales labores agrícolas; presenta el siguiente testimonio de un agricultor argentino:

\begin{abstract}
"Antes se veía como que tenías que tener un arado, un tractor. No te podías imaginar la figura del productor agropecuario sin un tractor y hoy hay mucha gente que trabaja su propia explotación y no tiene absolutamente nada. Hay gente de 100 ó 150 hectáreas que no tiene nada y contrata todos los servicios. Esto se ha dado también porque hay gran oferta de contratistas, lo que hizo que el precio por las labores por hectáreas disminuyera. Así, se pueden trabajar 100 o 150 hectáreas con maquinaria de primera generación sin necesidad de tenerla. Si yo quisiera tener esas maquinarias me tendría que dedicar a prestar servicios, no me podría dar el lujo de tenerlas para mí porque no las pagaría nunca". (Productor, cuasi-rentista - 32 años)
\end{abstract}

Entonces, en la agricultura tradicional se laboreaba directamente con tractor de propiedad del productor. En la actualidad, se contrata maquinaria de última generación para la siembra (sembradora directa), control de plagas y enfermedades (equipos de pulverización), y cosecha (cosechadoras modernas). Estas maquinarias, para América Latina, desarrollan las actividades agrícolas en menos tiempo. Antes trabajaban durante todo el periodo de siembras; ahora realizan, en pocos días, todo el proceso de instalación, entre otros.

En la realidad peruana, específicamente las comunidades rurales circundantes al lago Titicaca de la Región Puno, esta tecnología de última generación no es conocida; aspiran tener maquinaria agrícola constituida por tractor con arado de disco y rastra. Como se expuso, el deseo de tener este tipo de maquinaria en otras realidades está en declinación.

Los países andinos, excepto Brasil y México, son importadores de maquinaria agrícola, principalmente para los grandes productores. El crecimiento de la población en la región condiciona que exista mayor demanda de alimentos, reduciéndose a la vez las tierras productivas. Lo cual hace imprescindible la mejora de eficiencia en la producción para abastecer de los productos tradicionales. Sumado a esto, resalta el problema de la migración campesina que afecta a la población urbana y rural, pues, las tierras dejan de ser productivas por falta de mano de obra (Tapia y Tapia, 2017).

Otra necesidad de tecnología, en el componente agricultura, es el requerimiento de asistencia técnica en agricultura familiar. Dicha necesidad es un tema de educación no formal, con vía a la socialización de conocimientos de innovación tecnológica en cultivos de la región, para contribuir al mejoramiento de la agricultura de subsistencia, destinado al consumo familiar y excedente para el mercado. Esta necesidad es atendible, debido a que para la intervención se requiere condiciones políticas y económicas favorables, con personal capacitado y con experiencia para esta actividad.

Además, la necesidad de tecnología para el fortalecimiento de la ganadería familiar, es un componente importante de los sistemas de producción rural. Los requerimientos de tecnología en el rubro pecuario están constituidos por: mejoramiento genético en ganado vacuno y ovino, derivados lácteos, inseminación artificial, semilla de alfalfa, riego por aspersión para la implementación de la vaca productora de leche, construcción de establos, techado de establos ya construidos para ganado vacuno y asistencia técnica en ganadería familiar (referidos a sanidad, alimentación, reproducción, manejo, procesamientos, entre otros).

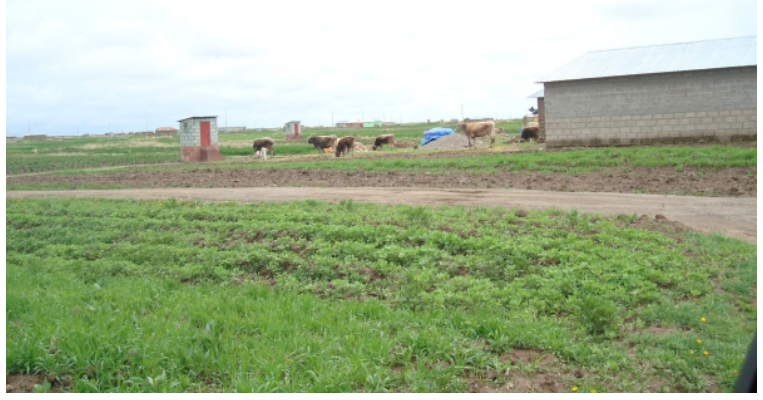

Figura 4. Ganadería familiar C.P.Accaso.

Consiguientemente, las necesidades de tecnología agropecuaria tienen dos componentes principales: agrícola y pecuario. Ambos son requerimientos viables; iniciando sobre esta base, es importante la intervención con procesos de investigación o generación de tecnología en rubros que sean necesarios con participación de los interesados, los productores. Seguido de acciones de educación no formal, con fines de fortalecer los conocimientos en gestión de los sistemas de producción familiar. Esto, siguiendo el propósito de mejorar la eficiencia en la producción, en el manejo racional de su predio, en la diversificación de sus actividades productivas, valor agregado en el procesamiento de sus productos agropecuarios, así como su organización para la comercialización de su producción y adquisición de insumos, entre otros. 
Existen antecedentes de capacitación rural. Por ejemplo, un informe de la Región Cusco, Perú, expone que las experiencias de capacitación campesina diseñada en función del interés de los productores y acorde con su contexto sociocultural producen resultados positivos. Este caso demuestra los cambios alcanzados en los medios de vida de promotores campesinos, denominados "kamayoq", en el transcurso de diez años en los andes cusqueños. Lo que, a su vez, demuestra que sí es posible transformar la economía campesina a partir del mejoramiento de capacidades (Solis, 2016).

Los fundamentos de dicho programa de capacitación fueron: la generación y difusión de tecnologías apropiadas, la preferencia por la producción en pequeña escala y por los productores de recursos escasos, el alto valor otorgado al conocimiento nativo y la cultura local, la promoción del uso racional de los recursos naturales y la conservación del medio ambiente (De la Torre, como se cita en Solis, 2016).

Se evidencia entonces, que las acciones de capacitación constituyen una de las modalidades de la educación no formal. Esto es ideal que se ubique en el marco de una concepción horizontal y dialógica entre los actores; que en la práctica se basa en la comunicación de ida y vuelta, sobre la problematización desde la fase inicial de identificación de las necesidades tecnológicas, seguido por el proceso de generación de tecnologías, socialización hacia los agricultores y la adopción o aplicación parcial en el sistema de producción familiar.

Al respecto de la adopción de tecnologías se tiene que, la decisión de los receptores de elegir, interpretar y adoptar o no una tecnología científica de producción es un proceso mental compuesto de varias fases. El objeto de la comunicación extensionista es proporcionar un conocimiento firme sobre el que pueda basarse la acción para convencer al agricultor de decidirse a ensayar la nueva tecnología, dar la información necesaria para su realización efectiva y proporcionar los datos que necesitará para apreciar los resultados de esa decisión (Rogers, 1966; Fliegel, 1987).

\section{Unidad familiar, tecnología y desarrollo}

Los integrantes de la unidad familiar son los actores principales del contexto rural circundante al lago Titicaca; en donde la agricultura y la ganadería constituyen formas de producción predominantes en estos sistemas rurales en base a la utilización de recursos propios, la tierra para cultivos andinos como la papa, quinua, entre otros. En el rubro pecuario, la crianza está constituida por animales mayores como vacunos y ovinos principalmente; y en menor proporción por camélidos sudamericanos como la alpaca. Además, con mano de obra familiar y extra familiar, instrumentos de laboreo tradicionales como el uso del tractor agrícola para preparación de suelos y algunas tareas de siembra, entre otras. Esta particularidad tecnológica se encuentra comprendida en el contexto global del sistema mundo.

La tecnología ha sido siempre un componente central de la vida humana y ha acompañado la evolución de las distintas culturas y civilizaciones. Pero durante los últimos dos siglos, en particular desde la revolución industrial, su desarrollo ha sido sorprendente. E1 sector rural no ha estado ajeno a este proceso (Cáceres, 2015).

El impacto de la tecnología sobre las sociedades rurales permite reflexionar acerca de los procesos de transferencia tecnológica; la tecnología es como el material genético: lleva implícito el código de la sociedad que la generó y tiende a reproducir las condiciones de la sociedad de origen. Por lo tanto, cuando se desarrolla la transferencia de tecnología, se produce el impacto de un tipo de conducta social sobre otra. Ni los desarrollos tecnológicos ni las elecciones tecnológicas son totalmente independientes de supuestos sociales y políticos. No es la tecnología sino la política la que define los criterios, las prioridades y las posiciones sociales (Cáceres, 2015).

A partir de las experiencias en extensión rural, los resultados de la generación de tecnologías agropecuarias en centros de investigación como el Instituto Nacional de Investigación Agropecuaria (INIA) por ejemplo, es aplicable a nivel espacial en un radio de 50 kilómetros aproximadamente por las características geo-sociales y ambientales similares. Frente a esta situación resulta más viable desarrollar investigación tecnológica en el predio del agricultor, con su participación activa en todo el proceso de intervención, desde la identificación de la necesidad tecnológica, la generación de tecnologías y la socialización hasta la adopción o adaptación a su sistema de producción.

La pequeña agricultura en el ámbito circundante al lago Titicaca es un componente fundamental del sistema de producción familiar, constituye la actividad principal de los productores rurales de este contexto alto andino. Tiene como objetivo la producción para el consumo familiar y los excedentes para el mercado local y regional desarrollado en ferias semanales o "qhatos" en diferentes distritos de la región Puno. Entonces, se 
desenvuelven en economías de subsistencia, que se caracterizan por haber superado el equilibrio trabajo-consumo, inherente a economías campesinas propias de otras realidades y de otras épocas.

La agricultura y la ganadería familiar son componentes estratégicos de las economías tradicionales para garantizar la producción y reproducción de su unidad familiar. Que, en este contexto global, se tiende a modernizar por la introducción de la maquinaria. El desarrollo de estas actividades se caracteriza por la utilización de tecnologías cuyos componentes son: recursos propios (tierra), variedades vegetales propios (semillas), instrumentos de producción tradicionales (herramientas), abono natural (estiércol de ovino y vacuno procedente de la ganadería familiar), uso racional del espacio agrícola (sistemas de rotación), cosecha y poscosecha (transformaciones). Los pequeños agricultores han creado $\mathrm{y} / \mathrm{o}$ heredado sistemas complejos de agricultura que, durante siglos, los han ayudado a satisfacer sus necesidades de subsistencia, incluso bajo condiciones ambientales adversas en suelos marginales, en áreas secas o de fácil inundación (Chávez y Llerena, 2015).

En consecuencia, estas economías familiares han perdurado en el tiempo durante siglos. Estos sistemas necesitan una innovación tecnológica muy sutil que se genere en el interior de las unidades familiares y en las parcelas agrícolas de los productores. Las tecnologías externas no validadas podrían provocar cambios bruscos, que en determinado momento generaría problemas sociales, económicos y ambientales.

Al haber transitado en el contexto de esta investigación, el conocimiento de la situación permite ir hacia la mejora de la producción con la innovación tecnológica, con la participación de técnicos, profesionales y científicos que logren contribuir al desarrollo de las capacidades personales y sociales, así como al mejoramiento de las condiciones de vida de los agricultores en estos contextos aimara y quechua del altiplano peruano. Nos referimos a las capacidades de gestión estratégica de su predio familiar, lo que contribuiría también al desarrollo local, regional y nacional.

A nivel global, la creciente población mundial y el incremento en la demanda de alimentos plantean retos para la agricultura, donde la producción global tendrá que aumentar en un $60 \%$ para el 2050; usando tierras que ya están siendo cultivadas para mayor producción, utilizar menos recursos naturales y hacer frente a un clima cambiante (Morales, Vivas y Terán, 2016).
Es innegable que la agricultura moderna incrementó los rendimientos absolutos por unidad de superficie, lo cual provocó el aumento de las producciones globales de alimento. Sin embargo, estos incrementos están basados en el uso intensivo de energías fósiles, lo que causa impactos ambientales negativos (Blanco, Suárez, Funes, Boillat, Martín y Fonte, 2014).

\section{Sectores sociales y desarrollo tecnológico}

Los sectores sociales participantes en el desarrollo tecnológico están constituidos por: a) los productores rurales como sector interesado y b) el sector institucional. Los productores constituyen los sujetos claves del desarrollo tecnológico, conocen realmente sus necesidades tecnológicas para adaptar o adoptar a su sistema de producción familiar. El sector institucional cumple un rol importante en el desarrollo tecnológico. Este sector contribuye con los lineamientos de políticas favorables, el apoyo económico y el equipo de profesionales y técnicos con el conocimiento científico y experiencias en procesos de desarrollo tecnológico.

Las consideraciones que se formulan pueden ser también aplicadas al desempeño de algunos organismos a los que se ha asignado una misión dual, consistente en difundir y promover el acceso a la tecnología por parte de los productores y al mismo tiempo realizar investigación científica orientada a la producción de conocimiento tecnológico (Albornoz, 2015). El autor se refiere al sector institucional como el Instituto Nacional de Investigación Agropecuaria (INIA), que realiza investigación agropecuaria en diferentes cultivos y crianzas en el ámbito de la estación experimental; a partir de este núcleo de investigación debe divulgar o socializar dichos conocimientos a productores y comunidades del ámbito de influencia.

En el enfoque tradicional la extensión es una continuidad de la investigación hacia la sociedad externa a la institución; se "extiende" el conocimiento hacia los potenciales usuarios. Bajo esta perspectiva, la extensión necesita de la investigación, cuyos resultados difunde de muchas maneras (Albornoz, 2015).

En consecuencia, las necesidades de tecnología agropecuaria identificadas en determinados casos tienen que ser asumidos y desarrollados por el componente de investigación agrícola y pecuaria; constituyen entonces insumos para emprender procesos de investigación tecnológica, preferentemente en condiciones del agricultor. Por otro lado, también es ideal validar las tecnologías existentes en el contexto del sistema de producción familiar para, luego, socializar estas tecnologías a productores vecinos de estos núcleos de investigación tecnológica. 


\section{CONCLUSIONES}

Los factores sociales y productivos de la unidad familiar tienen influencia diferenciada en la identificación de las necesidades de tecnología agropecuaria en el Centro Poblado Accaso del distrito de Pilcuyo, provincia de El Collao, Región Puno. Las variables edad, el tamaño de la familia, tamaño del predio e ingreso económico no tienen influencia en la identificación de necesidades de tecnologías en cultivos y crianzas, a excepción del nivel educativo que no es independiente de los requerimientos de innovaciones agropecuarias. El nivel de escolaridad tiene influencia en las necesidades de conocimientos tecnológicos, principalmente en ganadería familiar.

En el componente agrícola, el $12 \%$ de los productores necesitan conocimientos en asistencia técnica en agricultura familiar, maquinaria agrícola con sus respectivos equipos, y trilladora de quinua. En la ganadería familiar, el $52.4 \%$ de los productores expresan su necesidad de apoyo en el mejoramiento genético en vacunos y ovinos, procesamiento de derivados lácteos, inseminación artificial, semilla de alfalfa y riego por aspersión, construcción y techado de establos para vacunos y asistencia técnica en ganadería familiar, entre otros. El $23.6 \%$ tienen otras necesidades como apoyo económico para mejoramiento de la vivienda familiar y el pozo de agua, además de jaulas flotantes para la crianza de trucha en el lago Titicaca.

\section{REFERENCIAS BIBLIOGRÁFICAS}

Ahumada, R., Velázquez, G., y Ahumada, B. (2018). Adaptación del sector agrícola ante el cambio climático: propuesta de medidas a escala espacial fina en Guasave, Sinaloa, México. Acta Universitaria, 28(1), 46-56. doi:10.15174/au.2018.1351

Amaya, L. (2017). Prueba Chi-cuadrado en la estadística no paramétrica. Revista de investigación de la Facultad de Ciencias, 1(1), 13-17.

Albornoz, M. (2015). Cambio tecnológico y cultura institucional: el caso INTA. Revista CTS, 10(29), 41-64.

Andrade, F. (2011). La tecnología y la producción agrícola. El pasado y los actuales desafios. Buenos Aires, Argentina: INTA.

Arenas, M., Dovalina, M. y Licea, J., (2004). La investigación agrícola en América Latina y El Caribe desde una perspectiva bibliométrica. Anales de documentación, (7), 29-38. Recuperado de https://revistas.um.es /analesdoc/article/view/1731

Barreto, J., Canto, M. y Julca, A. (2015). Caracterización social y económica de la agricultura tradicional de Carhuaz, Ancash. Big Bang Faustiniano, Revista Indizada de Investigación Cientifica Huacho, Perú. 4(3)2015. $\mathrm{R}$ e c u p e r a d o d e : http://revistas.unjfsc.edu.pe/index.ph p/BIGBANG/article/view/186/196

Blanco, D., Suárez, J., Funes-Monzote, F., Boillat, S., Martín, G. y Fonte, L., (2014). Procedimiento integral para contribuir a la transición de fincas agropecuarias a agroenergéticas sostenibles en Cuba. Pastos y Forrajes, 37(3), 284-290. Recuperado de https://www.redalyc. org/articulo.oa? id=269133036005

Buitrago, R. y Peñuela, L. (2018). La papa: un alimento de oportunidades con opciones de comercialización internacional. Equidad y Desarrollo, (32), 181-206. doi:10.19052/ed.5135.

Cáceres, D. (2015). Tecnología agropecuaria y agronegocios. La lógica subyacente del modelo tecnológico dominante. Mundo Agrario, 16(31). Recuperado de http://www.mundoagrario.unlp.ed u.ar/article/view/MAv16n3la08.

Chávez, L. y Llerena, C. (2015). Inventario de tecnologías agrícolas tradicionales y modernas de adaptación al cambio climático en la zona andina del Perú (Tesis de pregrado). Universidad Nacional Agraria La Molina. Lima.

Damián, M., Ramírez, B., Parra, F., Paredes, J., Gil, A., López, J. y Cruz, A. (2007). Tecnología agrícola y territorio: el caso de los productores de maíz de Tlaxcala, México. Investigaciones Geográficas, (63), 35-55. Recuperado de http://www.scielo.org.mx/scielo.p $\mathrm{h} p$ ? $\mathrm{p}$ i $\mathrm{d}=\mathrm{S} \quad 0 \quad 1 \quad 8 \quad 8$ 46112007000200004\&script $=$ sci_artt ext\&tlng=pt

Fliegel, C. (1987). Comunicación extensionista y proceso de adopción en Extensión agrícola. Roma, Italia: Organización de las naciones Unidas para la agricultura y la alimentación - FAO.

García, J., Guzmán, E. y Fortis, M. (2006). Demanda y distribución de agua en la comarca lagunera, México. Agrociencia, 40(2), 269-276. Recuperado de http://www.redalyc.o $\mathrm{rg} / \mathrm{pdf} / 302 / 30240212 . \mathrm{pdf}$

Guevara, F. (2017). Propuesta metodológica para el estudio de actores y estrategias de intervención tecnológica en Chiapas, 
México. Cultivos Tropicales, 38(2), $103-112$. R e cu perado d e http://scielo.sld.cu/scielo.php?script= sci abstract\&pid=S 0258 $593 \overline{62} 017000200016 \& \operatorname{lng}=$ es\&nrm= iso

Hernández, R., Fernández, C. y Baptista, P. (2010). Metodología de la investigación ( $5^{\mathrm{a}} \mathrm{ed}$.). Lima, Perú: Mc Graw-Hill, El Comercio S.A.

Martínez, C., Mavarez, R., Rojas, L. y Carvallo, B. (2008). La responsabilidad social universitaria como estrategia de vinculación con su entorno social. Revista de Filosofía Jurídica, social y política. Instituto de Filosofía del derecho Dr. J.M. Delgado Ocando. Universidad de Zulia, 15(3), 81-103.

Medina, C. y Posso, C. (2018). Cambio técnico y polarización en el mercado laboral. Evidencia para Colombia. El trimestre económico, 85 (338), 365-410. doi:10.20430/ete.v85i338.349

Morales, S., Vivas, N. y Teran, V. (2016). Ganadería eco-eficiente y la adaptación al cambio climático. Biotecnología en el Sector Agropecuario y Agroindustrial, 14(1), 135-144.

Osorio, N., López, H., Gil, A., Ramírez, B., Gutiérrez, N., Crespo, G. y Montero, A. (2012). Utilización, oferta y demanda de tecnología para producción de maíz en el valle de Puebla, México. Agricultura. sociedad y desarrollo, 9(1), 55-69. Recuperado de http://www.scielo.org $. \mathrm{mx} / \mathrm{scielo}$.php? script $=$ sci abstract\&p $\mathrm{i} \mathrm{d}=\mathrm{S} 18-70$ $54722012000100004 \& \operatorname{lng}=\mathrm{es} \& \mathrm{nrm}=$ iso

Portilla, B. (2000). La política agrícola en Chile: lecciones de tres décadas. Santiago, Chile: CEPAL
Rogers, E. (1966). Elementos del cambio social: Difusión de innovaciones. Bogotá, Colombia: Tercer mundo.

Sánchez, M. (2017). Comprender la agricultura en los andes peruanos: economía y política en la comunidad de Yanque (Caylloma, Arequipa). Revista Antropologías del Sur, 4(7), 235-256. Recuperado de https://biblat.unam.m $\mathrm{x} / \mathrm{es} / \mathrm{revista/antropologias-del-}$ sur/articulo/comprender-laagricultura-en-los-andes-peruanoseconomia-y-politica-en-1acomunidad-de-yanque-cayllomaarequipa

Sangerman, D, Rangel, E., Villaseñor, H., Navarro, A., Larqué, B, De la Olán, M. y Torres, R. (2012). Transferencia de tecnología a los productores trigueros en Nanacamilpa, Tlaxcala Revista Mexicana de Ciencias Agrícolas, 3(8), 1591-1604. Recuperado de https://cienciasagricolas.inifap.gob.m $\mathrm{x} /$ editorial/index.php/agricolas/article /view/1323

Solís, J. (2016). La capacitación campesina como instrumento de transformación del agro andino. Anthropologica, 34(36), 53-81.

Tapia, M. y Tapia, E. (2017). Los mercados andinos y sus requerimientos de maquinaria agrícola. 3C Empresa, investigación y pensamiento crítico, $6(3), \quad 47-62 . \quad \mathrm{d}$ o i : 10.17993/3cemp.2017.060331.47-62

Urcola, M. (2013). Estrategias socio-productivas y agricultura familiar: las nuevas tecnologías y sus implicancias en las relaciones familiares y productivas en una localidad del sur santafesino. Mundo Agrario, 13(26). Recuperado de:http://www.scielo.org.ar/scielo.ph p? script $=$ sci arttext\&pid $=$ S 1515 $59942013000 \overline{1} 00003$ 


\title{
Producción de amilasas de Geobacillus themoparaffinivorans (CB-13) aisladas de los Géiseres de Candarave, Tacna
}

\author{
Production of amylases from Geobacillus themoparaffinivorans (CB-13) isolated \\ from Candarave Geysers, Tacna
}

${ }^{1}$ Delsy Espinal Quiñonez

${ }^{2}$ Ariadna Zuñiga Llanos

\author{
${ }^{3}$ Daladier Castillo Cotrina \\ ${ }^{4}$ Roberto Castellanos Cabrera
}

\section{RESUMEN}

La investigación tuvo como objetivo determinar el diámetro del halo de hidrólisis amilolítico, la producción de proteínas amilásicas y la actividad enzimática de las amilasas producidas por Geobacillus thermoparaffinivorans (CB-13) a diferentes tiempos de producción. La cepa amilolítica de Geobacillus thermoparaffinivorans (CB-13), aislada de los géiseres de Candarave, Tacna se reactivó e incubó en caldo Luria Bertani (LB) a $60{ }^{\circ} \mathrm{C}$ durante 24 horas y se sembró por puntura en agar almidón $1 \%$ para determinar los halos de hidrólisis amilolíticos. Posteriormente, se inoculó $5 \%$ (v/v) de medio caldo LB con crecimiento bacteriano en $50 \mathrm{ml}$ de medio de caldo almidón $1 \%$ por triplicado, después fue incubado en estufa con agitador orbital a $150 \mathrm{rpm}$ a $60^{\circ} \mathrm{C}$ durante 60 horas. Asimismo, se extrajeron de cada incubación, con periodos de tiempo de 12 horas, alícuotas de $1.5 \mathrm{ml}$ para ser centrifugadas y obtener el sobrenadante que se utilizó para determinar la concentración de proteínas $\left(\mathrm{mg} \mathrm{ml}^{-1}\right)$ como indicativo de la producción de amilasas, y la concentración de azúcares reductores como indicativo de la actividad enzimática $\left(\mathrm{U} \mathrm{ml}^{-1}\right)$. Se obtuvo un diámetro de halo de hidrólisis de almidón formado alrededor de la colonia de la cepa amilolítica de $10.6 \mathrm{~mm}$, una producción de amilasas máxima de $0.197 \mathrm{mg} \mathrm{ml}^{-1}$ a las 48 horas de producción y una actividad enzimática máxima a las 36 horas de producción de $0.505 \mathrm{U} \mathrm{ml}^{-1}$.

Palabras claves: Actividad enzimática, Geobacillus thermoparaffinivorans (CB-13), producción de amilasas.

\section{ABSTRACT}

The objective of this study was to determine the diameter of the amylolitic hydrolysis halo, the amylasic protein production and the enzymatic activity of the amylases produced by Geobacillus thermoparaffinivorans (CB-13) are determined at different production times of the amylases. The amilolytic strain of Geobacillus thermoparaffinivorans (CB-13) isolated from the Candarave geysers was reactivated and incubated in Luria Bertani (LB) broth at $60^{\circ} \mathrm{C}$ for 24 hours and planted by puncturing on $1 \%$ starch agar to determine the amylolitic hydrolysis halos. Subsequently, $5 \%$ (v/v) of LB medium broth with bacterial growth in $50 \mathrm{ml}$ of $1 \%$ starch broth medium, in triplicate. Then, it was incubated in an orbital shaker at $150 \mathrm{rpm}$ at $60^{\circ} \mathrm{C}$ for 60 hours. Likewise, aliquots of $1.5 \mathrm{ml}$ were extracted from each incubator with 12 hour period, to be centrifuged to obtain the supernatant, which was used to determine the concentration of proteins ( $\mathrm{mg} \mathrm{ml}-1)$ as indicative of the production of amylases and the concentration of reducing sugars as indicative of the enzymatic activity (U ml-1). It was obtained a diameter of hydrolysis halo of starch formed around the colony of the $10.6 \mathrm{~mm}$ amylolitic strain, a maximum amylase production of $0.197 \mathrm{mg} \mathrm{ml}-1$ after 48 hours of production, and a maximum enzymatic activity after 36 hours of production of $0.505 \mathrm{U} \mathrm{ml-1}$.

Key words: Production of amylases, enzymatic activity, Geobacillus thermoparaffinivorans (CB-13)

\footnotetext{
Laboratorio de Investigación Biotecnología Enzimática. Facultad de Ciencias. Universidad Nacional Jorge Basadre Grohmann, Tacna, Perú. E-mail: delsymirian@gmail.com

Laboratorio de Investigación Biotecnología Enzimática. Facultad de Ciencias. Universidad Nacional Jorge Basadre Grohmann, Tacna, Perú. E-mail: ariadnazunigallanos@gmail.com

${ }^{3}$ Facultad de Ciencias. Universidad Nacional Jorge Basadre Grohmann, Tacna, Perú. Email: daladiercastillo@hotmail.com

${ }^{4}$ Laboratorio de Investigación Biotecnología Enzimática. Facultad de Ciencias. Universidad Nacional Jorge Basadre Grohmann, Tacna, Perú. E-mail: robertocastellanos@yahoo.es
} 


\section{INTRODUCCIÓN}

Las amilasas son enzimas que hidrolizan las moléculas de almidón para dar productos que incluyen las dextrinas y unidades de glucosa (Windish y Mhatre, 1965; Guano, 2017; Robledo, 2018). Tienen aplicaciones en las industrias de comida, fermentación, textil y papelería (Gupta, Paresh, Mohapatra, Goswami \& Chauhan, 2003; Robledo, 2018; Aguirre y Anduezal, 2018). Derivan de varias fuentes incluyendo plantas, animales y microorganismos; siendo las de origen microbiano las que por lo general cumplen con las demandas industriales. Un gran número de amilasas microbianas son una variable comercial, sustituyendo casi por completo la hidrólisis química del almidón en la industria de procesamiento del almidón (Pandey, Nigam, Soccol, Soccol, Singh \& Mohan, 2000).

Los microorganismos productores de amilasas son numerosos; entre ellos están Bacillus licheniformis, Bacillus stearothermophilus y Bacillus amyloliquefaciens, muy conocidos por ser buenos productores de la enzima. Estos se han usado ampliamente para la producción comercial $\mathrm{y}$ en diversas aplicaciones industriales como en los alimentos, la fermentación, los textiles y el papel (Konsula y Kyriakides, 2007; Prakash y Jaiswal, 2009).

La termoestabilidad es una característica deseada de la mayoría de las enzimas industriales. Estas enzimas termoestables aisladas de organismos termófilos tienen un número de aplicaciones comerciales a causa de su estabilidad a altas temperaturas, lo que permite que sean empleadas en la licuefacción enzimática y sacarificación del almidón. Las enzimas amilolíticas termoestables se han investigado actualmente para mejorar los procesos industriales de la degradación del almidón (Gomes et al., 2003; Stamford Stamford, Coelho \& Araujo, 2001).

Geobacillus thermoparaffinivorans es una bacteria termófila productora de amilasas, termoestable (Gursahani, 2010). Una de sus cepas, la CB-13, presente en el laboratorio de Biotecnología enzimática de la Facultad de Ciencias de la Universidad Nacional Jorge Basadre Grohmann de Tacna-Perú y aislada de los géiseres de Candarave-Tacna, es una bacteria que aún no ha sido estudiada, por lo cual en este trabajo se estudió algunas características.

Establecer la producción de amilasas en términos de producción de proteínas y su actividad enzimática en función de diámetros de halos de hidrólisis y/o de unidades de actividad por ml, nos permitirá predecir el grado de hidrólisis del almidón, considerando que las amilasas son proteínas que actúan sobre el almidón (Windish y Mhatre, 1965; Pandey et al., 2000).

El presente trabajo se orientó en determinar el diámetro del halo de hidrólisis amilolítico, la producción y actividad enzimática de amilasas p roducidas por Geobacillus thermoparaffinivorans (CB-13) a diferentes tiempos de producción de amilasas, reportadas por primera vez.

\section{MATERIAL Y MÉTODOS}

\section{Procedencia y reactivación de la cepa Geobacillus thermoparaffinivorans (CB-13)}

La cepa bacteriana amilolítica Geobacillus thermoparaffinivorans (CB-13) fue aislada de los Géiseres de Calientes-Candarave, Tacna, Perú, identificada molecularmente y proporcionada por el Laboratorio de Investigación Biotecnología Enzimática de la Facultad de Ciencias de la Universidad Nacional Jorge Basadre Grohmann de Tacna, y replicada en agar nutritivo contenido en un tubo de ensayo, luego reactivado por triplicado en un $\mathrm{ml}$ de caldo Luria Bertani (LB) (peptona $10 \mathrm{gl}^{-1}$, extracto de levadura $5 \mathrm{gl}^{-1}$, cloruro de sodio $10 \mathrm{gl}^{-1}$ ) e incubada a $60^{\circ} \mathrm{C}$ por 24 horas.

\section{Determinación del halo amilolítico de la cepa Geobacillus thermoparaffinivorans (CB-13)}

Reactivada la cepa en caldo LB, se le extrajo un inóculo que se sembró por puntura en el medio Agar A(a)lmidón (peptona $0.5 \%$, extracto de levadura $0.2 \%$, cloruro de sodio $0.05 \%$, sulfato de magnesio $0.05 \%$, cloruro de calcio $0.015 \%$, almidón $1 \%$, agar 2\%) (Souza y Leal, 2000) contenido en placas Petri e incubado a $60^{\circ} \mathrm{C}$ por 24 horas. Al final de esta incubación, se reveló la zona de hidrólisis por amilasas alrededor de las colonias desarrolladas, cubriendo con lugol al 30 $\%$ por 5 minutos la superficie del medio contenida en la placa Petri, para finalmente retirar el lugol. Fue medido el diámetro del halo con ayuda de una regla milimetrada.

\section{Obtención de fermentaciones para determinación de proteínas y actividad enzimática de amilasas}

Todo el ml de medio caldo LB con la cepa reactivada se sembró en $4 \mathrm{ml}$ de caldo LB nuevo, 
por triplicado, y se incubó a $60{ }^{\circ} \mathrm{C}$ hasta obtener una densidad óptica (D.O.) de 0.3 en el espectrofotómetro a una longitud de onda de 600 $\mathrm{nm}$

Se inoculó $5 \%(\mathrm{v} / \mathrm{v})$ de medio caldo $\mathrm{LB}$ con crecimiento bacteriano en $50 \mathrm{ml}$ de medio de caldo almidón (peptona $5 \mathrm{gl}^{-1}$, extracto de levadura $5 \mathrm{gl}^{-1}$, almidón $10 \mathrm{gl}^{-1}, \mathrm{NaCl} 1 \mathrm{gl}^{-1}, \mathrm{KH}_{2} \mathrm{PO}_{4} 0.5 \mathrm{gl}^{-1}$, $\mathrm{MgSO}_{4} 0.5 \mathrm{gl}^{-1}, \mathrm{CaCl}_{2} 0.5 \mathrm{gl}^{-1}, \mathrm{~K}_{2} \mathrm{HPO}_{4} 1.2 \mathrm{gl}^{-1}$ ) (Manoj, 2013) a pH 7 contenido en matraces de $250 \mathrm{ml}$ por triplicado. Se incubaron los matraces en una estufa incubadora con agitador orbital (shaker mrc) a $150 \mathrm{rpm}$ a $60^{\circ} \mathrm{C}$ durante 60 horas. Extrayendo de cada matraz, desde la cero horas y cada 12 horas (Annamalai, Thavasi, Vijayalakshmi \& Balasubramanian, 2011), alícuotas de $1.5 \mathrm{ml}$ para ser centrifugadas a 10000 rpm durante 10 minutos, para obtener dos fracciones a) el sedimento, que fue descartado y b) el sobrenadante, que sirvió para determinar la concentración de proteínas $\left(\mathrm{mg} \mathrm{ml}^{-1}\right)$ como indicativo de la producción de amilasas y la concentración de azúcares reductores como indicativo de la actividad enzimática de las amilasas $\left(\mathrm{U} \mathrm{ml}^{-1}\right)$.

\section{Cuantificación de la producción de amilasas}

Se realizó por el método descrito por Bradford (1976), para lo cual se estableció una curva estándar de proteínas BSA (Albúmina Suero Bovina). Para establecer esta curva, se tomó como muestra $50 \mu \mathrm{l}$ de solución de proteínas BSA a diferentes concentraciones, para que cada una de ellas se mezclara con $500 \mu \mathrm{l}$ del reactivo de Bradford, dejándolo actuar por un minuto. Para el blanco del reactivo se usó la misma proporción y cantidad reemplazando la muestra con agua destilada. Finalmente se midió en el espectrofotómetro la absorbancia a $595 \mathrm{~nm}$.

En los tratamientos experimentales (sobrenadante de los matraces de las $0,12,24,36,48$ y 60 horas), la medición de la producción de amilasas (proteínas) se realizó siguiendo el procedimiento descrito por Bradford (1976), que consistió en mezclar la muestra (sobrenadante) con el reactivo Bradford, dejándolo actuar durante 1 minuto. Para, finalmente, medir en el espectrofotómetro la absorbancia, la cual al ser llevada a la curva patrón permitió la determinación de la concentración de proteínas (amilasas) $\left(\mathrm{mg} \mathrm{ml}^{-1}\right)$.

\section{Cuantificación de la actividad enzimática de las amilasas}

Se midió la actividad enzimática amilolítica, estableciendo previamente la curva estándar de concentraciones de soluciones de glucosa $\left(\mathrm{mg} \mathrm{ml}^{-1}\right)$. Para obtener esta curva se mezcló todos los tubos conteniendo solución de glucosa estándar de diferentes concentraciones para luego ser llevados al espectrofotómetro y leer las absorbancias a una longitud de onda de $540 \mathrm{~nm}$. Los valores de absorbancia obtenidos se graficaron con la concentración de glucosa que sirvió después para determinar la concentración de glucosa de los tratamientos experimentales.

En los tratamientos experimentales (sobrenadante de los matraces de las $0,12,24,36,48$ y 60 horas), la medición de la actividad enzimática de amilasas se realizó determinando previamente la concentración de glucosa, para lo cual se empleó el método de ácido 3.5 dinitrosalisílico (DNS).

Tabla 1. Procedimiento para medir la concentración de glucosa producto de la actividad enzimática de las amilasas

\begin{tabular}{|c|c|c|c|c|}
\hline Reactivos & BR & BS & BE & ES \\
\hline Buffer fosfato de sodio $\mathrm{pH} 7$ a $50 \mathrm{mM}(\mu \mathrm{l})$ & 150 & 50 & 100 & 0 \\
\hline Dilución de enzima $(\mu l)$ & 0 & 0 & 50 & 50 \\
\hline Sustrato almidón $1 \%(\mu l)$ & 0 & 100 & 0 & 100 \\
\hline \multicolumn{5}{|c|}{ Incubar los tubos ependorf a $60^{\circ} \mathrm{C}$ por 30 minutos } \\
\hline Reactivo DNS $(\mu \mathrm{l})$ & 250 & 250 & 250 & 250 \\
\hline \multicolumn{5}{|c|}{ Colocar los tubos en el baño de agua hirviendo durante 5 minutos e innmediatamente enfriarlos en baño de agua } \\
\hline Agua destilada $(\mu \mathrm{l})$ & 500 & 500 & 500 & 500 \\
\hline \multicolumn{5}{|c|}{ Agitar bien los tubos y leer las absorbancias a $540 \mathrm{~nm}$ contra el blanco de reactivo BR } \\
\hline \multicolumn{5}{|c|}{$\begin{array}{l}\text { Finalmente hacer corresponder las absorbancias obtenidas con las de la curva } \\
\text { patrón para establecer la concentración de glucosa producida }\end{array}$} \\
\hline \multicolumn{5}{|l|}{$\begin{array}{l}\text { * BR: tubo blanco del reactivo } \\
\text { BS: tubo blanco del sustrato } \\
\text { BE: tubo blanco de la enzima } \\
\text { ES: tubo con enzima sustrato }\end{array}$} \\
\hline
\end{tabular}

Fuente: Gutierrez y Villena, 2010. 
Luego, la actividad enzimática de amilasas se calculó mediante la siguiente expresión:

$$
\text { Amilasa }\left(\mathrm{U} \mathrm{ml}^{-1}\right)=[\mathrm{Glu}] \times 0.37 \times \text { dilución }
$$

Dónde: 0.37 es un factor para obtener el número de $\mu$ moles de glucosa formados en un minuto.

$\mathrm{La}$ actividad de amilasas fue expresada en $\mathrm{U} \mathrm{ml}^{-1}$, donde una unidad de enzima (U) se define como la cantidad de enzima que libera $1 \mu \mathrm{mol}$ de glucosa por minuto(Miller, 1959).

\section{RESULTADOS}

\section{Halo amilolítico originado por la cepa Geobacillus thermoparaffinivorans (CB-13)}

La actividad amilolítica de Geobacillus thermoparaffinivorans (CB-13) se muestra a través de los halos de hidrólisis de almidón formados alrededor de sus colonias, cuyo diámetro en promedio fue $10.6 \mathrm{~mm}$ que resultó de promediar el diámetro de 4 colonias $(10.0,10.0$, 11.0 y $11.5 \mathrm{~mm}$ ) (Figura 1 ).

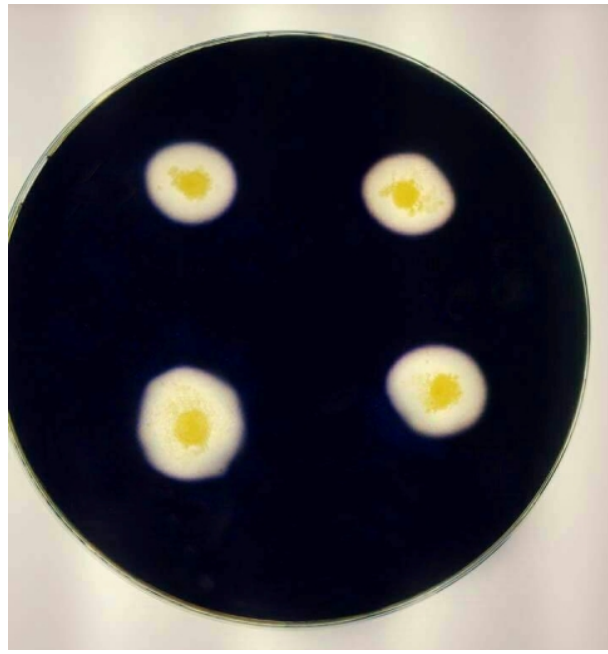

Figura 1. Halos amilolíticos alrededor de las colonias de Geobacillus thermoparaffinivorans (CB-13).

\section{Concentraciones de proteínas amilolíticas de Geobacillus thermoparaffinivorans (CB-13)}

En la Tabla 1, entre los valores promedio de producción de proteínas amilolíticas de Geobacillus thermoparaffinivorans (CB-13), obtenidas a diferentes tiempos de producción, se muestra que a las 48 horas de producción se obtiene el mayor valor de concentración de proteínas $0.197 \mathrm{mg} \mathrm{ml}^{-1}$.
Tabla 1. Valores promedio de producción de proteinas amilolíticas de Geobacillus thermoparaffinivorans (CB-13) a diferentes tiempos de producción

\begin{tabular}{|c|c|c|c|}
\hline $\begin{array}{l}\text { Tiempo } \\
\text { (horas) }\end{array}$ & Repeticiones & $\begin{array}{l}\text { Producción de } \\
\text { proteínas } \\
\left.(\mathbf{m g ~ m l})^{-1}\right)\end{array}$ & Promedi \\
\hline \multirow{3}{*}{$\mathbf{0}$} & I & 0.094 & 0.095 \\
\hline & II & 0.083 & \\
\hline & III & 0.107 & \\
\hline \multirow{3}{*}{12} & I & 0.113 & 0.115 \\
\hline & II & 0.117 & \\
\hline & III & 0.116 & \\
\hline \multirow{3}{*}{24} & I & 0.121 & 0.128 \\
\hline & II & 0.129 & \\
\hline & III & 0.134 & \\
\hline \multirow{3}{*}{36} & I & 0.193 & 0.195 \\
\hline & II & 0.203 & \\
\hline & III & 0.188 & \\
\hline \multirow{3}{*}{48} & I & 0.192 & 0.197 \\
\hline & II & 0.217 & \\
\hline & III & 0.182 & \\
\hline \multirow{3}{*}{60} & I & 0.170 & 0.168 \\
\hline & II & 0.166 & \\
\hline & III & 0.168 & \\
\hline
\end{tabular}

Medias y 95,0\% de Fisher LSD

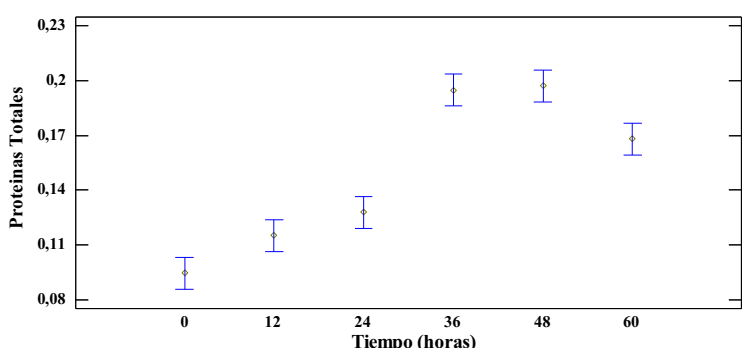

Figura 2. Valores promedio de producción de proteínas amilolíticas de Geobacillus thermoparaffinivorans (CB-13) a diferentes tiempos de producción en forma gráfica.

Fuente: Statgraphics centurión XVI

El análisis de varianza aplicado a los valores promedio de proteínas de la Tabla 1 da un resultado que, al ser el valor-P de la prueba $\mathrm{F}$ menor que 0.05 , indica que existe una diferencia estadísticamente significativa entre las medias de los valores promedios de producción de proteínas 
con un nivel del $95.0 \%$ de confianza; es decir que el tiempo afecta considerablemente la producción de proteínas amilolíticas. Por la prueba de Tukey se demuestra que la mayor producción de proteínas amilolíticas fue a las 48 horas de producción con el valor de $0.197 \mathrm{mg} \mathrm{ml}^{-1}$ (Tabla 1) (Figura 2).

\section{Actividad enzimática amilolítica de Geobacillus thermoparaffinivorans (CB-13)}

En la Tabla 2, entre los valores promedio de actividad amilolítica de las amilasas de Geobacillus thermoparaffinivorans (CB-13), obtenidas a diferentes tiempos de producción de amilasas, se muestra que a las 36 horas de producción se obtiene el mayor valor de actividad enzimática $\left(0.505 \mathrm{U} \mathrm{ml}^{-1}\right)$.

Tabla 2. Valores promedio de actividad amilolitica de las amilasas de Geobacillus thermoparaffinivorans (CB-13) a diferentes tiempos de producción de las amilasas

\begin{tabular}{|c|c|c|c|}
\hline $\begin{array}{l}\text { Tiempo } \\
\text { (horas) }\end{array}$ & Repeticiones & $\begin{array}{l}\text { Actividad } \\
\text { en } \mathrm{ml}^{-1}\end{array}$ & $\begin{array}{c}\text { Promedio } \\
\mathrm{U} \mathrm{ml}^{-1}\end{array}$ \\
\hline \multirow{3}{*}{ 0 } & I & 0.028 & 0.027 \\
\hline & II & 0.026 & \\
\hline & III & 0.029 & \\
\hline \multirow{3}{*}{12} & I & 0.065 & 0.070 \\
\hline & II & 0.074 & \\
\hline & III & 0.072 & \\
\hline \multirow{3}{*}{24} & I & 0.154 & 0.158 \\
\hline & II & 0.161 & \\
\hline & III & 0.158 & \\
\hline \multirow{3}{*}{36} & I & 0.511 & 0.505 \\
\hline & II & 0.565 & \\
\hline & III & 0.438 & \\
\hline \multirow{3}{*}{48} & I & 0.351 & 0.349 \\
\hline & II & 0.333 & \\
\hline & III & 0.362 & \\
\hline \multirow{3}{*}{60} & I & 0.122 & 0.122 \\
\hline & II & 0.128 & \\
\hline & III & 0.116 & \\
\hline
\end{tabular}

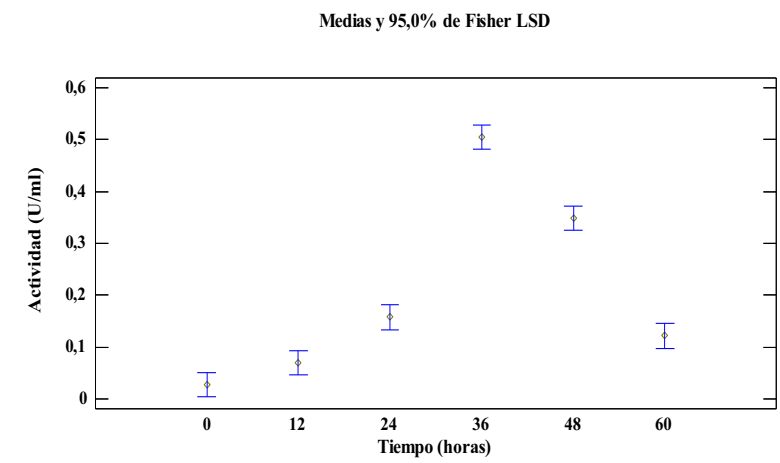

Figura 3. Valores promedio de actividad amilolítica de las amilasas de Geobacillus thermoparaffinivorans (CB-13) a diferentes tiempos de producción de las amilasas en forma gráfica.

Fuente: Statgraphics centurión XVI

El análisis de varianza, aplicado a los valores de actividad enzimática de la Tabla 2, da como resultado que al ser el valor-P de la prueba $\mathrm{F}$ menor que 0.05 , indica que existe una diferencia estadísticamente significativa entre las medias de las actividades enzimáticas $\left(\mathrm{U} \mathrm{ml}^{-1}\right)$ con un nivel del $95.0 \%$ de confianza; es decir, que el tiempo de producción afecta considerablemente la actividad enzimática. Por la prueba de Tukey se demuestra que la mayor actividad enzimática de las amilasas fue a las 36 horas de producción con el valor de $0.505 \mathrm{U} \mathrm{ml}^{-1}$ (Tabla 2) (Figura 3).

\section{DISCUSIÓN}

Los halos de hidrólisis de almidón, la producción de amilasas y la determinación de la actividad amilolítica puede variar en sus valoraciones. El valor que se obtenga depende principalmente del medio de nutriente, $\mathrm{pH}$, temperatura y el tiempo de incubación (Figen, Bilal, Seda \& Tulin, 2006). En este trabajo es evidente que la máxima producción de amilasas, así como el máximo valor de actividad enzimática, dependen mucho del tiempo de incubación; en este caso, estos fueron alcanzados cerca a las 60 horas de incubación de producción de proteínas amilolíticas, manteniendo constante los otros parámetros de concentración de almidón al $1 \%$, $\mathrm{pH}$ del medio igual a 7, temperatura de incubación $60{ }^{\circ} \mathrm{C}$ y agitación constante. 
El halo de hidrólisis de almidón de la cepa microbiana, aspecto cualitativo de la actividad enzimática amilolítica, con un diámetro de 10.6 $\mathrm{mm}$ da el indicativo que la actividad enzimática de Geobacillus thermoparaffinivorans (CB-13) es significativo. Este valor supera al diámetro de halos de hidrólisis de almidón encontrados en otros microorganismos, Levadura AAA 6 (10 $\mathrm{mm}$ ), Bacillus spp. (9 mm) (Gómez, Sarmiento y Delgado, 2013).

El aspecto cuantitativo determinado en la actividad enzimática en su valor máximo, $0.505 \mathrm{U}$ $\mathrm{ml}^{-1}$, para Geobacillus thermoparaffinivorans (CB-13) indica que las amilasas producidas por esta cepa tienen excelentes propiedades hidrolíticas. Las actividades enzimáticas de estas amilasas no están lejos de otras amilasas, siendo en la mayoría de los casos la actividad enzimática muy superior. Unal (2015), quien trabajó con especies de Aspergillus, logró obtener al sétimo día de producción $0.75 \mathrm{U} \mathrm{ml}^{-1}$ de actividad enzimática para Aspergillus terreus. Kumar, Raut, Satpathy, Ranjan \& Bandvopadhyay (2014), quienes trabajaron con bacterias termófilas productoras de amilasa, $B$. barbaricus durante 24 horas, obtuvieron una actividad máxima de amilasa de $0.574 \mathrm{U} \mathrm{ml}^{-1}$. Por otro lado, Gusakov, Kondratyeva \& Sinitsyn (2011), en un estudio sobre $\alpha$-amilasa alcalófila de la cepa GM8901 de Bacillus, por el método DNS encontraron que la actividad enzimática máxima fue de $0.75 \mathrm{U} \mathrm{ml}^{-1}$, después de la incubación de 24 horas. No obstante, Hasan, Wal, Hosna, Hakim \& Kalam (2017) obtuvieron del Bacillus spp. $3.50 \mathrm{U} \mathrm{ml}^{-1} \mathrm{de}$ actividad enzimática en 48 horas. Oyeleke, Auta \& Egwim (2010) reportaron para la amilasa de Bacillus megaterium $0.31-0.46 \mathrm{U} \mathrm{ml}^{-1} \mathrm{de}$ actividad enzimática amilolítica a $\mathrm{pH}$ alcalino.

\section{CONCLUSIONES}

Las a milas as de Geobacillus thermoparaffinivorans (CB-13) originan un diámetro de halo de hidrólisis de almidón de 10.6 $\mathrm{mm}$ con una producción de amilasas máxima de $0.197 \mathrm{mg} \mathrm{ml}^{-1}$, obtenida a las 48 horas y una actividad enzimática máxima de $0.505 \mathrm{U} \mathrm{ml}^{-1}$ a las 36 horas.

\section{AGRADECIMIENTO}

Al Proyecto de Investigación "Producción Biotecnológica de enzimas industriales a partir de microorganismos termófilos de los Géiseres de
Calientes, Candarave - Tacna (R.R. N ${ }^{\circ}$ 37142018-UN/JBG), por brindarnos las facilidades y el apoyo en el desarrollo de esta investigación.

\section{REFERENCIAS BIBLIOGRÁFICAS}

Aguirre, M. y Anduezal, F. (2018). Caracterización biotecnológica de bacterias aisladas de aguas termales del cantón Baños y sus posibles aplicaciones industriales (tesis de pregrado). Universidad Central del Ecuador, Ecuador.

Annamalai, N., Thavasi, R., Vijayalakshmi, S. \& Balasubramanian, T. (2011). Extraction, Purification and Characterization of Thermostable, Alkaline Tolerant $\alpha$-Amylase from Bacillus cereus. Indian Journal of Microbiology, 51(4), 424-429. doi: 10.1007/s12088-011-0160-Z

Bradford, M. (1976). A rapid and sensitive method for the quantitation of microgram quantities of protein utilizing the principle of protein-dye binding. Analytical Biochemistry, 72(1-2), 248-254. doi:10.1016/00032697(76) $90527-3$

Figen, E., Bilal, B., Seda, B. \& Tulin, A. (2006). Solid State Fermentation for the Production of $\alpha$ - Amylase from Penicillium chrysogenum Using Mixed Agricultural By-Products as Substrate. Biologia, Bratislava, 61(6), 657- 661. doi:10.2478/s11756-006$0137-2$

Gómez, S., Sarmiento, L. y Delgado, C. (2013). Caracterización de microorganismos celulolíticos y amilolíticos de residuos sólidos orgánicos dispuestos en la planta Ecosangil del municipio de San Gil, Santander. Revista Matices Tecnológicos, (5), 29-36. Recuperado de:http://publicaciones.unisangil.edu. co/index.php/revista-maticestecnologicos/article/view/206/193

Gomes, I., Gomes, J. \& Steiner, W. (2003). Highly thermostable amylase and pullulanase of the extreme thermophilic eubacterium Rhodothermus marinus: production and partial characterization. Bioresource Technology, 90(2), 207-214.

Guano, F. (2017). Evolución de las actividades celulasa, B-glucosidasa y amilasa durante el compostaje de lodos de depuradora y restos vegetales (tesis de maestría). Universidad de Almería, España. 
Gupta, R., Paresh, G., Mohapatra, H., Goswami, V. \& Chauhan, C. (2003). Microbial aamylases: a biotechnological perspective. Process Biochemistry, $38\left(\begin{array}{ll}1 & 1\end{array}\right), 1599-1616$. doi:10.1016/S0032-9592(03)00053-0

Gursahani, H. (2010). Studies on microbial thyermophilles of hot water springs of Maharashtra State (Ph.D. Thesis,) University, Aurangabad.

Gusakov, A., Kondratyeva, E. \& Sinitsyn, A. (2011). Comparison of Two Methods for Assaying Reducing Sugars in the Determination of Carbohydrase Activities. International Journal of A n a $1 \mathrm{y} \mathrm{t}$ i c a $1 \mathrm{Ch}$ e m i s t r y. doi:10.1155/2011/283658

Hasan, M., Wal, L.; Hosna, A.; Hakim, A. \& Kalam, A. (2017). Optimization of some fermentation conditions for the production of extracellular amylases by using Chryseobacterium and Bacillus isolates from organic kitchen wastes. Journal of Genetic Engineering and Biotechnology, $15(1)$ ) $59-68$. doi:10.1016/j.jgeb.2017.02.009

Konsoula, Z. \& Liakopoulou, M. (2007). Coproduction of alpha-amylase and betagalactosidase by Bacillus subtilis in complex organic substrates. Bioresource Technology,98 (1), 150157.

10.1016/j.biortech.2005.11.001

Kumar, S., Raut, S., Satpathy, S., Ranjan, P. \& Bandvopadhyay, B. ( 201014$)$. Characterizing Novel Thermophilic Amylase Producing Bacteria From Taptapani Hot Spring, Odisha, India. Jundishapur Journal of Microbiology, $7\left(\begin{array}{ll}1 & 2\end{array}\right)$, e 11800 . d o i : $10.5812 /$ jjm. 11800 .

Manoj, N. (2013). Thermostable alpha-amylase enzyme production from Bacillus laterosporus: Statisticaloptimization, purification and characterization. Biocatalysis and Agricultural Biotechnology,2(1), 38-44. doi: 10.1016/j.bcab.2012.10.005

Miller, G. (1959). Use of Dinitrosalicylic Acid Reagent For Determination of Reducing Sugar. Amal Chem., 31(3), 426-428.doi:10.1021/ac60147a030

Oyeleke, S., Auta, H. \& Egwim, E. (2010). Production and characterization of amylase produced by Bacillus megaterium isolated from a local yam peel dumpsite in Minna, Niger State. Journal of Microbiology and Antimicrobials, 2(7), 88-92. Recuperado de https://www.research gate.net/publication/228513933_Prod uction_and characterization_of amyl ase produced by Bacillus megateri um_isolated from_a local_yam peel dümpsite_in_Minna_Niger_State

Pandey, A., Nigam, P., Soccol, C., Soccol, V, Singh, D. \& Mohan, R. (2000). Advances in microbial amylases. Applied Biochemistry and Biotechnology, (31), 135-152. Recuperado de https://pdfs.semantic scholar.org/79ad/7f31 ee3d1900a706b 400bdca796afce35a11.pdf

Prakash, O. \& Jaiswal, N. (2009). An Ideal Representative of Thermostable Enzymes. Applied biochemistry and biotechnology, 160(8), 2401-2414. doi: $10.1007 / \mathrm{s} 12010-009-8735-4$

Robledo,T. (2018). Estudio de los procesos biológicos y de la estructura de las comunidades microbianas en el proceso de compostaje de lodos de depuradora de aguas residuales urbanas en sistemas de membrana semipermeable (tesis doctoral). Universidad de Granada. España.

Souza, C. \& Leal, M. (2000). Culture conditions for the production of thermostable amylase by Bacillus sp. Brazilian Journal of Microbiology, 31(4), 298302 . R e c u p e r a d o d e http://www.scielo.br/pdf/bjm/v3 1 n $4 / a$ $11 \mathrm{v} 3 \ln 4$

Stamford, T., Stamford, N., Coelho, L. \& Araujo, J. ( $\left.\begin{array}{llll}2 & 0 & 0 & 1\end{array}\right)$. Production and characterization of a thermostable alpha-amylase from Nocardiopsis sp. endophyte of yam bean. Bioresource Technology, 76(2), 137-141.

Unal, A. (2015). Production of a-amylase from some thermophilic aspergillus species and optimization of its culture medium and enzyme activity. Academic journals, 14(47) 317093183. doi: 10.5897/AJB2015.14924

Windish, W. \& Mhatre, N. (1965).. Advances in applied microbiology. Microbial amylases, ( 7 ), $273-304$. doi:10.1016/S0065-2164(08)70389-7 


\title{
Evaluación de post larvas de camarón de río (Cryphiops caementarius) en Boca del Río Sama, Tacna 2015
}

\author{
Post larvas evaluation of river shrimp (Cryphiops caementarius) Sama river \\ mouth, Tacna 2015
}

${ }^{1}$ Freddy Delgado Cabrera
${ }^{2}$ Luis Espinoza Ramos

\author{
${ }^{3}$ Luis Bernardo Rivera Chipana \\ ${ }^{4}$ Calixto Quispe Pilco
}

\section{RESUMEN}

La investigación tuvo como objetivo evaluar la población de post larvas de camarón de río (Cryphios caementarius), existente en la zona de la desembocadura del río Sama, así como conocer los valores de los parámetros físico químico y biológicos de esta zona, donde se desarrolla la especie en estudio. Sobre la metodología, para conocer las características de la población de post larvas de camarón, se planificó la obtención de muestras mediante la captura de post larvas usando un carcal de boca media luna de $50 \mathrm{~cm}$, de base con bolsa malla mosquitera plástica. De cada estación, georreferenciada, se extrajo todos los ejemplares del estudio. Cada muestra obtenida se analizó mediante cuantificación, medición y pesaje. Luego de su realización, se llegó a las siguientes conclusiones: La población, estimada de 149 post larvas de camarón, es insignificante; esto sugiere que, para la sostenibilidad de la especie camarón se debe realizar repoblamiento con semilla de otros ríos como Camaná, Ocoña y Majes. Asimismo, se determinó que la cantidad necesaria para repoblar el río Sama es de 150 millares de post larvas de camarón anualmente, esta cantidad permitirá mantener el equilibrio bioecológico y asegurar la sustentabilidad del camarón en este río. Durante las salidas al campo, se verificó que las aguas del río Sama no desembocaron normalmente, debido a las actividades antrópicas para la captación de agua para uso de la agricultura hasta 21 de febrero del 2016. Estas evacuaciones están impactando negativamente, contribuyendo a la degradación del hábitat y extinción del camarón. Por último, en el año 2015 y en salidas de campo durante el mes de abril, se observó una elevada mortalidad de post larvas de camarón de río en el área comprendida de la desembocadura y el puente del río Sama, (kilómetro 46 carretera Costanera Tacna - Ilo), uno de los factores que alteró la cadena biológica de esta especie.

Palabras clave: Crustacea, Cryphios caementarius, Perú, post larva, Tacna.

\section{ABSTRACT}

This research aimed to evaluate the population of post larvae of river shrimp (Cryphios caementarius) existing in the area Sama River mouth, as well as knowing the values of the physical, chemical and biological parameters of this area where this species is developed, and after its realization, the following conclusions were reached: The estimated 149 post larvae shrimp population is insignificant suggesting that for the sustainability of the species shrimp should be performed repopulation with seed from other rivers such as Camana, Ocoña and Majes, which determined that the amount needed to repopulate Sama river is 150 thousands of post larvae shrimp annually, this amount keeps the bioecological balance and ensures the sustainability of shrimp in this river. During field trips, it was verified that the Sama river waters did not disengage normally due to anthropogenic activities to capture water for agriculture use until 21 February 2016. These evacuations are negatively impacting, contributing to habitat degradation and shrimp extinction. Finally, in 2015 the field trips during April, high mortality of post larvae river shrimp was observed in the area between Sama river mouth and bridge (46 kilometer coastal road Tacna - Ilo), one of the factors that affected the biological chain of this species.

Keywords: Crustacea, Cryphios caementarius, Peru, post larva, Tacna.

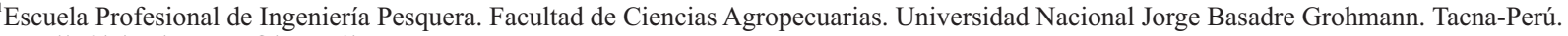
E-mail: fdelgado2001c@hotmail.com

${ }^{2}$ Escuela Profesional de Ingeniería Pesquera. Facultad de Ciencias Agropecuarias. Universidad Nacional Jorge Basadre Grohmann. Tacna-Perú. E-mail: laer54@hotmail.com

${ }^{3}$ Escuela Profesional de Ingeniería Pesquera. Facultad de Ciencias Agropecuarias. Universidad Nacional Jorge Basadre Grohmann. Tacna-Perú. E-mail: consultorespesqueros4093@hotmail.com

${ }^{4}$ Programa Nacional de Innovación en Pesca y Acuicultura (PNIPA). Tacna-Perú. E-mail: calixto_81@hotmail.com 


\section{INTRODUCCIÓN}

La contribución de la acuicultura a la producción pesquera mundial tuvo un aumento del $44 \%$ de media en 2013-2015 y superará a la pesca de captura en 2021. En 2025, esta cuota alcanzará el $52 \%$. Esta circunstancia pone de relieve el inicio de una nueva etapa e indica que la acuicultura se convertirá en el principal impulsor del cambio en el sector pesquero y acuícola. Este crecimiento sigue siendo más rápido que el logrado en cualquier otro sector de producción de alimentos de origen animal (FAO, 2016).

En el Perú, la acuicultura está creciendo; esto debido a que la Ley de Promoción y Desarrollo de la Acuicultura (Ley 27460, 2001) y su reglamento permiten realizar programas de cultivo extensivos, semiintensivos e intensivos; en el primer caso, utilizando únicamente el alimento natural existente en el medio acuático, aquí también se consideran los programas de repoblamiento de especies, ya sea peces, moluscos o crustáceos.

Elias (1974) indica que, en la región, el camarón de río (Cryphiops caementarius) constituye un recurso de los ríos de las cuencas del río Sama y Locumba, cuya pesquería se realiza desde tiempos antiguos. La actividad pesquera sobre este recurso ha disminuido con el correr del tiempo, debido a la casi desaparición de este recurso por la intervención antrópica en sus zonas de reproducción (IMARPE, 2009). Sin embargo, debido a las acciones de repoblamiento realizadas por diversas instituciones regionales como locales, se pretende obtener la presencia de este recurso en las dos cuencas anteriormente indicadas (DIREPE-TACNA, 1996).

\section{MATERIAL Y MÉTODOS}

Cryphiops caementarius, "camarón de río", como menciona Molina (1782), es un artrópodo que vive en aguas continentales, ya sean de ríos, riachuelos y lagunas occidentales de los Andes peruanos; pero, su hábitat principal se encuentra en los ríos, hallándose, durante el día, en las partes profundas, específicamente entre las piedras (Mayta, 1973). Su alimentación se basa sobre todo de algas, restos de caracol, larvas de Chironomidae, Ephemeroptera y Coleoptera (Hartman, 1998). En cuanto a su crecimiento, este es variable y retardado (Tello, 1972).

Para conocer las características de la población de post larvas de camarón, se planificó la obtención de muestras mediante la captura de post larvas usando un carcal de boca media luna de $50 \mathrm{~cm}$, de base con bolsa malla mosquitera plástica.

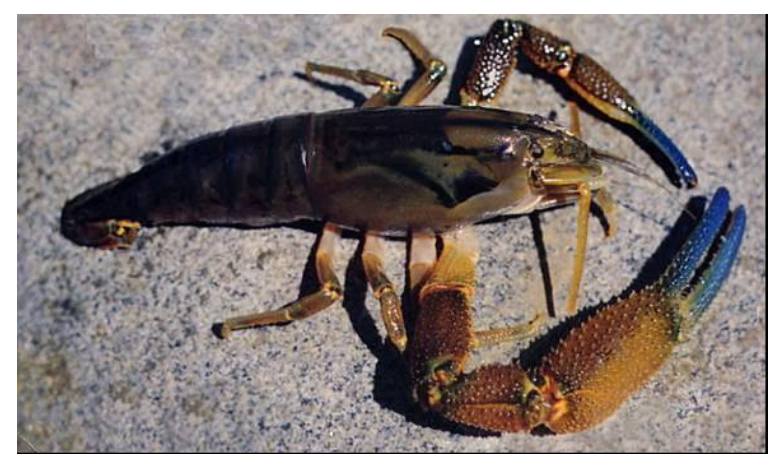

Figura 1. Camarón de río

Fuente: Hartman (1998)

Norambuena (1977) señala que, el Cryphiops caementarius es una especie común de agua de la costa oeste de América y es conocida desde Perú a Chile: Pacasmayo, Chancay, Ancón, río Chillón, Callao, Lima, Arequipa, río Tambo, Norte de Chile Coquimbo, etc.

\section{Técnicas e instrumentos de recolección de datos}

La zona de trabajo se georreferenció estimando caudal, profundidad, características del fondo y otros parámetros. La aplicación de la unidad de muestreo se basó principalmente en las características del recurso a evaluar, características operativas del sector, factibilidad técnica y capacidad de la asimilación de la metodología por parte de los participantes de la actividad. Se planteó inicialmente la aplicación de un cuadrante de $1 \mathrm{~m}^{2}$ para la evaluación del recurso (Robothann, 1995).

De cada estación, georreferenciada, se extrajo todos los ejemplares del estudio. Cada muestra obtenida se analizó mediante cuantificación, medición y pesaje.

\section{Métodos y técnicas de procesamiento y análisis de datos}

Para la determinación de la estructura comunitaria, se tuvo en cuenta la distribución y cuantificación directa de las especies, asimismo, se determinó los principales indicadores comunitarios. Se registraron datos de posición geográfica empleando un GPS, datos de profundidad y área efectiva o área rocosa disponible (hábitat) en porcentaje (cobertura espacial) y confirmación visual del sustrato.

\section{RESULTADOS}

\section{Ubicación del muestreo}

Los muestreos se realizaron en tres zonas: E-1=Lat.18 9'29,034" Log. 7040'11,537'; 
E-2=Lat.18 9'37,989”' Log. 7040'9,992”; $\mathrm{E}-3=18^{\circ} 9^{\prime} 44,889^{\prime \prime} \log .70^{\circ} 40^{\prime} 15,090^{\prime \prime}$; como se observa en la Figura 2.

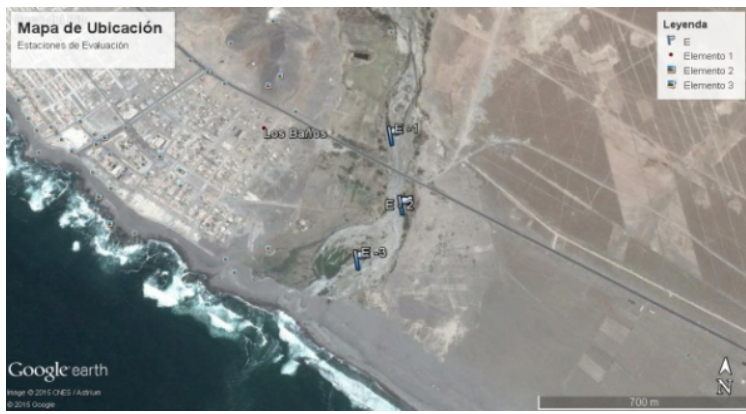

Figura 2. Mapa de ubicación

Fuente: Google Earth (2015)

\section{Trabajo de campo primera etapa}

Como lo planteado para la primera parte del proyecto, se realizó la salida de campo para observar las post larvas de camarón de río; asimismo, georreferenciar las zonas para determinar las zonas de extracción de pos larvas.

Se observó la mortalidad de un elevado número de post larvas como consecuencia de que algunos pescadores utilizaron sustancias tóxicas, alterando el ecosistema del río Sama en cuanto a post larvas de camarón se refiere.

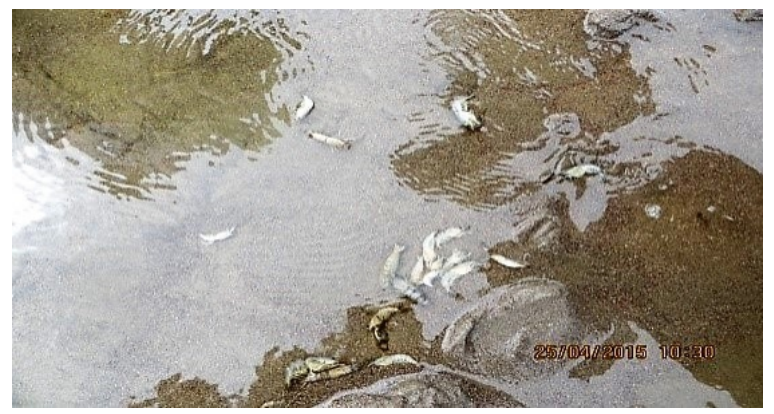

Figura 3. Mortalidad de larvas Zonas E-1, E-2 y E-3.

Determinación de las características de la población de post larvas de camarón de río $(C$. caementarius) existente en la zona de la desembocadura del río Sama. Año 2016

Durante las salidas al campo, se verificó que las aguas del río Sama no desembocaron normalmente, debido a las actividades antrópicas para la captación de agua para uso de la agricultura hasta el 21 de febrero del 2016; estas evacuaciones están impactando negativamente, contribuyendo a la degradación del hábitat y extinción del camarón. Esto no coincide con lo encontrado por Viacava (1978). Para el río
Camaná, con flujo de agua durante todo el año, Llanos (1981) informaba al respecto situaciones similares.

No obstante, el 22 de febrero del 2016, se presentó un ingreso de agua con un caudal de $70 \mathrm{~m}^{3} / \mathrm{s}$, debido a las fuertes lluvias en la zona andina de la Región Tacna. Estos ingresos de agua permitieron trasladar camarones reproductores con ovas embrionadas a la zona estuarina de Boca del Río. Sin embargo, durante la evaluación y captura de post larvas de camarón, estas fueron mínimas, registrándose una moda de $13 \mathrm{~mm}$ de longitud total.

Ante la ausencia de refugios formados por plantas como el gramadal, junco y monte ribereño que forman parte del hábitat del camarón, muy esencial en el mantenimiento, se podría decir que el refugio para las post larvas de camarón fue muy escaso, conllevando a las bajas condiciones de supervivencia del camarón, ya que el ingreso de agua solo duró 4 días, tiempo insuficiente para que los camarones puedan trasladarse a zonas más altas de la desembocadura del río, y posteriormente pueda repoblar todo el río Sama, esto coincide con lo manifestado por Chauca (1979) sobre la prospección del recurso camarón en la Región Arequipa, asimismo con lo vertido por la DIREPE - TACNA (1996), a realizar programas en las cuencas del río Sama y Locumba.

Estimar la población post larvas de camarón de río (C. caementarius) existente en la zona de la desembocadura del río Sama, con fines de repoblamiento. Salida de campo viernes 11 de marzo del 2016

En la Figura 4 se observan las estaciones que se ubicaron en zonas con condiciones de habitabilidad de post larvas en presencia de gramadal (Cynodon dactylon), junco (Scirpus lacustris) y monte ribereño.

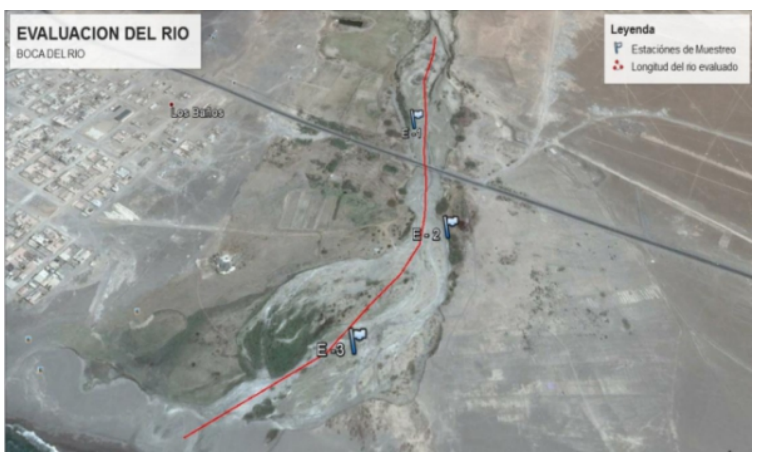

Figura 4. Mapa de estaciones de muestreo 
Se evaluó la longitud total del río (1 000 metros) y, con el uso de GPS, se determinó la longitud efectiva, presentando condiciones de habitabilidad de post larvas de camarón, logrando obtener una longitud efectiva, y considerando ambos márgenes del río de 280 metros de longitud efectiva que representa el $14 \%$.

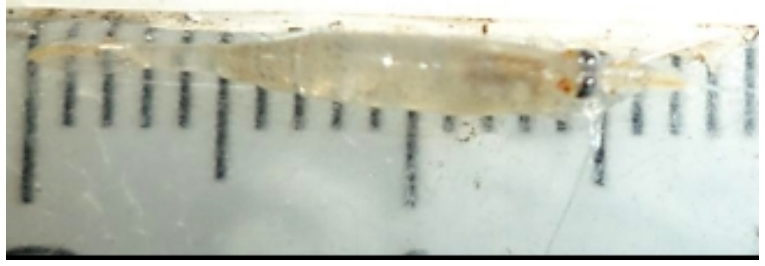

Figura 7. Registro de longitud total de post larvas de camarón

Este hábitat de reclutamiento de post larvas de camarón se muestra como muy frágil, principalmente por escases de agua que discurra en cantidad y de manera permanente formando un caudal ecológico que permita la repoblación de camarón en forma natural.

Tabla 1. Captura de post larvas en las tres estaciones de muestreo

$\begin{array}{lcc}\begin{array}{c}\text { ESTACIONES } \\ \text { DE MUESTREO }\end{array} & \begin{array}{c}\text { NÚMERO DE } \\ \text { INDIVIDUOS } \\ \text { CAPTURADOS }\end{array} & \begin{array}{c}\text { LONGITUD } \\ \text { MUESTREADA }\end{array} \\ \text { E-1 })\end{array}$

Población estimada $=280 \times 2.66666667$

Población estimada $=149$ post larvas de camarón

La población estimada de post larvas de camarón es insignificante, lo que sugiere que para la sostenibilidad de la especie se debe realizar repoblamiento con semilla de otros ríos como Camaná, Ocoña y Majes, tal como lo ejecutó la DIREPE-TACNA(1996).

Se determinó que, la cantidad necesaria para repoblar el río Sama es de 150 millares de post larvas de camarón anualmente, esta cantidad permitirá mantener el equilibrio bioecológico y asegurar la sustentabilidad del camarón en este río.

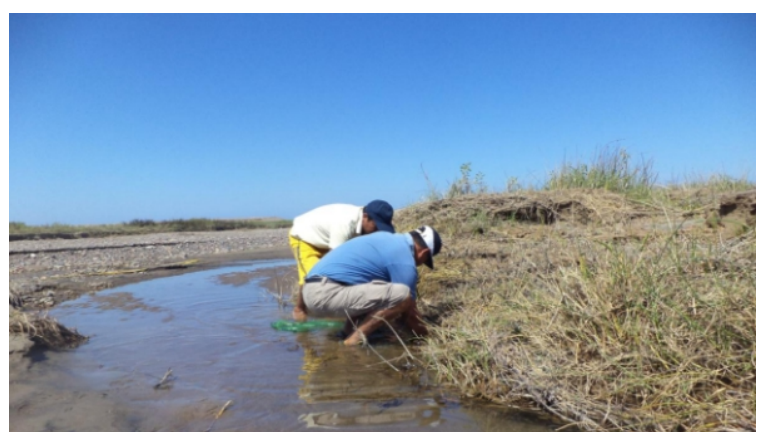

Figura 5. Evaluación en la estación de muestreo zona II

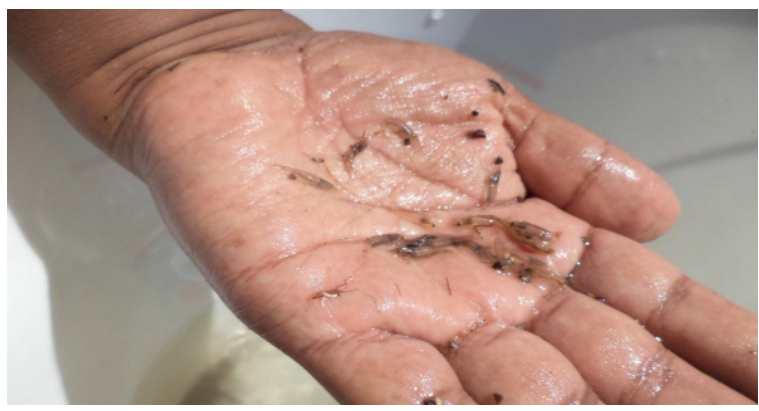

Figura 6. Muestras Obtenidas de post larvas de camarón

\section{CONCLUSIONES}

La población estimada de 149 post larvas de camarón es insignificante, lo que sugiere que para la sostenibilidad de la especie camarón se debe realizar repoblamiento con semilla de otros ríos como Camaná, Ocoña y Majes.

Se ha determinado que la cantidad necesaria para repoblar el río Sama es de 150 millares de post larvas de camarón anualmente, esta cantidad permitirá mantener el equilibrio bioecológico y asegurar la sustentabilidad del camarón en este río.

Durante las salidas al campo se verificó que las aguas del río Sama no desembocaron normalmente, debido a las actividades antrópicas de la captación de agua para uso de la agricultura hasta 21 de febrero del 2016. Estas evacuaciones están impactando negativamente contribuyendo a la degradación del hábitat y extinción del camarón.

En el año 2015 y en salidas de campo durante el mes de abril se observó una elevada mortalidad de post larvas de camarón de río, en área que comprende la desembocadura y el puente del río Sama, (kilómetro 46 de la carretera Costanera Tacna - Ilo), uno de los factores que alteró la cadena biológica de esta especie. 


\section{REFERENCIAS BIBLIOGRÁFICAS}

Chauca, L. (1979). Niveles proteicos en la alimentación artificial del camarón de río Cryphiops caementarius. Tesis UNA La Molina, Prog. Acad. de Pesquería, Lima.

DIREPE - TACNA (1996) Repoblamiento de camarón de río en las cuencas de Sama y Locumba. Dirección Regional de Pesquería Tacna. Recuperado de $\mathrm{http} / / /$ produce.regiontacna.gob.pe/web/d ir_institucion.php

Elías, H. (1974). El Camarón de río Cryphiops caementarius. Revista Documenta, 47(48), 36-45. Lima.

FAO. (2016). El estado mundial de la Pesca y la acuicultura. Roma. Recuperado de http://www.fao.org/3/a-i5555s.pdf

Hartmann, G. (1998). Apuntes sobre la biología del camarón de río, Cryphiops caementarius. Rev. Pesca y Caza (Min. Agric. Lima-Perú).

IMARPE. (2006). El camarón de río, evolución de la biomasa en Arequipa. Recuperado de http://www.imarpe.gob.pe/imarpe/

IMARPE. (2009). El camarón de río. Estadística de extracción del recurso. Recuperado de http://www.imarpe.gob.pe/imarpe/
Ley $N^{o}$ 27460. (2001). Ley de Promoción y Desarrollo de la Acuicultura. (publicado el 2001/mayo/21). Diario Oficial El Peruano.

Llanos, J. (1981). Avances en el Cultivo de Crustáceos realizados en el IMARPE, II Symposium sobre el desarrollo de la Acuicultura en el Perú. UNA La Molina, MIPE.

Mayta, L. (1973). Informe final del estudio del ciclo vital del camarón Cryphiops caementarius, Molina en su ambiente natural y controlado de las cascadas de Barranco. Convenio MIPE - UNA.

Molina, O. (1782) en el estero "El Culebrón" (Crustacea, Decapoda, Palaemonidae). Biol. Pesq. Chile.

Norambuena, R. (1977). Antecedentes biológicos de Cryphiops caementarius

Robothan, H. (1995). Curso Regional: El muestreo en poblaciones biológicas. Programas de Cooperación Técnica para la Pesca CEE-VECEP ALA.

Tello, E. (1972). Anotaciones sobre el camarón de río. Revista Documenta, (18). 5-9.

Viacava, C. (1978). Estudio del Camarón en el Perú, 1975-1976. IMARPE, Boletín. Vol. $3, \mathrm{~N}^{\circ} 5$, Callao. 


\title{
Preñez en ovejas Dohne Merino por inseminación artificial con dos dilutores y tiempos de refrigeración
}

\author{
Pregnancy in Dohne merino sheeps for artificial insemination with two diluters \\ and refrigeration times
}

\author{
${ }^{1}$ Miguel Guillén Portugal
}

\section{RESUMEN}

En la Estación Experimental Agraria Illpa, propiedad del Instituto Nacional de Investigación Agraria (INIA), se evaluó la preñez resultante de la inseminación artificial (IA) cervical con semen ovino, diluido y refrigerado a $5{ }^{\circ} \mathrm{C}$ con dos tipos de dilutores A (Tris) y B (Triladyl) a 0,24 y 48 horas en una dilución de 1:2 (semen/dilutor), y con dosis de $250 \times 10^{6}$ millones de espermatozoides por inseminación. Asimismo, se determinó las características seminales antes de cada inseminación. Ciento diecisiete ovejas primíparas y multíparas de la raza Dohne Merino fueron separados al azar en tres grupos de 39 individuos cada uno, a su vez por cada horario establecido ( 0,24 y 48 horas) se utilizó 13 animales. Todas fueron inseminadas de la siguiente manera: T1: semen fresco sin diluir (solo a 13 animales, ya que la mortalidad espermática era total a las 9 horas), T2: semen diluido en Triladyl (39 animales) y T3: semen diluido en Tris (39 animales). Los resultados de preñez y características seminales fueron analizados mediante la prueba de Chi-cuadrada y Tuckey, respectivamente. La preñez a 24 horas fue $B=69.2 \%(9 / 13)$ y con dilutor $A=46.2 \%(6 / 13)$. La preñez a 48 horas fue de $\mathrm{B}=30.8 \%(4 / 13)$ y $\mathrm{A}=46.2 \%(6 / 13)$. Los resultados evidenciaron que la preñez se ve afectada por el dilutor y tiempo de refrigeración a $5{ }^{\circ} \mathrm{C}$, mediante inseminación artificial con dosis de 250 millones de espermatozoides.

Palabras clave: Inseminación, motilidad, oveja, temperatura, viabilidad.

\section{ABSTRACT}

In the Agricultural Experimental Station "ILLPA", property of the National Institute of Agrarian Research (INIA), the pregnancy resulting from cervical artificial insemination (AI) with sheep semen, diluted and refrigerated at $5^{\circ} \mathrm{C}$ was evaluated with two types of diluents $\mathrm{A}$ (Tris) and $\mathrm{B}$ (Triladyl) at 0.24 and 48 hours, in a dilution of 1:2 (semen / dilutor), and doses of $250 \times 106$ million sperm by insemination. Likewise, the seminal characteristics were determined before each insemination. One hundred and seventeen primiparous and multiparous sheep of the Dohne Merino breed were randomly separated into three groups of 39 individuals each. Moreover, 13 animals were used for each established schedule ( 0.24 and 48 hours). Each sheep was inseminated, as follows: T1: undiluted fresh semen (only 13 animals, since sperm mortality was total at 9 o'clock), T2: semen diluted in Triladyl (39 animals) and T3: semen diluted in Tris (39 animals). The results of pregnancy and seminal characteristics were analyzed by the Chi-square test and Tuckey, respectively. The pregnancy at 24 hours was $B=69.2 \%(9 / 13)$ and with dilutor $A=46.2 \%$ (6/13); and the pregnancy at 48 hours was $B=30.8 \%(4 / 13)$ and $A=46.2 \%(6 / 13)$. The results showed that the pregnancy was affected by the dilutor and cooling time at $5^{\circ} \mathrm{C}$, by artificial insemination with doses of 250 million sperm.

Keywords: Viability, temperature, insemination, motility, sheep.

${ }^{1}$ Maestrante en Producción Animal y Reproducción Animal. Programa de Pós - Graduaçao em Zootecnia. Universidade Tecnologica Federal do Paraná. Estado de Paraná-Brasil. E-mail: miguelguillenportugalvet@gmail.com 


\section{INTRODUCCIÓN}

La inseminación artificial (IA) es un método importante en la producción ganadera, que permite difundir en la descendencia buenas características fenotípicas y genotípicas de un macho reproductor.

Las ovejas son poliéstricas estacionales. El ciclo estral es determinado por la estación del año y es influenciado por el fotoperiodo corto (otoño, invierno) (Gibbons, Cueto y García, 2007). En la región sur, el porcentaje de parición anual en ovinos fue de $41.4 \%$ en el año 2013, alcanzando la mayor actividad reproductiva en los meses de mayo-julio(MINAGRI, 2013).

Durante estos meses, los carneros utilizados como reproductores se ven sometidos a periodos de intensa actividad física, tolerando movimientos a diferentes predios y otras condiciones de estrés (trasporte, cambios de ambiente y alimentación, etc.). Por otro lado, existen riesgos físicos y sanitarios, que afectan la calidad seminal y ocasionan un bajo poder fecundante(Olivera, Gil, Gamarra y Fierro, 2011). Además, se pierde gran cantidad de espermatozoides en la monta natural, ya que la carga espermática excede la cantidad necesaria de espermios que se requiere para que la hembra quede preñada. Inclusive el carnero, en cada cubrición disminuye la cantidad del eyaculado y concentración espermática, provocando la reducción del porcentaje de fertilidad (Sepulveda, 2012). Desde que se iniciaron los primeros experimentos de la I.A. en ovinos, se utilizó semen fresco con resultados satisfactorios. Sin embargo, se comenzó a utilizar dilutores que, aparte de proteger el semen sin alterar sus características, aumentaron la dosis por inseminación, logrando abarcar una mayor cantidad de hembras por majada e incrementar la viabilidad de los espermatozoides a bajas temperaturas $\left(5^{\circ} \mathrm{C}\right)$ (Aisen, 2009b).

Dado el avance del uso de los dilutores, se realizaron estudios para evaluar, analizar, seleccionar y conservar las mejores características del material espermático, haciendo uso de diferentes parámetros evaluativos (motilidad individual progresiva, concentración espermática, integridad de membrana y vitalidad espermática), asegurando su calidad para la inseminación.

Con base a lo descrito, el presente trabajo tuvo como finalidad determinar la preñez comparando dos dilutores, uno comercial (Triladyl) y otro elaborado por medios caseros (Tris), realizando la inseminación en distintos horarios (24 y 48 horas), donde se evaluaron las características seminales a bajas temperaturas.

\section{MATERIAL Y MÉTODOS}

El trabajo se realizó en la Estación Experimental Agraria Illpa - INIA, ubicada en el distrito de Paucarcolla de la provincia de Puno, Región Puno. A $15^{\circ} 40^{\prime} 37^{\prime \prime}$ latitud sur y $70^{\circ} 04^{\prime} 38^{\prime \prime}$ longitud oeste, a una altitud promedio de $3815 \mathrm{~m}$, donde la temperatura fluctúa entre 1.60 a 16.30 ${ }^{\circ} \mathrm{C}$; con una media anual de $7{ }^{\circ} \mathrm{C}$ (CONCYTEC, 2007).

\section{Materiales}

\section{a. Material biológico}

Se utilizó 117 ovejas y 1 carnero de la raza Dohne Merino, además de 1 macho vasectomizado (retajo). Los ovinos fueron debidamente desparasitados con ivermectina al $1 \%$ (IBOMEC L.A. ( $)$, aplicada subcutáneamente (1 $\mathrm{ml} /$ animal).

Adicionalmente, se dosificó vía oral con albendazol al $12.5 \%$.

\section{b. Material empleado para la colecta de semen}

- Bolsitas de plástico en forma de cono para tubo colector.

- Tubo de metal para ovinos con escotilla de presión.

- Elásticos de jebe.

- Tubos Falcon (15 ml).

- Fundas de látex.

- Termo.

- Toalla para mantener la temperatura de vagina artificial.

- Cinta masking tape.

- Plumones de tinta indeleble.

\section{c. Material de laboratorio}

- Vórtex.

- Termómetro.

- Microscopio óptico.

- Platina calefactable.

- Láminas portaobjetos y cubreobjetos.

- Micropipeta graduada.

- Tubos de ensayo.

- Vaso de precipitado.

- Cámara Neubauer. 
- Jeringas hipodérmicas \#21, 23.

- Jeringa tuberculina (1 ml).

- Calentador.

- Hervidor eléctrico.

- Refrigeradora.

- Equipo de proctoscopía (proctoscopio y fuente de luz).

- Fundas de inseminación tipo pico de pato.

- Papel toalla.

- Estufa.

\section{Dilutores}

Se usó el dilutor Tris y Triladyl.

\section{a. Tris}

- Tris (hydroxymethyl aminomethano).

- Fructosa.

- Ácido cítrico 1-hidrato.

- Gentamicina-Estreptomicina.

- Yema de huevo.

- Agua bidestilada.

\section{b. Triladyl}

- Tris (hydroxymethyl aminomethano).

- Agua bidestilada.

- Glicerol.

- Ácido cítrico.

- Fructosa.

-Por cada $100 \mathrm{ml}$, se añadió los siguientes antibióticos: tilosina $5 \mathrm{mg}$, gentamicina 25 $\mathrm{mg}$, espectinomicina $30 \mathrm{mg}$ y lincomisina $15 \mathrm{mg}$.

Los reactivos utilizados en la tinción eosinanigrosina fueron:

- Eosina (soluble en agua).

- Nigrosina (soluble en agua).

- Tricitrato de sodio.

- Agua bidestilada.

\section{Método}

- Por cada $100 \mathrm{ml}$, se añadió los siguientes antibióticos: tilosina $5 \mathrm{mg}$, gentamicina 25 $\mathrm{mg}$, espectinomicina $30 \mathrm{mg}$ y lincomisina $15 \mathrm{mg}$. Los reactivos utilizados en la tinción eosinanigrosina fueron:

El método descrito respetó el código de ética aprobado para el uso de animales en experimentos científicos. En ese sentido, se seleccionaron 39 ovejas por cada tratamiento (T1, T2 y T3), las mismas fueron repartidas a su vez en grupos de 13 animales por cada horario ( $0,24 \mathrm{y} 48$ horas).

- Tratamiento 1 (T1): Fue el grupo control (semen fresco sin diluir). Se inseminó a las 0 horas y solo a 13 ovejas de las 39 , ya que hubo una mortalidad total de la muestra seminal a las 9 horas post colecta.

- Tratamiento 2 (T2): En este grupo se usó el dilutor Tris, inseminando 39 ovejas, las que fueron divididas en 3 horarios ( 0,24 y 48 horas). Fueron utilizados 13 animales por cada horario.

- Tratamiento 3 (T3): El semen fue diluido con el dilutor comercial Triladyl, inseminando 39 ovejas en celo, las cuales se distribuyeron en grupos de 13 por cada horario $(0,24$ y 48 horas).

\section{Preparación de los dilutores}

La preparación del dilutor Tris se realizó en forma mecánica con ayuda de una balanza digital previamente calibrada, y en el caso del dilutor Triladyl se realizó según las especificaciones del laboratorio(Minitube, 2010).

\section{d. Diluyente TRIS}

Para $10 \mathrm{ml}$ de dilutor:

$\begin{array}{lr}\text { - Tris buffer } & 0.36 \mathrm{~g} \\ \text { - Ácido cítrico } & 0.19 \mathrm{~g} \\ \text { - Fructosa } & 0.50 \mathrm{~g} \\ \text { - Yema de huevo } & 14 \% \\ \text { - Gentamicina } & 0.1 \mathrm{ml} \\ \text { - Agua bidestilada } & 7 \mathrm{ml}\end{array}$

\section{e. Diluyente TRILADYL}

Para $10 \mathrm{ml}$ de dilutor:

- Dilutor Triladyl 1 porción

- Yema de huevo 1 porción

- Agua bidestilada 3 porciones

Se diluye por unos minutos en el vórtex homogenizando la dilución.

\section{Colección de semen}

Se utilizó una hembra en celo para estimular la libido y la monta del carnero. El semen se colectó mediante la vagina artificial, ajustada a una temperatura de $55-60{ }^{\circ} \mathrm{C}$ y buena presión para el característico "golpe de riñón”. 


\section{Dilución de semen}

La dilución de semen se realizó en relación 1:2 (semen/dilutor)(Da Silva Maia, 2014). Se hizo de manera rápida para evitar el shock térmico. El dilutor, previamente preparado, fue puesto en un termo a baño maría a una temperatura de $37^{\circ} \mathrm{C}$ aproximadamente. Luego del eyaculado, fue extraído con una jeringa y añadido por la pared del tubo colector de acuerdo con el volumen de semen.

\section{Evaluación microscópica del semen a las 0, 24}

\section{y 48 horas}

\section{Motilidad individual progresiva}

Se calculó con un valor subjetivo mayor a 4 (con escala de $0-6$ ).

Tabla 1. Calidad de movimientos: Tipos

\begin{tabular}{cl} 
ESCALA & \multicolumn{1}{c}{$\begin{array}{c}\text { OBSERVACIÓN } \\
\text { (DESCRIPCIÓN) }\end{array}$} \\
& \multicolumn{1}{c}{$\begin{array}{c}\text { Espermatozoides sin movimiento } \\
\text { Espermatozoides con movimiento } \\
\text { pobre. Las cabezas de los } \\
\text { espermatozoides quedan fijas y } \\
\text { solo se mueven las colas, } \\
\text { pudiendo girar sobre sí mismos. }\end{array}$} \\
& $\begin{array}{l}\text { Espermatozoides sin movimiento. } \\
\text { Es per mato z o i d e s c o n } \\
\text { desplazamiento en círculos y } \\
\text { algunos progresivos. } \\
\text { Movimientos progresivos } \\
\text { sinuosos. } \\
\text { Movimientos progresivos } \\
\text { rápidos. } \\
\text { Movimientos progresivos muy } \\
\text { rápidos. }\end{array}$ \\
\end{tabular}

Fuente: Manual práctico para profesionales Biotecnología reproductiva - Inseminación artificial porcina (2007)

\section{Concentración espermática}

Se determinó mediante una fórmula validada (Hafez, 2000) el promedio del conteo de 5 cuadros que están ubicados en el centro de las dos retículas (superior/inferior) en la cámara de Neubauer, se multiplicó por 10000 y después por el volumen de la dilución.

\section{Concentración \\ $=$ prom. $\mathrm{x} 10000=$ núm. de espermios por $\mathrm{ml}$}

\section{Recuento espermático}

$=$ conc. $\mathrm{x}$ vol. de dilución $=$ núm. total de esp. en eyaculado

\section{Evaluación de vitalidad espermática}

Se colocó una gota de semen en una lámina portaobjeto y otra gota de coloración supravital eosina-nigrosina sobre la primera (Da Silva Maia, 2014). En un ángulo de $45^{\circ}$, se deslizó la muestra con otra lámina portaobjetos, procurando que la tinción sea uniforme y de película fina en toda la lámina. Se realizó el recuento de 200 espermatozoides, diferenciando vivos y muertos.

\section{Evaluación de integridad de membrana espermática (Hypoosmotic swelling Test)}

En un tubo de ensayo, se colocó $900 \mu \mathrm{l}$ de solución hiposmótica y $0.1 \mathrm{ml}$ de semen a una temperatura de $37^{\circ} \mathrm{C}$ por 1 hora para que ocurra la reacción (hinchazón de la cola); seguidamente, se le agregó $900 \mu \mathrm{l}$ de formol para detener la reacción(Aisen, 2009a). Se extrajo una gota que fue colocada en una lámina portaobjetos y visualizada en el microscopio óptico; se cuentan 100 espermatozoides.

\section{Refrigeración de semen}

La refrigeración se realizó en el tubo colector, descendiendo de una temperatura ambiente de 35 ${ }^{\circ} \mathrm{C}$ a $25-30{ }^{\circ} \mathrm{C}$, y posteriormente se bajó gradualmente en un refrigerador a $5{ }^{\circ} \mathrm{C}$ (Gibbons et al., 2007).

La dosis por inseminación se realizó de la siguiente manera:

\# Ovejas a I.A. $=\frac{\text { Conc.esp. } x \text { esp.vivos } x \text { esp.normales }}{250000000}$

Dosis/I.A. $=\frac{\text { Vol.total }}{\# \text { de ovejas }}$

\section{Inseminación artificial}

Para realizar la inseminación artificial, se apartó a las hembras en celo marcadas en la grupa por el retajo. Con ayuda de un operario, se suspendió a la 
hembra en forma adecuada. Una vez en posición, se limpió la vulva con papel toalla y se introdujo el proctoscopio en la vagina en un ángulo de $45^{\circ}$. Seguidamente, se adaptó la fuente de luz para la visualización de la cérvix y se introdujo la funda de inseminación con el semen ya cargado dentro de esta, procurando pasar la mayor cantidad de anillos cervicales (inseminación artificial vía cervical) depositando el semen en su interior.

\section{Determinación de fertilidad mediante ecografía a los 40 días}

Se utilizó un ecógrafo modelo ALOKA (5 mhz) vía transrectal para el diagnóstico de preñez a los 40 días post-inseminación, en este periodo el diagnóstico de gestación tiene una certeza muy alta $(95-100 \%)$.

\section{Análisis estadístico}

Los resultados de fertilidad y características seminales fueron analizados mediante la prueba de Chi-cuadrada en el programa SPSS V.19 y la prueba de Tuckey en el programa SAS (Statistical Analysis System) V.1999, respectivamente.

\section{RESULTADOS}

Tabla 2. Porcentaje de concentración espermática según dilutor y hora

\begin{tabular}{|c|c|c|c|c|}
\hline Dilutor & $\begin{array}{c}\text { Hora } \\
\text { de } \\
\text { análisis }\end{array}$ & $\mathbf{N}$ & $\mathrm{ml} \pm \mathrm{SD}$ & C.V \\
\hline Tris & 0 & 10 & $\begin{array}{l}3700 \times 10^{6} \pm \\
767028900^{\mathrm{a}}\end{array}$ & $28.92 \%$ \\
\hline Triladyl & 0 & 10 & $\begin{array}{r}3863 \times 10^{6} \pm \\
1117259047^{a}\end{array}$ & $20.73 \%$ \\
\hline
\end{tabular}

En la Tabla 2 se observa que la concentración espermática de la muestra seminal, es de 3863 x $10^{6}$ para el dilutor Triladyl y $3.7 \times 10^{6}$ para el dilutor Tris, no existe diferencia estadística entre ambos dilutores ( $\mathrm{p}>0.05)$.
Tabla 3. Porcentaje de motilidad individual progresiva, según dilutor y hora

\begin{tabular}{|c|c|c|c|c|}
\hline Dilutor & $\begin{array}{c}\text { Hora } \\
\text { de análisis }\end{array}$ & $\mathbf{N}$ & $\begin{array}{l}\text { Prom. } \\
\%\end{array}$ & $\begin{array}{l}\text { CV } \\
\%\end{array}$ \\
\hline \multirow[t]{3}{*}{ Tris } & 0 & 10 & $\begin{array}{l}5.20 \pm \\
0.79^{\mathrm{a}}\end{array}$ & 15.17 \\
\hline & 24 & 10 & $\begin{array}{l}3.60 \pm \\
0,99^{\mathrm{b}}\end{array}$ & 27.62 \\
\hline & 48 & 10 & $\begin{array}{l}2.55^{ \pm} \\
1.12^{\mathrm{b}}\end{array}$ & 43.80 \\
\hline \multirow[t]{3}{*}{ Triladyl } & 0 & 10 & $\begin{array}{l}5.40 \pm \\
0.52^{\mathrm{a}}\end{array}$ & 9.56 \\
\hline & 24 & 10 & $\begin{array}{l}3.70 \pm \\
0.48^{\mathrm{b}}\end{array}$ & 13.06 \\
\hline & 48 & 10 & $\begin{array}{l}2.80 \pm \\
0.48^{c}\end{array}$ & 17.25 \\
\hline
\end{tabular}

Letras diferentes $(a, b, c)$ en la misma columna, indican que hay diferencia significativa $(\mathrm{p}<0.05)$

En la Tabla 3 se observa que la motilidad individual progresiva (MIP) con dilutor Trisyema de huevo desciende por acción del tiempo de refrigeración. Donde a las 0 horas, se obtuvo el mayor porcentaje de MIP (5.20\%) a comparación del semen refrigerado a las 48 horas con un porcentaje de $2.55 \%$. El análisis estadístico indica que el factor tiempo de refrigeración ejerce una influencia significativa entre estos dos horarios $(\mathrm{p}<0.01)$. Resultados similares se obtuvieron con el dilutor Triladyl a las 0, 24 y 48 horas donde la motilidad individual progresiva desciende en un mayor porcentaje a las 48 horas $(2.80 \%)$ respecto a las 24 horas de refrigeración $(3.70 \%)(\mathrm{p}<0.01)$.

Tabla 4. Porcentaje de integridad de membrana por prueba de HOST, según dilutor y hora

\begin{tabular}{|lccccc|}
\hline Dilutor & $\begin{array}{c}\text { Hora } \\
\text { de } \\
\text { análisis }\end{array}$ & $\begin{array}{c}\text { Promedio } \\
\%\end{array}$ & $\begin{array}{c}\text { CV } \\
\%\end{array}$ & Mínimo / Máximo \\
\hline Tris & 0 & $71.50 \pm 3.95^{\mathrm{a}}$ & 5.53 & 65.00 & 77.00 \\
& 24 & $60.80 \pm 7.00^{\mathrm{b}}$ & 11.52 & 52.00 & 70.00 \\
\hline & 48 & $50.78 \pm 4.89^{\mathrm{c}}$ & 9.64 & 45.00 & 60.00 \\
\hline Triladyl & 0 & $72.80 \pm 5.59^{\mathrm{a}}$ & 7.68 & 64.00 & 82.00 \\
& 24 & $60.40 \pm 9.72^{\mathrm{b}}$ & 16.09 & 43.00 & 75.00 \\
& 48 & $37.80 \pm 8.68^{\mathrm{c}}$ & 22.95 & 23.00 & 52.00 \\
\hline
\end{tabular}


En la Tabla 4 se observa que el porcentaje de integridad de membrana, según la prueba de HOST, tuvo una reacción positiva decreciente a las 0,24 y 48 con el dilutor Tris siendo de $71.50 \%$, $60.80 \%$ y $50.78 \%$, respectivamente. El análisis estadístico indica que el factor tiempo de refrigeración tiene influencia significativa sobre el porcentaje de integridad de membrana $(p<0.01)$, siendo a las 0 horas de análisis donde se observó el mayor porcentaje de integridad de membrana. Resultados similares se obtuvieron con el dilutor Triladyl a las 0, 24 y 48 horas con $72.80 \%, 60.40 \%$ y $37.80 \%$, respectivamente; donde se evidencia que el tiempo de refrigeración a las 48 horas muestra el valor más bajo en comparación a las 24 horas de refrigeración $(\mathrm{p}<0.01)$.

Tabla 5. Porcentaje de vitalidad espermática, según dilutory hora

\begin{tabular}{|c|c|c|c|c|c|}
\hline Dilutor & $\begin{array}{l}\text { Hora de } \\
\text { análisis }\end{array}$ & $\mathbf{N}$ & Promedio \% & $\begin{array}{r}\mathrm{CV} \\
\%\end{array}$ & Mínimo \\
\hline Tris & 0 & 10 & $\begin{array}{c}64.25 \pm \\
3.45^{\mathrm{a}}\end{array}$ & 5.37 & 59.62 \\
\hline \multirow{5}{*}{ Triladyl } & 24 & 10 & $\begin{array}{c}53.45 \pm \\
5.59^{\mathrm{b}}\end{array}$ & 10.46 & 39.42 \\
\hline & 48 & 10 & $\begin{array}{c}45.84 \pm \\
4.11^{\mathrm{c}}\end{array}$ & 8.98 & 39.00 \\
\hline & 0 & 10 & $\begin{array}{c}65.11 \pm \\
2.89^{\mathrm{a}}\end{array}$ & 4.44 & 60.00 \\
\hline & 24 & 10 & $\begin{array}{c}56.52 \pm \\
2,65^{\mathrm{b}}\end{array}$ & 4.69 & 53.85 \\
\hline & 48 & 10 & $\begin{array}{c}37.23 \pm \\
5.93^{\mathrm{c}}\end{array}$ & 15.92 & 25.74 \\
\hline
\end{tabular}

La Tabla 5 muestra que la prueba de tinción supravital (eosina-nigrosina) en la vitalidad espermática, utilizando el dilutor elaborado a base de Tris-yema evaluado a las 0 horas, presenta el mayor porcentaje de espermatozoides vivos $(64.25 \%)$ en comparación con el semen refrigerado a las $24(53.45 \%)$ y 48 horas $(45.84$ $\%$ ), es decir, existe una influencia significativa del tiempo de refrigeración $(p<0.01)$. Un resultado similar se ha obtenido utilizando el dilutor comercial Triladyl; sin embargo, con este último, el porcentaje de vitalidad a las 48 horas de refrigeración fue mucho menor en comparación al dilutor Tris.

\section{Porcentaje de preñez}

Tabla 6. Diagnóstico de preñez con semen fresco, Tris y Triladyl a las 0 horas

\begin{tabular}{|c|c|c|c|c|}
\hline & \multicolumn{2}{|c|}{ Preñadas } & Vacías & Total \\
\hline \multirow{3}{*}{$\begin{array}{l}\text { FRESCO } \\
\text { 0 H. }\end{array}$} & $\begin{array}{l}\text { Frecuencia } \\
\text { observada }\end{array}$ & 10 & 3 & 13 \\
\hline & $\begin{array}{l}\text { Frecuencia } \\
\text { esperada }\end{array}$ & 8.5 & 4.5 & 13.0 \\
\hline & $\begin{array}{l}\% \text { de } \\
\text { FERT. }\end{array}$ & $76.9 \%$ & $23.1 \%$ & $100 \%$ \\
\hline \multirow{3}{*}{$\begin{array}{l}\text { TRIS } \\
\text { 0 H. }\end{array}$} & $\begin{array}{c}\text { Frecuencia } \\
\text { bservada }\end{array}$ & 7 & 6 & 13 \\
\hline & $\begin{array}{l}\text { Frecuencia } \\
\text { esperada }\end{array}$ & 8.5 & 4.5 & 13.0 \\
\hline & $\begin{array}{l}\% \text { de } \\
\text { FERT. }\end{array}$ & $53.8 \%$ & $46.2 \%$ & $100 \%$ \\
\hline \multirow{3}{*}{$\begin{array}{l}\text { TRILA } \\
\text { DYL } \\
0 \text { H. }\end{array}$} & $\begin{array}{l}\text { Frecuencia } \\
\text { observada }\end{array}$ & 9 & 4 & 13 \\
\hline & $\begin{array}{l}\text { Frecuencia } \\
\text { esperada }\end{array}$ & 9.5 & 3.5 & 13.0 \\
\hline & $\begin{array}{l}\% \text { de } \\
\text { FERT. }\end{array}$ & $69.2 \%$ & $30.8 \%$ & $100 \%$ \\
\hline
\end{tabular}

En la Tabla 6 se observan los resultados del diagnóstico de preñez a los 40 días post inseminación artificial. A las 0 horas, con semen fresco, dilutor Tris y dilutor Triladyl, se observa un porcentaje de $76.9 \%, 53.8 \%$ y $69.2 \%$, respectivamente. La prueba de Chi-cuadrada, indica que no hay asociación estadística entre el porcentaje de preñez y los tratamientos ( $p>0.05)$. Entonces, se puede entender que al añadir el dilutor Tris o dilutor Triladyl a un eyaculado e inseminar artificialmente por vía cervical a las 0 horas no incrementa significativamente el porcentaje de preñez en comparación con semen fresco sin diluir, al realizar el mismo método biotecnológico.

Tabla 7. Diagnóstico de preñez con semen diluido en Tris y Triladyl a las 0 horas

\begin{tabular}{|c|c|c|c|c|}
\hline & & Preñadas & Vacías & Total \\
\hline \multirow{3}{*}{$\begin{array}{l}\text { TRIS } \\
\text { O H. }\end{array}$} & $\begin{array}{l}\text { Frecuencia } \\
\text { observada }\end{array}$ & 7 & 6 & 13 \\
\hline & $\begin{array}{l}\text { observada } \\
\text { Frecuencia } \\
\text { esper ada }\end{array}$ & 8.0 & 5.0 & 13.0 \\
\hline & $\begin{array}{l}\% \text { de } \\
\text { FERT. }\end{array}$ & $53.8 \%$ & $46.2 \%$ & $100 \%$ \\
\hline
\end{tabular}




$\begin{array}{llccc}\text { TRILA } & \begin{array}{l}\text { Frecuencia } \\ \text { observada }\end{array} & 9 & 4 & 13 \\ \begin{array}{l}\text { DYL } \\ \text { O H }\end{array} & \begin{array}{l}\text { Frecuencia } \\ \text { esperada } \\ \text { \% de }\end{array} & 8.0 & 5.0 & 13.0 \\ & \text { FERT. } & \mathbf{6 9 . 2} \% & \mathbf{3 0 . 8} \% & \mathbf{1 0 0} \% \\ & \begin{array}{l}\text { Frecuencia } \\ \text { observada }\end{array} & 16 & 10 & 26 \\ \text { TOTAL } & \begin{array}{l}\text { Frecuencia } \\ \text { esperada } \\ \text { \% de }\end{array} & 16.0 & 10.0 & 26.0 \\ & \text { FERT. } & \mathbf{6 1 . 5} \% & \mathbf{3 8 . 5} \% & \mathbf{1 0 0} \% \\ & & & \end{array}$

La Tabla 7 indica que los porcentajes de preñez obtenidos con el dilutor Tris yema de huevo y el dilutor comercial Triladyl, realizando inseminación artificial inmediatamente después de la dilución en las muestras colectadas a las 0 horas, fueron $53.8 \%$ y $69.2 \%$, respectivamente. El análisis de Chi-cuadrado indica que no hay asociación estadística entre el porcentaje de preñez y los tratamientos.

Tabla 8. Diagnóstico de preñez con semen diluido en Tris y Triladyl a las 24 horas

\begin{tabular}{|c|c|c|c|c|}
\hline & & Preñadas & Vacías & Total \\
\hline \multirow{3}{*}{$\begin{array}{l}\text { TRIS } \\
24 \mathrm{H} .\end{array}$} & $\begin{array}{l}\text { Frecuencia } \\
\text { observada }\end{array}$ & 6 & 7 & 13 \\
\hline & $\begin{array}{l}\text { Frecuencia } \\
\text { esperada }\end{array}$ & 7.5 & 5.5 & 13.0 \\
\hline & $\begin{array}{l}\% \text { de } \\
\text { FERT. }\end{array}$ & $46.2 \%$ & $53.8 \%$ & $100 \%$ \\
\hline \multirow{3}{*}{$\begin{array}{l}\text { TRILA } \\
\text { DYL } \\
24 \text { H. }\end{array}$} & $\begin{array}{l}\text { Frecuencia } \\
\text { observada }\end{array}$ & 9 & 4 & 13 \\
\hline & $\begin{array}{l}\text { Frecuencia } \\
\text { esperada }\end{array}$ & 7.5 & 5.5 & 13.0 \\
\hline & $\begin{array}{l}\% \text { de } \\
\text { FERT. }\end{array}$ & $69.2 \%$ & $30.8 \%$ & $100 \%$ \\
\hline \multirow{3}{*}{ TOTAL } & $\begin{array}{l}\text { Frecuencia } \\
\text { observada }\end{array}$ & 15 & 11 & 26 \\
\hline & $\begin{array}{l}\text { Frecuencia } \\
\text { esperada }\end{array}$ & 15.0 & 11.0 & 26.0 \\
\hline & $\begin{array}{l}\% \text { de } \\
\text { FERT. }\end{array}$ & $57.7 \%$ & $42.3 \%$ & $100 \%$ \\
\hline
\end{tabular}

La Tabla 8 indica, respectivamente, un $46.2 \%$ y $69.2 \%$ de preñez usando los dilutores Tris y Triladyl a la misma hora de refrigeración. El análisis de Chi-cuadrado indica que no hay asociación entre el porcentaje de preñez y los tratamientos utilizados.
Tabla 9. Diagnóstico de preñez con semen diluido en Tris y Triladyl a las 48 horas

\begin{tabular}{|c|c|c|c|c|}
\hline & & Preñadas & Vacías & Total \\
\hline \multirow{3}{*}{$\begin{array}{l}\text { TRIS } \\
48 \mathrm{H} .\end{array}$} & $\begin{array}{c}\text { Frecuencia } \\
\text { observada }\end{array}$ & 6 & 7 & 13 \\
\hline & $\begin{array}{c}\text { Frecuencia } \\
\text { esperada }\end{array}$ & 5.0 & 8.0 & 13.0 \\
\hline & $\begin{array}{l}\% \text { de } \\
\text { FERT. }\end{array}$ & $46.2 \%$ & $53.8 \%$ & $100.0 \%$ \\
\hline \multirow{3}{*}{$\begin{array}{c}\text { TRILA } \\
\text { DYL } \\
48 \text { H. }\end{array}$} & $\begin{array}{c}\text { Frecuencia } \\
\text { observada }\end{array}$ & 4 & 9 & 13 \\
\hline & $\begin{array}{c}\text { Frecuencia } \\
\text { esperada }\end{array}$ & 5.0 & 8.0 & 13.0 \\
\hline & $\begin{array}{l}\% \text { de } \\
\text { FERT. }\end{array}$ & $30.8 \%$ & $69.2 \%$ & $100.0 \%$ \\
\hline \multirow{3}{*}{ TOTAL } & $\begin{array}{c}\text { Frecuencia } \\
\text { observada }\end{array}$ & 10 & 16 & 26 \\
\hline & $\begin{array}{l}\text { Frecuencia } \\
\text { esperada }\end{array}$ & 10.0 & 16.0 & 26.0 \\
\hline & $\begin{array}{l}\% \text { de } \\
\text { FERT. }\end{array}$ & $38.5 \%$ & $61.5 \%$ & $100.0 \%$ \\
\hline
\end{tabular}

La Tabla 9 revela un $46.2 \%$ y $30.8 \%$ de preñez a los 40 días post inseminación artificial con semen diluido con Tris yema de huevo y Triladyl a las 48 horas de refrigeración. El análisis de Chicuadrado indica que no hay asociación estadística entre la tasa de preñez y los horarios de refrigeración $(p>0.05)$.

\section{DISCUSIÓN}

Los resultados obtenidos en el grupo control con semen fresco sin diluir fue de $76.9 \%$; siendo superior a resultados de preñez hallados por Naim, Cueto y Gibbons (2004), con porcentajes de 58-65 \%. Según Milczewski, Kozicki, Luz y Neves (2000), la reducción como el aumento de la $\mathrm{T}^{\mathrm{o}}$ y la manipulación de semen promueven una disminución en la motilidad y daños estructurales bioquímicos y funcionales en los espermatozoides. Esto quedó confirmado al observar que las características seminales (MIP, HOST y vitalidad) descienden y se comportan de manera similar con ambos dilutores a 24 horas de refrigeración. Al mismo horario, la tasa de preñez con dilutor Tris es de $46.2 \%$, siendo superior a los resultados encontrados por Menchaca, Pinczak y Queirolo (2005) con $34.5 \%$. Tal descenso es ratificado por Evans y Maxwell (1990), quienes señalan que, durante el proceso de refrigeración, la fertilidad disminuye entre $10 \%$ a $35 \%$ por día de almacenamiento. Por otro lado, la tasa de preñez con dilutor comercial Triladyl no se ve 
afectada a pesar del descenso de la calidad seminal; y esto posiblemente gracias al glicerol presente en su medio, que funciona como un protector eficiente hasta las 24 horas. A las 48 horas de refrigeración, se observa una caída altamente significativa tanto en la preñez (30.8\%) como en sus características evaluadas. Según Gao (1992), el proceso de congelación rápida y descongelación lenta implicaría daños causados por la formación de pequeños cristales de hielo, los cuales se pueden agrupar formando cristales grandes, que rompen la membrana espermática, esto también fue confirmado por Fahy Lilley, Linsdell y Douglas (1990), que indican, el efecto protector del glicerol de las membranas del espermatozoide durante la criopreservación, y su efecto tóxico sobre ellas.

\section{CONCLUSIONES}

El dilutor y tiempo de refrigeración influyen en el porcentaje de fertilidad en ovejas Dohne Merino. Los dilutores Tris y Triladyl tienen diferentes efectos sobre las características seminales a 24 y 48 horas de conservación.

La utilización del semen hasta las 48 horas de refrigeración con dilutor Tris, tiene buenos índices de preñez.

\section{REFERENCIAS BIBLIOGRÁFICAS}

Aisen, E. (2009a). Reproducción ovina y caprina. Buenos Aires, Argentina: Editorial Inter-Médica.

Aisen, E. (2009b). Reproducción ovina y caprina, exploración clínica. Buenos Aires, Argentina: Editorial Inter-Médica.

CONCYTEC. (2007). CIT Illpa Estación Experimental Illpa - Puno.

Da Silva Maia, M. (2014). Tecnología de semen e inseminacion artificial em caprinos. Acta Veterinaria Brasilica 8 (suppl. 2), 389-95.

Evans G. y Maxwell W. (1990). Inseminación artificial en ovejas y cabras. Zaragoza, España: Editorial Acribia.

Fahy, G., Lilley, T., Linsdell, H. y Douglas, J. (1990). Cryoprotectant toxicity and cryoprotectan toxcicity reduction. In search of molecular mechanisms. Cryobiology, 27(3), 247-68. Recuperado de https://www.ncbi.nlm .nih.gov/pubmed/2199153

Gao, D. (1992). Glycerol permeability of human spermatozoa and its activation-energy.
Cryobiology, 29(6), 657-67. Recuperado de https://www.ncbi.nlm .nih.gov/pubmed/1478095

Gibbons, A., Cueto, M. y García, J. (2007). Obtención, procesamiento y conservación del semen ovino. INTA Bariloche.

Hafez, E. (2000). Reproducción e inseminación artificial de animales. México: Interamericana - McGraw Hill.

Menchaca, A., Pinczak, A. y Queirolo, D. (2005). Storage of ram semen at $5{ }^{\circ} \mathrm{C}$ : Effects of preservation period and timed artificial insemination on pregnancy rate in ewes. Anim Reprod, 2 (3), 195198. Recuperado de http://animalreproduction.org/article/5b5a6088f77 $83717068 \mathrm{~b} 47 \mathrm{fb}$

Milczewski, V., Kozicki, L., Luz, S. y Neves, P. $(2000)$. Inseminação artificial intrauterina e cervical em ovelhas utilizando sêmen refrigerado. Archives of veterinary science, 5 (1), 35-39. Recuperado de https://revistas.ufpr.b $\mathrm{r} /$ veterinary/article/view/3883

MINAGRI. (2013). Cadena productiva de ovinos. Recuperado de http://agroaldia.mina gri.gob.pe/biblioteca/download/pdf/a groeconomia/agroeconomia_ovino.pd $\mathrm{f}$

Minitube. (2010). Manual Triladyl ${ }^{\circledR}$ diluyente de semen bovino. Minitube 49(0), 0-3. Recuperado de http://www.perulacte a.com/wpcontent/uploads/2012/09/DI LUYENTE-DE-SEMEN-BOVINOTRILADYL.pdf

Naim, P., Cueto, M. y Gibbons, A. (2004). Inseminación artificial a tiempo fijo con semen ovino refrigerado. Archivos de zootecnia, 58 (223), 435-440. Recuperado de https://docplayer.es/1 7794389-Inseminacion-artificial-atiempo-fijo-con-semen-ovinorefrigerado.html

Olivera, J., Gil, A., Gamarra, J. y Fierro, S. (2011). Preservación seminal y su uso en programas de inseminación artificial a tiempo fijo en ovinos. Seminario Internacional de Ovinos, Paysandú Uruguay.

Sepulveda, N. (2012). Inseminación artificial en ovinos. XVI congreso Venezolano de producción e industria animal. XVI Congreso. Venezuela. 


\title{
Prevalencia de huevos de Toxocara spp. en áreas recreacionales del distrito Gregorio Albarracín Lanchipa y el nivel de contaminación (ligero, moderado, alto)
}

\author{
Prevalence of Toxocara spp. eggs in recreational areas of Gregorio Albarracín \\ Lanchipa district and the level of pollution (light, moderate, high)
}

\author{
${ }^{1}$ Diana Farfán Pajuelo \\ ${ }^{2}$ Rosalía Quispe Quispe
}

\author{
${ }^{3}$ Anthony Rivera Prado \\ ${ }^{4}$ Luis Lloja Lozano
}

\section{RESUMEN}

El objetivo de la investigación consistió en determinar la prevalencia de huevos de Toxocara spp. en áreas recreacionales del distrito Gregorio Albarracín Lanchipa (Tacna-Perú) y el nivel de contaminación (ligero, moderado, alto). La población estuvo formada por 69 áreas recreativas (considerando parques, plazas y jardines), tomándose como muestra (al azar) a 10 de estas áreas. Para la recolección de muestras se utilizó el método de la "W". Se realizó el muestreo de suelo y/o césped, depositando cada muestra en una bolsa de polietileno. Posteriormente, se rotuló y transportó al Laboratorio de Parasitología de la Universidad Nacional Jorge Basadre Grohmann (UNJBG). Durante el procesamiento de la muestra, se empleó el método de flotación de Willis $\mathrm{NaCl}$ al $25 \%$ (P/P) y la observación microscópica para identificación, según las características morfológicas de la forma evolutiva parasitaria. Posteriormente, se realizó la categorización de acuerdo al grado de contaminación por número de huevos encontrados en la muestra. Los resultados se expresaron como número de huevos por cada $50 \mathrm{~g}$ de suelo. De acuerdo a los resultados, se determinó que, la prevalencia de Toxocara spp. es del $70 \%$. Con respecto a la contaminación del suelo, el $60 \%$ de áreas recreativas tienen un nivel de contaminación ligera, mientras que el $10 \%$ tienen un nivel de contaminación moderado y el $30 \%$ de áreas recreativas no presenta algún nivel de contaminación.

Palabras Claves: Infección parasitaria, Toxocara spp., zoonosis.

\section{ABSTRACT}

The objective of the research was to determine the prevalence of Toxocara spp. egges in recreational areas of the Gregorio Albarracín Lanchipa district (Tacna-Peru) and the pollution level: light, moderate, high. The population was formed by 69 recreational areas (considering parks, squares and gardens) from which 10 areas were taken as a random sample of 10 was taken. For the collection of samples, the "W" method was used.The soil and / or grass sampling was carried out by depositing it in a polyethylene bag. Later it was labeled and transported to the Parasitology Laboratory of the UNJBG. During the processing of the sample, the Willis $\mathrm{NaCl}$ flotation method at $25 \%$ ( $\mathrm{P} / \mathrm{P}$ ) was used, as well as the microscopic observation for identification according to the morphological characteristics of the parasitic evolutionary form. Subsequently, the categorization was done according to the degree of contamination by egg number found in the sample. The results were expressed as egg number per $50 \mathrm{~g}$ of soil. According to the results, it was determined that the prevalence of Toxocara spp. was of $70 \%$. Regarding soil contamination, $60 \%$ of recreational areas had a light level of pollution, while $10 \%$ had a moderate level of pollution and $30 \%$ of recreational areas did not show any level of contamination.

Keywords: Parasitic infection, Toxocara spp., zoonosis.

\footnotetext{
${ }^{1}$ Laboratorio de Parasitología. Facultad de Ciencias. Universidad Nacional Jorge Basadre Grohmann. Tacna-Perú. E-mail: dianafarfan23.df@gmail.com ${ }^{2}$ Laboratorio de Parasitología. Facultad de Ciencias. Universidad Nacional Jorge Basadre Grohmann. Tacna-Perú. E-mail: rosaliavq16@gmail.com ${ }^{3}$ Laboratorio de Parasitología. Facultad de Ciencias. Universidad Nacional Jorge Basadre Grohmann. Tacna-Perú. E-mail: brayandna64@gmail.com ${ }^{4}$ Laboratorio de Parasitología. Facultad de Ciencias. Universidad Nacional Jorge Basadre Grohmann. Tacna-Perú. E-mail: lullolo62@hotmail.com
} 


\section{INTRODUCCIÓN}

Los animales son considerados huéspedes de diversos parásitos de importancia en patogenia humana con alto potencial zoonótico, ya que estos albergan en su tracto intestinal gran cantidad de diversas especies de nematodos, cestodos y protozoos de carácter clínico. El término zoonosis hace referencia a las enfermedades e infecciones que se comparten entre animales vertebrados y humanos. En ese contexto, los lugares de esparcimiento que se comparten entre animales y el hombre, caso de los parques públicos, constituyen un punto de contaminación zoonótica por la mala higiene e inadecuado control de heces y excretas caninas.

Por lo cual es muy importante, realizar estudios de contaminación parasitaria del suelo, ya que este constituye un indicador directo del riesgo de infección al que están expuestas las personas que visitan frecuentemente los parques (Córdoba, Ciarmela, Pezzani, Gamboa, De Luca, Minvielle \& Basualdo, 2002).

\section{METODOLOGÍA}

Con respecto al área de estudio, el distrito de Coronel Gregorio Albarracín Lanchipa se encuentra ubicado en el llamado "Cono Sur" de la provincia de Tacna, cuya capital es la Villa Alfonso Ugarte. Su jurisdicción está configurada sobre la demarcación del entonces Centro Poblado Menor Nueva Tacna. Su extensión es de $187.74 \mathrm{~km}^{2}$, representando aproximadamente el $1.2 \%$ de la extensión departamental y el $2.4 \%$ de la extensión total de la provincia de Tacna. Con respecto a su altitud, se encuentra ubicado aproximadamente a $560 \mathrm{msnm}$ (Municipalidad distrital Gregorio Albarracín Lanchipa, 2009)

Norte: Inicia en la intersección de la avenida la Bohemia Tacneña con la avenida Collpa, en el Ovalo Tarapacá.

Sureste: El límite se inicia en el cauce de la quebrada de Cauñani, continua en dirección Sur Oeste, agua abajo por el cauce de la quebrada de Cauñani.

Este: El límite se inicia en la intersección de la avenida Gregorio Albarracín con la avenida Collpa.

Oeste: El límite se inicia en la intersección de la quebrada de Cauñani con la carretera Panamericana.

\section{Unidad de análisis}

La unidad de análisis es la muestra de cada punto de muestreo del suelo de parques, jardines y plazas públicas del distrito de Gregorio Albarracín Lanchipa.

\section{Población y muestra}

La población está formada por 69 áreas recreativas (considerando parques, plazas y jardines), de los cuales se tomó como muestra al azar a 10 de ellas (Tabla 1). Con un muestreo no probabilístico intencional o de conveniencia. Para realizar una mejor distribución de los 10 parques a elegir, el área de estudio fue dividido en estratos, debido a que la población era heterogénea con respecto al tamaño del parque, jardín o plaza (Variables: nivel de contaminación de cada parque y la prevalencia de parásitos en cada parque muestreado).

\section{Tamaño de las áreas recreativas}

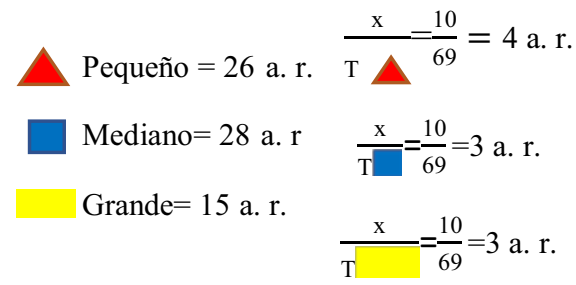

10 muestra ----69 población

*Donde a.r.: áreas recreativas

Tabla 1. Relación de las áreas recreativas consideradas para estudio en el distrito Gregorio Albarracín Lanchipa, Tacna

\begin{tabular}{|cl|}
\hline Numero & \multicolumn{1}{c|}{ Nombre } \\
\hline $\mathbf{1}$ & Plaza Jorge Chávez \\
$\mathbf{2}$ & Plaza Federico Ríos \\
$\mathbf{3}$ & PlazaLas Américas \\
$\mathbf{4}$ & Plaza Santa Rosa de Lima \\
$\mathbf{5}$ & PlazaLas Violetas \\
$\mathbf{6}$ & Plaza Margaritas \\
$\mathbf{7}$ & Plaza Pérez Gamboa \\
$\mathbf{8}$ & ParqueLas Aralias \\
$\mathbf{9}$ & Parque Amapolas \\
$\mathbf{1 0}$ & ParqueLos Laureles \\
\hline
\end{tabular}

\section{MATERIAL Y MÉTODOS}

\section{Material biológico}

- Muestra de tierra y/o césped

\section{Material de laboratorio \\ Reactivos}

- Solución de $\mathrm{NaCl}$ al 25 \% (P/P) 
- Lugol parasitológico

- Agua destilada

Material y equipo

- Centrifuga

- Microscopio

- Balanza analítica

- Guantes desechables

- Mascarillas desechables

- Envases de plástico de $250 \mathrm{ml}$ boca ancha

- Bagueta

- Colador

- Vasos de precipitación

- Probeta

- Tubos de ensayo

- Gasa

- Goteros Pasteur

- Gradilla

- Laminas portaobjetos y cubreobjetos

\section{Materiales de campo:}

-Libreta

- Pala pequeña

- Bolsas de polietileno

- Bolsas de almacenamiento

- Tijera

- Cinta Masking Tape

\section{Tipo y diseño de la investigación}

El estudio es de tipo descriptivo, transversal (debido a que la observación fue en un momento dado) y prospectivo. El diseño de la investigación es diseño no experimental porque no se manipularon las variables (Morales, 2014).

\section{Método de la investigación}

Para el muestreo, se usó el método de la doble "W" en parques y jardines (Morales, 2014). Se determinó la longitud de cada "W" en pasos y estimando en forma proporcional el número de puntos de muestreo (dependiendo del tamaño de cada cuadrante). (Cáceres, Bustinza \& Valderrama, 2017). Para procesar las muestras se empleó el método de flotación de Willis $\mathrm{NaCl}$ al $25 \%(\mathrm{P} / \mathrm{P})$

\section{Diseño procedimental}

\section{Obtención de la muestra del suelo}

En cada punto de muestro se recogió 500 gramos con ayuda de una pequeña pala, para formar una muestra de $6 \mathrm{~kg}$ a $8 \mathrm{~kg}$ en cada recorrido, considerando que cada parque se subclasificó en cuadrantes. La muestra fue de un área de $135 \mathrm{~cm}^{2}$ y a una profundidad de $5 \mathrm{~cm}$ a $7 \mathrm{~cm}$. Se determina la cantidad de puntos de muestreo según el tamaño de cada cuadrante.

Las muestras de suelo y/o césped se colocaron en bolsas de polietileno rotuladas y conservadas a temperatura ambiente durante 2 a 3 días hasta su análisis parasitológico (Morales, 2014).

\section{Procedimiento de campo}

Se realizó el muestreo de suelo y/o césped depositándola en una bolsa de polietileno. Posteriormente, se rotuló y transportó al Laboratorio de Parasitología de la UNJBG para su respectivo análisis.

\section{Análisis parasitológico}

El análisis parasitológico de las muestras de suelo, luego de la técnica empleada, método de Wilis al $25 \%(\mathrm{P} / \mathrm{P})$, fue realizada por observación microscópica. Donde se identificó, de acuerdo a las características que presentaba, la forma evolutiva del parásito encontrado y para el grado de contaminación del suelo se clasificó de acuerdo al número de huevos observados en la muestra en ligera (de 1 a 5 huevos), moderada (de 6 a 10 huevos) e intensa (más de 10 huevos) en las láminas montadas por muestra (4 láminas por muestra.) Los resultados se expresaron como número de huevos/50 g de suelo. (Morales, 2014)

\section{Procedimiento de laboratorio: Laboratorio de Parasitología de UNJBG)}

\section{Método de flotación con $\mathrm{NaCl} 25 \%(\mathrm{P} / \mathrm{P})$ : (Método de Willis)}

La técnica de flotación con $\mathrm{NaCl}$ al $25 \%(\mathrm{P} / \mathrm{P})$, técnica de flotación y sedimentación para determinación de huevos y estados larvarios de helmintos (Cáceres et al., 2017).

1. Se homogenizó la muestra por punto con ayuda de una tijera. Luego se juntó las muestras según el cuadrante perteneciente.

2. Se tomó $50 \mathrm{~g}$ de dicha muestra de cada cuadrante de parque, jardín o plaza y se añadió 50 $\mathrm{ml}$ de agua corriente. Se homogenizó.

3. Se filtró usando un colador y un tamiz triple de gasa. 
4. La muestra filtrada se repartió a un tubo de ensayo de $10 \mathrm{ml}$ de capacidad. Se centrifugó a 2 400 rpm por 4 minutos.

5. Posteriormente, se eliminó el sobrenadante y se volvió a repetir el lavado 3 veces.

6. Se los depósitos en viales de vidrio de $60 \mathrm{ml}$.

7. Luego se volvió a centrifugar, se eliminó el sobrenadante y se le añadió la solución de $\mathrm{NaCl}$ al $25 \%(\mathrm{P} / \mathrm{P})$. Se centrifugó.

8. Con la ayuda de un gotero se adicionó el $\mathrm{NaCl}$ al $33 \%$, con el fin de formar un menisco convexo sobre el cual se colocó una lámina cubreobjetos.

9. Luego de 15 minutos se colocó la lámina cubreobjetos a una lámina portaobjetos. Tinción con 1 gota Lugol.

10. Seguidamente, se hizo la lectura al microscopio en objetivos 10x y 40x.

11. Finalmente, se interpretó según grado de contaminación expresado como número de huevos/50 gramos de suelo.

\section{Para determinar la prevalencia}

Se tabuló los datos de la positividad obtenida en cada parque, mediante el programa Excel. Luego, se procedió a calcular la prevalencia de parásitos zoonóticos de los parques y plazas públicas del distrito de Gregorio Albarracín Lanchipa (Miranda, 2017).

$$
\text { Prevalencia }=\frac{\mathrm{N}^{\circ} \text { de parques positivos }}{\mathrm{N}^{\circ} \text { total de parques }} \times 100
$$

\section{RESULTADOS}

Contaminación en áreas recreativas (plazas, parques y jardines públicos) con huevos de Toxocara spp. en el distrito de Gregorio Albarracín Lanchipa.

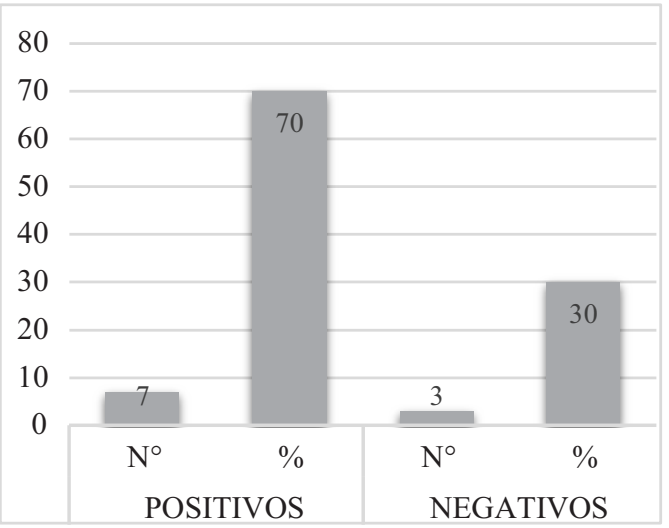

Figura 1. Prevalencia, huevos de Toxocara sp. en plazas, parques y jardines públicos del distrito de Gregorio Albarracín Lanchipa, Tacna 2018.
En la Figura 1 se observó que la prevalencia positiva a huevos de Toxocara spp. fue del $70 \%$ en todas las plazas, parques y jardines estudiados en el distrito Gregorio Albarracín Lanchipa. Esto se debió a que el análisis se hizo por cada cuadrante de cada uno de las áreas recreativas (un total de 93 láminas a observar), obteniendo una muestra más diversa. Asimimismo, dio como prevalencia negativa un $30 \%$, esto debido a que estos son parásitos de mayor distribución en diferentes especies de animales, en especial perros.

Tabla 2. Nivel de contaminación por Toxocara spp. encontrados en plazas, parques y jardines públicos del distrito de Gregorio Albarracín Lanchipa, Tacna 2018

\begin{tabular}{ccc}
\hline & $\mathbf{N}^{\circ}$ & \% \\
\hline Plaza 1 & 10 & 43.48 \\
\hline Plaza 2 & 1 & 4.35 \\
\hline Plaza 3 & 5 & 21.74 \\
\hline Plaza 4 & 1 & 4.35 \\
\hline Plaza 5 & 0 & 0.00 \\
\hline Plaza 6 & 1 & 4.35 \\
\hline Plaza 7 & 1 & 4.35 \\
\hline Plaza 8 & 0 & 0.00 \\
\hline Plaza 9 & 0 & 0.00 \\
\hline Plaza 10 & 4 & 17.39 \\
\hline
\end{tabular}

Donde:
Contaminación ligera
Contaminación moderada
Contaminación intensa

NIVEL DE CONTAMINACION DEL SUELO

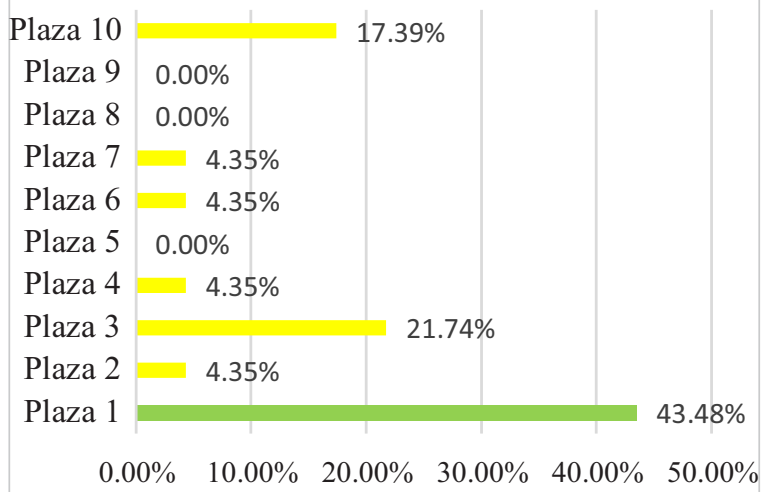

Figura 2. Nivel de contaminación por Toxocara spp. encontrados en plazas, parques y jardines públicos del distrito de Gregorio Albarracín Lanchipa, Tacna 2018. 1)Plaza Jorge Chávez, 2) Plaza Federico Ríos, 3) Plaza Las Américas, 4) Plaza Santa Rosa de Lima, 5) Plaza Las Violetas, 6) Plaza Margaritas, 7) Plaza Pérez 
Gamboa, 8) Parque Las Aralias, 9) Parque Amapolas, 10) Parque Los Laureles.

Se observó que, la Plaza Jorge Chávez tiene un nivel de contaminación moderada de parásitos con 43.48 \%; mientras que el Parque Los Laureles tiene un nivel de contaminación moderada con $17.39 \%$, Plaza Las Américas presenta un nivel de contaminación moderada con $21.74 \%$. Por otro lado, la Plaza Pérez Gamboa, Plaza Margaritas, Plaza Santa Rosa de Lima y Plaza Federico Ríos tienen un nivel de contaminación bajo con $4.35 \%$. Por lo contrario, se muestra que el Parque Amapolas, el Parque las Aralias y la Plaza las Violetas no mostraron presencia de Toxocara spp.

Tabla 3. Nivel de contaminación de las plazas, parques y jardines públicos del distrito de Gregorio Albarracín Lanchipa, Tacna 2018

\begin{tabular}{|ccc|}
\hline Nivel & Frecuencia & \% \\
\hline Ligera & 6 & 60 \\
Moderada & 1 & 10 \\
Intensa & 0 & 0 \\
TOTAL & 10 & \\
\hline
\end{tabular}

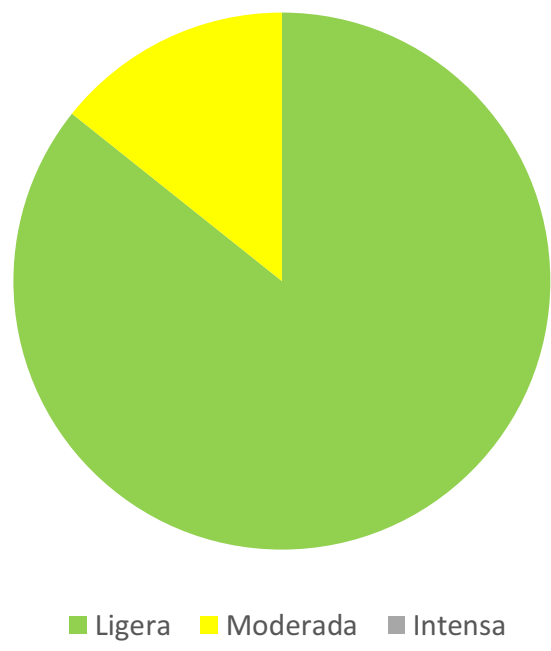

Figura 3. Nivel de contaminación de las plazas, parques y jardines públicos del distrito de Gregorio Albarracín Lanchipa, Tacna 2018.

Se puede observar que el $60 \%$ de áreas recreativas tienen un nivel de contaminación ligero, mientras que el $10 \%$ tienen un nivel de contaminación moderado y el $30 \%$ de áreas recreativas no presenta algún nivel de contaminación.

\section{Parásitos identificados en las áreas recreativas}

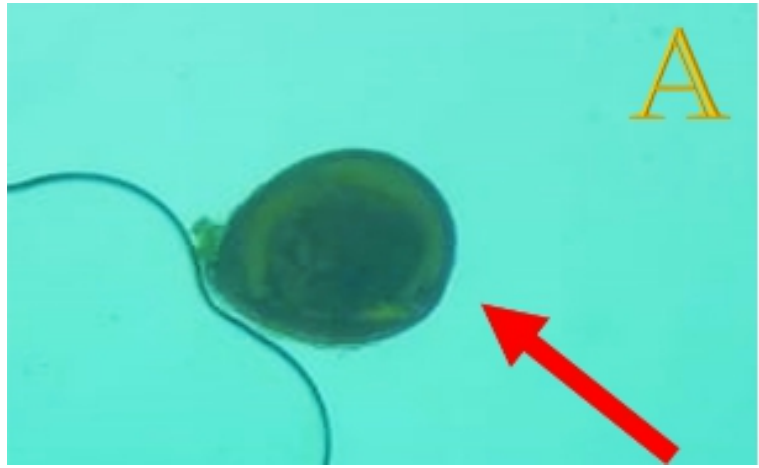

Figura 4. Huevo no embrionado de Toxocara sspp.

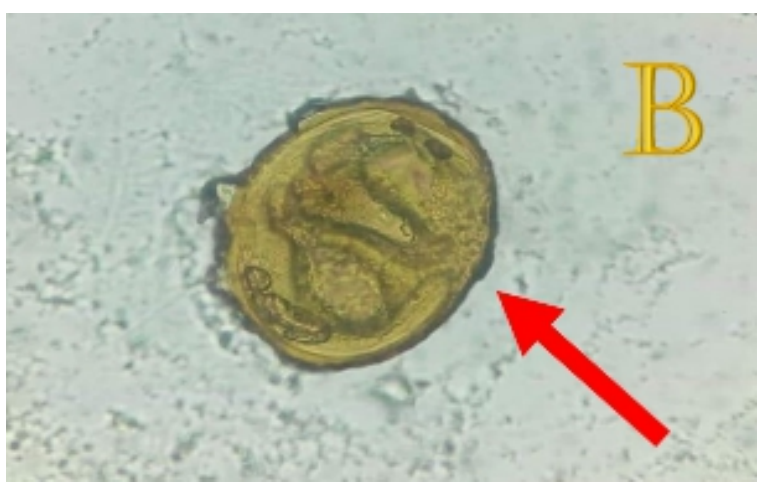

Figura 5. Huevo larvado de Toxocara sspp.

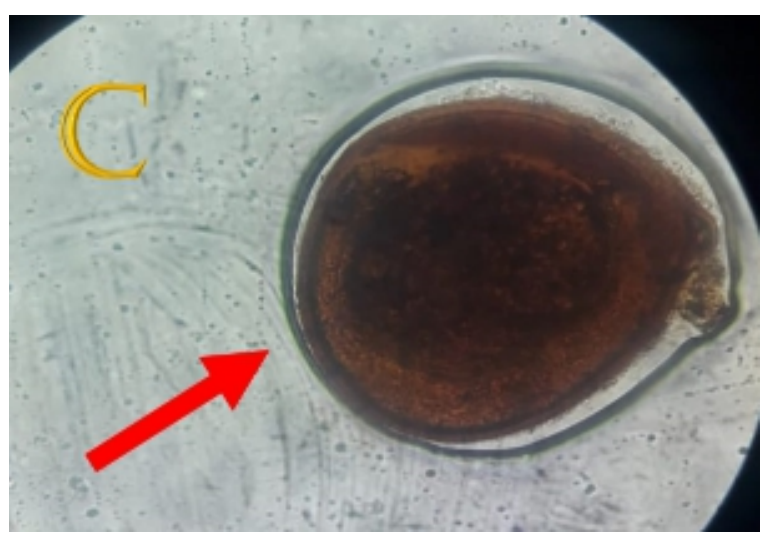

Figura 6. Huevo no embrionado de Toxocara sspp.

\section{DISCUSIÓN}

El presente trabajo obtiene los fundamentos para su desarrollo en la importancia clínicoepidemiológica de los lugares de esparcimiento 
público de nuestra ciudad, al considerarse uno de los principales focos de infección de parásitos implicados en patogenia humana procedentes principalmente de excretas de animales domésticos. El desconocimiento de esta situación limita las acciones tomadas por las instituciones responsables del manejo y administración de los parques públicos.

La transmisión de zoonosis parasitarias a humanos se puede producir de forma directa por heces diseminadas o puede estar asociada con factores socioculturales; como la falta de hábitos higiénicos, carencia de instalaciones adecuadas, falta de control en el manejo de mascotas y animales callejeros (Iannacone, Alvariño, \& Cárdenas, 2012). La contaminación de espacios públicos debido a heces fecales facilita la transmisión (Marder, Ulon, Bottinelli, Meza, Lotero \& Ruiz, 2004) y compromete seriamente la salud humana (Iannacone et al., 2012).

Los lugares que tienen mayor contaminación parasitaria son las áreas recreativas (parques, plazas y jardines). Estos son visitados frecuentemente por personas con sus mascotas y constituyen un sitio de recreación para los habitantes de las ciudades. Los niños son considerados la población más susceptible por llevar a cabo, entre otras acciones, prácticas de geofagia (ingesta de tierra) (Iannacone et al., 2012).

Mediante esta investigación se busca mostrar la situación actual de las áreas recreativas analizadas del distrito Gregorio Albarracín Lanchipa, con la finalidad de crear una línea de trabajo base para la posterior búsqueda de soluciones y medidas de prevención en salud, teniendo en cuenta que estos parásitos son transmitidos por animales domésticos (mascotas). Por ello, el control y la desparasitación de estos animales, ya sean mascotas o en condición de abandono, sería la medida de acción más importante a considerar para la posteridad.

Se eligió el método de muestreo en W, ya que es considerado el más representativo para establecer la contaminación por huevos de parásito en una superficie de tierra (Morales, 2014). A su vez, se clasificaron los parques en estratos diferenciándolos en tamaños, ya que se reporta que los parques públicos con mayor área presentan mayores niveles de contaminación (Iannacone et al., 2012). Se utiliza el método de Willis, ya que es utilizado para separar los parásitos en todos sus estadios de otros objetos, basados en sus diferentes densidades. (Cáceres, 2017)
Los huevos de helmintos de importancia en salud pública encontrados fueron del género Toxocara spp., con una prevalencia del $70 \%$ en plazas, parques y jardines públicos del distrito de Gregorio Albarracín Lanchipa. Lo mencionado se debe a que son parásitos de mayor distribución en diferentes especies de animales, especialmente en perros. Con respecto a los resultados de otros estudios similares sobre la prevalencia de huevos de Toxocara spp., se obtuvieron datos similares. Por ejemplo, en Lima, los resultados obtenidos en laboratorio mostraron que existe prevalencia positiva de $28.6 \%$ de Toxocara spp. en parques (Carrasco, 2014). En Cusco, se concluyó que la prevalencia de Toxocara canis es de $61.29 \%$ (Bravo, 2015). En Trujillo, resultados obtenidos muestran una prevalencia positiva de $28 \%$ a huevos de Toxocara canis en parques, que determinaría un nivel de contaminación moderado (Requena, 2015). En la ciudad de Juliaca, investigaciones muestran que la prevalencia general de Toxocara spp en parques fue de $51.67 \%$ (Quenaya, 2017). En Ayacucho, se comprobó que $71 \%$ de áreas recreacionales se encuentran contaminadas con huevos de Toxocara spp. (Oras. 2012). En Tacna, la prevalencia de Toxocara spp en parques públicos fue de $53.8 \%$ (Alania, 2004). De los resultados obtenidos podemos decir que la prevalencia de Toxocara spp. es elevada, encontrándose por encima del promedio nacional que es de $52.5 \%$ (Iannacone et al., 2012), asimismo, la condición de parques negativos a Toxocara no indica que esta sea su condición real, sino que la cantidad relativa de huevos es menor al límite inferior de detección de los métodos utilizados (Canese, Domínguez, Otto, Ocampos \& Mendonca, 2003)

Esta prevalencia se puede atribuir a que los huevos de Toxocara canis presentan una cubierta gruesa, la que proporciona una gran resistencia a las condiciones adversas, como la presencia de productos químicos y la falta de humedad, por lo que pueden permanecer viables hasta 5 años. Esto le confiere una mayor capacidad de diseminación en el suelo y por lo tanto un mayor riesgo potencial de infección independiente de la época del año, por lo que generalmente su frecuencia no tiene una marcada estacionalidad, como ha sido demostrado en varios estudios (Peña, Vidal, del Toro, Hernández, Zapata, 2017).

Los huevos están expuestos a la desecación y a los rayos solares que los destruyen en corto tiempo y a la presencia de canes que deambulan en los lugares de estudio, esto explicaría nuestros 
resultados. Este elevado nivel de contaminación del suelo de las áreas recreacionales evaluadas con heces de perros con Toxocara spp. confirma los resultados de estudios previos, que señalan al suelo como fuente de infección de Toxocariosis en seres humanos, en especial en niños por sus hábitos de juego y sus inadecuadas medidas de higiene (Guardis, Radman y Archelli, 2000).

Estas variaciones en cuanto a la prevalencia de los parásitos en los distintos lugares de estudio, incluso entre regiones de una misma área geográfica, se debería a diversos factores, entre ellos destaca el aumento del número de mascotas. Según Ríos (2002), quien señala la existencia de 01 perro por cada 10 personas (considerándose los reportes del INEI), mostrándose un crecimiento exponencial en estos últimos años, sobre todo en lugares de recreación como son las plazas, parques y jardines. Además, otro factor sería el estado en el que se encuentran esos espacios públicos.

Respecto a los niveles de contaminación, cabe mencionar que este parámetro se encuentra influenciado directamente por factores indistintos a la limpieza de las áreas recreacionales, condiciones de higiene o medidas sanitarias. Por otro lado el mantenimiento de áreas recreacionales es otro factor importante en el desarrollo y presencia de huevos de parásitos, se confirma lo mencionado por Liñán y Castellanos (2010).

\section{CONCLUSIONES}

La prevalencia de Toxocara spp., que se presentan en cada parque muestreado del distrito Gregorio Albarracín Lanchipa, es del $70 \%$.

En el nivel de contaminación del suelo, se muestra que el $60 \%$ de las áreas recreacionales muestreadas tienen un nivel de contaminación ligera, el $10 \%$ tiene un nivel de contaminación moderada y el $30 \%$ restante no presenta.

\section{REFERENCIAS BIBLIOGRÁFICAS}

Alania, A. (2004). Contaminación de parques públicos con huevos de Toxocara spp. en la zona urbana de Tacna (tesis de pregrado). Universidad Nacional Jorge Basadre Grohmann, Tacna.
Bravo, W. (2015). Contaminación de los suelos en los parques del distrito de Wanchaq, Cusco. Con Toxocara Canis, Cusco 2015 (tesis de pregrado). Universidad Católica de Santa María, Arequipa.

Cáceres, C., Bustinza, R. \& Valderrama, A. (2017). Contaminación con Huevos de Toxocara sp y Evaluación Sanitaria de Parques en la Ciudad de Abancay, Perú. Revista de Investigaciones Veterinarias del Perú, 28(2), 376-386. doi:10.15381/rivep.v28.i2.13064.

Carrasco, V. (2015). Determinación de la presencia de 7 huevos de Toxocara sp. $Y$ Ancylostoma sp. en parques del distrito de Barranco-Lima - Perú 2014 (tesis de pregrado). Universidad Científica del Sur, Lima.

Canese, A., Domínguez, R., Otto, C., Ocampos, C. \& Mendonca, E. (2003). Huevos infectivos de toxocara, en arenas de plazas y parques de Asunción, Paraguay. Revista chilena de pediatria, 74(6), 611-616. d o i : $10.4067 / \mathrm{S} 0370$ 41062003000600010

Córdoba, A., Ciarmela, M., Pezzani, B., Gamboa, M., De Luca, M., Minvielle, M., \& Basualdo, J. (2002). Presencia de parásitos intestinales en paseos públicos urbanos en La Plata Argentina. Parasitología latinoamericana, 57(1-2), 25-29. d o i : $10.4067 / \mathrm{S} 0717$ 77122002000100007

Fonrouge, R., Guardis, M., Radman, N. y Archelli, S. (2000), Contaminación de suelos con huevos de Toxocara spp. en plazas y parques públicos de la ciudad de La Plata, Buenos Aires, Argentina, Boletín chileno de parasitología, 55(34), 83-85. doi:10.4067/S036594022000000300009

Iannacone, L., Alvariño, L. \& Cárdenas, J. (2012). Contaminación de los suelos con huevos de toxocara canis en parques públicos de Santiago de Surco, Lima, Perú 2007-2008. Neotropical Helminthology, 6(1), 97-108. Recuperado de https://dialnet.unirioj a.es/servlet/articulo? codigo $=3974849$

Liñan, R. y Castellanos, R. (2010). Contaminación con huevos de Toxocara canis en plazas y parques públicos del distrito Gregorio 
Albarracín Lanchipa. REBIOL, 30(1), $65-68$. R e c u p e r a d o d e http://www.facbio.unitru.edu.pe/inde x.php?option $=$ com_content $\&$ view $=$ ar ticle\&id $=66 \&$ Itemid $=98$

Marder, G., Ulon, S., Bottinelli, O., Meza, Z., Lotero, D., \& Ruiz, R. (2004). Infestación parasitaria en suelos y materia fecal de perros y gatos de la ciudad de Corrientes. Revista Veterinaria, 15(2), 70-72. Recuperado de http://revistas.unne.edu.ar/index.p $\mathrm{hp} / \mathrm{vet} /$ article/view/1999

Miranda, T. (2017). Contaminación por parásitos de importancia zoonótica en parques y plazas públicas del distrito de Miraflores, Arequipa-2017 (tesis de pregrado). Universidad Nacional de San Agustín de Arequipa.

Morales, M. (2014). Contaminación del suelo de viviendas y parques con huevos de entero parásitos de importancia en salud pública en el distrito de Alta de la Alianza- Tacna 2013 (tesis de pregrado). Universidad Nacional Jorge Basadre Grohmann, Tacna, Perú.

Municipalidad distrital Gregorio Albarracín Lanchipa. (2009). Plan de desarrollo concertado distrito Crnl. Gregorio Albarracín Lanchipa 2009 - 2016 [Ebook] (pp. 21-24). Tacna. Recuperado de http://www.peru.gob. pe/docs/PLANES/12667/PLAN_126 67 Plan de Desarrollo Concertado --_MDCGĀL__2009_2011.pdf.
Oras, Y. (2012). Presencia de huevos de Toxocara spp. en parques públicos durante los meses de agosto y setiembre (tesis de pregrado). La Universidad Nacional de San Cristóbal de Huamanga, Ayacucho.

Peña, I., Vidal, F., del Toro, A., Hernández, A. y Zapata, M. (2017) Zoonosis parasitarias causadas por perros y gatos, aspecto a considerar en Salud Pública de Cuba. Revista Electrónica de Veterinaria, 18(10), 1-11. Recuperado de http://www.redalyc.o rg/articulo.oa?id=63653470002

Quenaya, V. (2017). Toxocariosis canina y contaminación de parques de la ciudad de Juliaca con huevos de Toxocara spp. (tesis de pregrado). Universidad Nacional del Altiplano, Puno.

Requena, N. (2015). Nivel de contaminación de los parques recreacionales con huevos de Toxocara spp en el distrito La Esperanza, Trujillo, Perú. Eneromarzo 2015 (tesis de pregrado). Universidad Privada Antenor Orrego, Trujillo, Perú.

Ríos, A. (2002). Parasitismo gastrointestinal en caninos (Canis familiaris) en Tacna. (Tesis de pregrado). Universidad Nacional Jorge Basadre de Grohmann, Tacna, Perú. 


\title{
Relación entre conciencia ambiental y conducta pro ambiental en estudiantes de primer ciclo de la Universidad María Auxiliadora Lima-Perú
}

\author{
Relation between environmental awareness and pro environmental behavior in \\ first-cycle students at Maria Auxiliadora University Lima-Peru
}

\author{
${ }^{1}$ Victor Chero Pacheco \\ ${ }^{2}$ José Oruna Lara
}

\author{
${ }^{3}$ Silvia Jaimes Garay \\ ${ }^{4}$ Meri Tovar Baca
}

\section{RESUMEN}

El presente estudio tuvo como objetivo determinar la relación entre la conciencia ambiental y la conducta pro ambiental en los estudiantes de primer ciclo de la Universidad María Auxiliadora. De acuerdo a los materiales y métodos, fue un estudio con enfoque cuantitativo, diseño no experimental, relacional y transversal. La muestra estuvo constituida por 236 estudiantes seleccionados por muestreo probabilístico de una población de 610 estudiantes de primer ciclo. El instrumento de recolección de datos utilizado para la medición de la conciencia ambiental fue la Escala Nuevo Paradigma Ecológico Revisada conformada por 15 ítems, y el instrumento de recolección de datos utilizado para la medición de la conducta pro ambiental fue adaptado a partir de la Escala de Conductas Protectoras del Ambiente, conformada por 16 ítems. En relación a la conciencia ambiental, 223 estudiantes (94.5\%) muestran un nivel apropiado (alternativas "de acuerdo" y "completamente de acuerdo"), 13 estudiantes (5.5\%) presentan un nivel no apropiado (alternativas "completamente en desacuerdo", "en desacuerdo" y "no estoy seguro"). En relación a la conducta pro ambiental, 133 estudiantes (56.3\%) muestran una conducta apropiada (alternativas "muchas veces" "y "siempre") y 103 estudiantes (43.7\%) muestran una conducta no apropiada (alternativas "casi nunca" y "a veces"). Se concluye que, existe predominio de un nivel alto de conciencia ambiental, además predominio de una conducta pro ambiental apropiada. Existe relación directa entre la conciencia ambiental y la conducta pro ambiental.

Palabras clave: Conciencia ambiental, conducta pro ambiental, medio ambiente.

\begin{abstract}
The aim of this study was to determine the relation between environmental awareness and pro-environmental behavior of first-cycle students in Maria Auxiliadora University. According to materials and methods, it was a quantitative approach study and it was a non-experimental, correlational and transversal design. The sample included 236 students selected by probability sampling from 610 first-cycle students at Maria Auxiliadora University. It was used the Revised New Paradigm Environmental Scale that included 15 items to measure the environmental awareness, and the pro-environmental behavior was measured using a modified scale from the original Environmental Protection Behavior Scale that included 16 items. Regarding the environmental awareness, 223 students (94.5\%) students had an appropriate level (agree and completely agree options), and 13 students (5.5\%) had a low level (completely disagree, disagree and unsure options). In relation to pro-environmental behavior, 133 students $(56.3 \%$ ) developed an appropriate behavior (many times and always options), and 103 students $(43.7 \%)$ developed an inappropriate behavior (sometimes and hardly ever options). There was direct relation between environmental awareness and pro-environmental behavior. It was concluded that there was a high level of environmental awareness. Pro-environmental behavior was developed appropriately. There was direct relation between environmental awareness and pro-environmental behavior.
\end{abstract}

Keywords: Environmental awareness, pro-environmental behavior, environment. 


\section{INTRODUCCIÓN}

El ambiente universitario es propicio para la transmisión de información respecto al cuidado del medio ambiente. De acuerdo a esto, habría que considerar si la preocupación sobre las propiedades del entorno ambiental, se halla en relación a una conducta adecuada hacia la protección del mismo. Puede considerarse que, la instauración de un estado de preocupación por la conservación ambiental sería indispensable como un paso previo al desarrollo de estrategias dirigidas al control y recuperación de los elementos constituyentes del ambiente, pero dada la complejidad de la conducta humana, esta podría orientarse de acuerdo a diversos estímulos que no obedezcan necesariamente al aspecto reflexivo. El cuidado del medio ambiente inculcado a los estudiantes puede requerir el empleo de estrategias educativas que posibiliten la introducción de conceptos nuevos para su comprensión inicial y posterior toma de conciencia. Puede ser necesario, además, estimular la participación activa en tareas de prevención y control respecto a la afección del entorno. Es necesario resaltar las características del estudio en un ámbito específico y reducido, ya que situaciones como las referidas en la presente investigación más que la búsqueda de generalización de resultados, se orienta a la identificación exacta de elementos en un área reducida, desde donde es más precisa la adecuación o aplicación de estrategias para optimizar resultados.

Respecto a la conciencia, Dehaene (2015) y Valderas (2017) concuerdan en que involucra percepciones, pensamientos, sentimientos y sociabilidad; es decir, se trata de un proceso por el cual los individuos se percatan de los fenómenos. Asimismo, se considera que la conciencia es un saber implícito en algo; es decir, cuando nos hacemos conscientes, lo que hacemos es recuperar la conciencia de algo que ya existe (Scaramelli, 2011). Las características previamente consideradas serán aplicadas al identificar las alteraciones o daño ambiental pudiendo establecerse un diagnóstico o materia de preocupación, siendo esto el fundamento de lo que es en esencia la conciencia ambiental. Por su parte, Mosterín (2010) señala la importancia de la conciencia para identificar los desórdenes progresivos en el entorno del ser humano.

En relación a la conducta como eje guía de las actividades desarrolladas por los individuos, esta se manifiesta como una reacción de los sujetos frente a diversas situaciones (Consuegra, 2009). Además, dicha conducta puede observarse y medirse. De acuerdo a los factores que originan la conducta, los fenómenos psíquicos son aquellos que propician las manifestaciones corporales, lo cual es denominado perspectiva idealista; además, la influencia social también contribuye sobre la conducta, y esto es considerado como una concepción materialista (Grande-García, 2013).

$\mathrm{Al}$ desarrollar una conducta dirigida a proteger el entorno físico o natural se establece la definición de conducta pro ambiental o llamada también pro ecológica. Con base en las actividades específicas que dicha conducta incluye, son señalados el reciclaje, acciones de estética ambiental, compra de productos no dañinos para el ambiente, ahorro de agua, ahorro de energía eléctrica, reducción en el uso de automóviles, ahorro de combustible, revisión de temas ambientales, persuasión pro ecológica (Corral, 2012). El ser humano, gracias a su conducta, es capaz de controlar y atenuar los efectos nocivos sobre el ambiente, ya que se dispone de la tecnología necesaria e idónea para cada aspecto involucrado (Flannery, 2011; Williams, 2018; Lanegra, 2017).

El estudio se justifica por la importancia de la recuperación del entorno o mitigación de efectos dañinos a causa de la actividad humana, lo cual debe tomarse en cuenta en las instituciones educativas; en el presente caso, desde el ámbito universitario.

Considerando lo señalado, el objetivo principal del presente estudio consiste en determinar la relación entre la conciencia ambiental y la conducta pro ambiental en los estudiantes universitarios de primer ciclo.

\section{MATERIAL Y MÉTODOS}

El estudio es cuantitativo con diseño no experimental, relacional y transversal. Se ejecutó en el distrito de San Juan de Lurigancho, siendo el ámbito específico la Universidad María Auxiliadora. La población estuvo constituida por 236 estudiantes seleccionados por muestreo probabilístico de una población de 610 estudiantes de primer ciclo de las facultades de Ciencias de la Salud y Ciencias Empresariales. Los criterios de inclusión fueron: Estudiantes regulares de la universidad, pertenecientes al primer ciclo de estudios. Se excluyeron a aquellos que por diversas circunstancias presentaban dificultades para el normal desarrollo de sus 
actividades en la institución. La técnica de recolección de datos fue la encuesta y los instrumentos empleados correspondieron a escalas. Se aplicaron dichos instrumentos en las aulas.

Para evaluar la conciencia ambiental, se empleó la Escala Nuevo Paradigma Ecológico Revisada desarrollada por Dunlap, Van Liere, Mertig y Jones (2000) (Adaptación de la escala NEP del año 1978 elaborada por Dunlap y Van Liere) (Dunlap \& Van Liere, 2008). La medición de la conducta pro ambiental se realizó por medio de un instrumento adaptado a partir de la Escala de Conductas Protectoras del Ambiente de Corral, Hess, Hernández y Suárez elaborada en el año 2002 (Corral, Frías y González, 2003).

Para el análisis de datos se empleó el programa estadístico IBM SPSS versión 23, desarrollando el análisis descriptivo de las dimensiones $e$ indicadores correspondientes, así como el análisis inferencial durante la evaluación de la relación (prueba de correlación Rho de Spearman) entre variables. De acuerdo al aspecto ético, las actividades desarrolladas en el estudio no representaron riesgo alguno para los individuos participantes quienes aceptaron voluntariamente su inclusión tras la comunicación de las características y procedimientos involucrados.

\section{RESULTADOS}

En la tabla 1 se evidencia el predominio de la opción "Completamente de acuerdo" con 137 casos (58.1\%), seguido de las opciones "De acuerdo", "No estoy seguro", "En desacuerdo" y "Completamente en desacuerdo con 86 casos (36.4\%), 9 casos (3.8\%), 3 casos $(1.3 \%)$ y 1 caso $(0.4 \%)$, respectivamente. Considerando que las respuestas favorables corresponden a las opciones "Completamente de acuerdo" y "De acuerdo", se asume que es apropiado el nivel de conciencia ambiental.

Tabla1. Conciencia ambiental en estudiantes de primer ciclo de la Universidad María Auxiliadora

\begin{tabular}{|llcccc|} 
& Frecuencia & Porcentaje & $\begin{array}{c}\text { Porcentaje } \\
\text { válido }\end{array}$ & $\begin{array}{r}\text { Porcentaje } \\
\text { acumulado }\end{array}$ \\
\hline \multirow{3}{*}{ Válidos } & Completamente en desacuerdo & 1 & 0.4 & 0.4 & 0.4 \\
& En desacuerdo & 3 & 1.3 & 1.3 & 1.7 \\
& No estoy seguro & 9 & 3.8 & 3.8 & 5.5 \\
& De acuerdo & 86 & 36.4 & 36.4 & 41.9 \\
& Completamente de acuerdo & 137 & 58.1 & 58.1 & 100 \\
& Total & 236 & 100 & 100 &
\end{tabular}

En la tabla 2 se evidencia el predominio de la opción "Muchas veces" con 115 casos (48.7\%), seguido de la opción "A veces" con 95 casos (40.3\%). El tercer lugar corresponde a la opción "Siempre" con 18 casos $(7.6$ $\%)$.
Finalmente, el cuarto lugar corresponde a la opción "Casi nunca" con 8 casos (3.4\%). Considerando que las respuestas favorables corresponden a las opciones "Muchas veces" y "Siempre", se asume que la conducta pro ambiental es desarrollada apropiadamente.

Tabla 2. Conducta pro ambiental en estudiantes de primer ciclo de la Universidad María Auxiliadora

\begin{tabular}{|c|c|c|c|c|c|}
\hline & & Frecuencia & Porcentaje & $\begin{array}{c}\text { Porcentaje } \\
\text { válido }\end{array}$ & $\begin{array}{l}\text { Porcentaje } \\
\text { acumulado }\end{array}$ \\
\hline \multirow{5}{*}{ Válidos } & Casi nunca & 8 & 3.4 & 3.4 & 3.4 \\
\hline & A veces & 95 & 40.3 & 40.3 & 43.6 \\
\hline & Muchas veces & 115 & 48.7 & 48.7 & 92.4 \\
\hline & Siempre & 18 & 7.6 & 7.6 & 100 \\
\hline & Total & 236 & 100 & 100 & \\
\hline
\end{tabular}


En la tabla 3, se evidencia que el resultado de la prueba no paramétrica Rho de Spearman es 0.210, lo cual sugiere una relación no muy significativa pero positiva. El valor en la prueba de significación bilateral de 0.001 resulta menor a la probabilidad de 0.05 , lo cual corrobora la existencia de relación directa entre las variables.

Tabla 3. Relación entre la conciencia ambiental y la conducta pro ambiental

\begin{tabular}{|lllcc} 
& & & $\begin{array}{c}\text { Conciencia } \\
\text { ambiental }\end{array}$ & $\begin{array}{c}\text { Conducta pro } \\
\text { ambiental }\end{array}$ \\
\hline & Conciencia & Coeficiente de correlación & 1.000 & 0.210 \\
Rho de & ambiental & Sig. (bilateral) & & 0.001 \\
Spearman & N & Coeficiente de correlación & 0.210 & 236 \\
& Conducta pro & Sig. (bilateral) & 0.001 & 1.000 \\
& ambiental & N & 236 & 236 \\
\end{tabular}

En la tabla 4 se evidencia, de acuerdo al valor de la significancia inferior a $0.05(5 \%)$, relación entre los resultados de los ítems p2:c11, p2:c16, p3:c6, p3:c13, p3:c14, p5:c8, p5:c9, p5:c10, p5:c11, p5:c12, p5:c13, p5:c14, p7:c12, p8:c12, p9:c12, p10:c11, p10:c12, p10:c14, p10:c15, p11:c3, p11:c11, p11:c13, p11:c15, p12:c1, p12:c3, p12:c12, p12:c14, p13:c3, p13:c6, p13:c7, p13:c11, p13:c12, p13:c14, p13:c16, siendo señaladas las Escalas con los ítems respectivos.

Escala Nuevo Paradigma Ecológico Revisada (Dunlap, Van Liere, Mertig y Jones, 2000)

1. Nos estamos aproximando al número límite de personas que la tierra puede albergar.

2 . Los seres humanos no tienen derecho a modificar el medio ambiente para adaptarlo a sus necesidades.

3. Cuando los seres humanos interfieren en la naturaleza, a menudo las consecuencias son desastrosas.

4. La creatividad humana no evitará que el planeta se dañe.

5. Los seres humanos están abusando seriamente del medio ambiente.

6. La tierra tiene recursos naturales que deben ser protegidos.

7. Las plantas y los animales tienen tanto derecho como los seres humanos a existir.

8. La naturaleza no puede soportar todo el daño que le causan.

9. Los seres humanos debemos respetar las leyes de la naturaleza.

10. La humanidad será afectada por los problemas ambientales.
11. La tierra tiene recursos que pueden agotarse.

12. Los seres humanos no tienen derecho a dominar la naturaleza.

13. El equilibrio de la naturaleza es muy delicado y fácilmente alterable.

14. Los seres humanos no han cuidado adecuadamente a la naturaleza.

15. Si las cosas continúan como hasta ahora, pronto experimentaremos una gran catástrofe ecológica.

Escala de Conductas Protectoras del Ambiente (Corral, Frías y González, 2009).

1. Leo sobre temas de Ecología.

2. Llamo la atención a quien daña el ambiente.

3. Converso sobre temas de Ecología.

4. Veo o escucho programas sobre Ecología.

5. Recojo envolturas o envases descartables que otras personas arrojan.

6. Apago las luces si otros las dejan encendidas.

7. Apago la radio o la televisión si otros las dejan encendidas.

8. Al lavar utensilios cuido el agua.

9. Al lavar ropa cuido el agua.

10. Al cepillarme los dientes cuido el agua.

11. Uso los frascos de vidrio de los productos envasados que he comprado.

12. Cuando escribo sobre papel trato de abarcar la mayor superficie posible.

13. Uso las latas de aluminio de los productos envasados que he comprado.

14. Compro productos elaborados con materiales reciclados.

15. Compro productos que no dañen el ambiente.

16. Compro bebidas con envase retornable. 
Tabla 3. Relación entre la conciencia ambiental y la conducta pro ambiental

\begin{tabular}{|c|c|c|c|c|c|c|c|c|c|c|c|c|c|c|c|c|c|}
\hline & & c1 & c2 & c3 & c4 & c5 & c6 & c7c & c8 & c9 & c10 & c11 & c12 & c13 & c14 & c15 & c16 \\
\hline \multirow{3}{*}{$\mathrm{p} 1$} & Corr. & 0.052 & 0.014 & 0.113 & 0.040 & -0.076 & 0.034 & 0.075 & -0.101 & -0.046 & -0.034 & 0.024 & 0.043 & 0.099 & 0.098 & -0.007 & 0.008 \\
\hline & & & & & & & & & & & & & & & & & \\
\hline & Sig. & 0.428 & 0.834 & 0.084 & 0.537 & 0.245 & 0.608 & 0.251 & 0.122 & 0.481 & 0.601 & 0.715 & 0.514 & 0.131 & 0.132 & 0.914 & 0.901 \\
\hline \multirow{2}{*}{ p2 } & Corr. & 0122 & 0.031 & 0.104 & 0.124 & -0.106 & 0.024 & 0.035 & 0.015 & -0.030 & 0.006 & $0.144^{*}$ & 0.102 & 0.043 & 0.064 & 0.071 & $0.143^{*}$ \\
\hline & Sig. & 0.062 & 0.640 & 0.112 & 0.057 & 0.104 & 0.718 & 0.595 & 0.821 & 0.647 & 0.926 & 0.027 & 0.117 & 0.515 & 0.327 & 0.281 & 0.028 \\
\hline \multirow{2}{*}{ p3 } & Corr. & 0.101 & -0 . & 0.072 & 0.096 & -0.007 & 0.169 & 0.101 & 0.081 & 0.038 & -0.003 & 0.090 & 0.068 & 0.137 & $0.162^{*}$ & 0.058 & 0.057 \\
\hline & Sig. & 0.121 & 0.773 & 0.272 & 0.140 & 0.912 & 0.009 & 0.121 & 0.215 & 0.559 & 0.967 & 0.168 & 0.298 & 0.035 & 0.013 & 0.372 & 0.383 \\
\hline \multirow{3}{*}{$\mathrm{p} 4$} & Corr. & 0.028 & 0.068 & 0.015 & 0.007 & -0.013 & 0.016 & 0.084 & 0.009 & 0.062 & 0.114 & 0.010 & -0.019 & -0.026 & -0.015 & 0.086 & 0.125 \\
\hline & & & & & & & & & & & & & & & & & \\
\hline & Sig. & 0.672 & 0.302 & 0.813 & 0.911 & 0.849 & 0.807 & 0.198 & 0.890 & 0.343 & 0.080 & 0.879 & 0.771 & 0.686 & 0.820 & 0.187 & 0.054 \\
\hline \multirow{2}{*}{ p5 } & Corr. & -0.030 & 0.058 & 0.048 & 0.097 & 0.009 & 0.106 & 0.055 & $0.140^{*}$ & $0.128^{\circ}$ & 0.179 & $0.130^{*}$ & $0.177^{\text {t+ }}$ & 0.141 & $0.134^{*}$ & 0.101 & 0.024 \\
\hline & Sig. & 0.646 & 0.374 & 0.461 & 0.139 & 0.885 & 0.105 & 0.404 & 0.032 & 0.049 & 0.006 & 0.046 & 0.006 & 0.030 & 0.040 & 0.122 & 0.709 \\
\hline \multirow{2}{*}{ p6 } & Corr. & -0.029 & -0 & 0.061 & 0.024 & -0.002 & 0.098 & 0.034 & 0.066 & -0.006 & 0.041 & 0.055 & 0.098 & 0.088 & 0.114 & 0.110 & 0.046 \\
\hline & Sig. & 0.662 & 0.915 & 0.351 & 0.713 & 0.978 & 0.132 & 0.606 & 0.313 & 0.926 & 0.531 & 0.399 & 0.135 & 0.175 & 0.081 & 0.091 & 0.480 \\
\hline \multirow{2}{*}{ p7 } & Corr. & -0.030 & -0 & -0.052 & 0.007 & 0.032 & -0.005 & 0.024 & 0.057 & -0.029 & 0.017 & 0.084 & $0.128^{*}$ & 0.092 & 0.062 & 0.020 & -0.012 \\
\hline & Sig. & 0.642 & 0.317 & 0.424 & 0.912 & 0.630 & 0.940 & 0.718 & 0.383 & 0.657 & 0.794 & 0.199 & 0.049 & 0.160 & 0.346 & 0.765 & 0.857 \\
\hline \multirow{2}{*}{ p8 } & Corr. & -0.046 & 0.009 & 0.089 & 0.044 & -0.071 & 0.058 & 0.047 & 0.031 & 0.041 & 0.020 & 0.126 & $0.150^{*}$ & 0.123 & 0.120 & 0.090 & 0.058 \\
\hline & Sig. & 0.480 & 0.890 & 0.173 & 0.501 & 0.280 & 0.376 & 0.474 & 0.638 & 0.533 & 0.762 & 0.054 & 0.021 & 0.060 & 0.066 & 0.170 & 0.379 \\
\hline \multirow{2}{*}{ p9 } & Corr. & -0.019 & 0.001 & 0.010 & 0.004 & -0.005 & 0.020 & 0.032 & 0.054 & 0.048 & 0.023 & 0,105 & $0.159^{\star}$ & 0.079 & 0.077 & 0.061 & 0.031 \\
\hline & Sig. & 0.775 & 0.984 & 0.880 & 0.956 & 0.939 & 0.755 & 0.621 & 0.407 & 0.466 & 0.728 & 0.108 & 0.014 & 0.225 & 0.237 & 0.349 & 0.632 \\
\hline \multirow{2}{*}{10} & Corr. & 0.057 & 0.068 & $0.155^{*}$ & 0.051 & 0.061 & 0.124 & 0.111 & 0.071 & 0.037 & 0.110 & $0.227^{* *}$ & $0.215^{*+}$ & 0.085 & $0.135^{*}$ & $0.216^{* *}$ & $0.128^{*}$ \\
\hline & Sig. & 0.381 & 0.295 & 0.017 & 0.439 & 0.353 & 0.058 & 0.088 & 0.277 & 0.569 & 0.092 & 0.000 & 0.001 & 0.193 & 0.039 & 0.001 & 0.050 \\
\hline \multirow{2}{*}{ p11 } & Corr. & 0.079 & 0.021 & 0.143 & 0.057 & -0.001 & 0.023 & 0.049 & 0.087 & 0.037 & 0.034 & $0.213^{* *}$ & 0.120 & 0.144 & 0.126 & 0.231 & 0.029 \\
\hline & Sig. & 0.224 & 0.751 & 0.028 & 0.385 & 0.994 & 0.728 & 0.451 & 0.183 & 0.568 & 0.602 & 0.001 & 0.065 & 0.027 & 0.053 & 0.000 & 0.656 \\
\hline \multirow{3}{*}{ p12 } & Corr. & $0.129^{*}$ & -0 & 0.172 & 0.082 & -0.039 & 0.018 & 0.035 & 0.056 & 0.015 & 0.048 & 0.124 & $0.192^{*+*}$ & 0.078 & $0.142^{*}$ & 0.101 & 0.022 \\
\hline & & & & & & & & & & & & & & & & & \\
\hline & Sig. & 0.048 & 0.907 & 0.008 & 0.211 & 0.546 & 0.783 & 0.589 & 0.395 & 0.816 & 0.464 & 0.057 & 0.003 & 0.232 & 0.029 & 0.124 & 0.737 \\
\hline \multirow{3}{*}{ p13 } & Corr. & 0.101 & 0.048 & 0.159 & 0.062 & -0.043 & 0.161 & $0.133^{*}$ & 0.052 & 0.033 & 0.055 & $0.169^{* *}$ & $0.188^{* *}$ & 0.111 & $0.159^{*}$ & 0.081 & $0.140^{*}$ \\
\hline & & & & & & & & & & & & & & & & & \\
\hline & Sig. & 0.122 & 0.466 & 0.014 & 0.339 & 0.515 & 0.013 & 0.042 & 0.424 & 0.609 & 0.400 & 0.009 & 0004 & 0.088 & 0.014 & 0.214 & 0.032 \\
\hline \multirow{3}{*}{ p14 } & Corr. & 0029 & 0.049 & 0.102 & 0.048 & 0.002 & 0.044 & 0.114 & 0.053 & 0.040 & 0.045 & 0.075 & 0.099 & 0.083 & 0.076 & 0.063 & 0.020 \\
\hline & & & & & & & & & & & & & & & & & \\
\hline & Sig. & 0.657 & 0.456 & 0.118 & 0.459 & 0.974 & 0.500 & 0.080 & 0.421 & 0.545 & 0.488 & 0.251 & 0.130 & 0.205 & 0.244 & 0.339 & 0.759 \\
\hline \multirow{3}{*}{ p15 } & Corr. & -0.061 & 0.007 & 0.074 & 0.051 & 0.088 & 0.061 & 0.078 & 0.023 & -0.005 & -0.007 & 0.071 & 0.061 & 0.000 & 0.009 & 0.021 & 0.049 \\
\hline & & & & & & & & & & & & & & & & & \\
\hline & Sig. & 0.351 & 0.918 & 0.261 & 0.439 & 0.178 & 0.350 & 0.232 & 0.729 & 0.939 & 0.921 & 0.276 & 0.352 & 0.994 & 0.896 & 0.745 & 0.456 \\
\hline
\end{tabular}

\section{DISCUSIÓN}

Es indispensable mantener el equilibrio en el entorno o medio ambiente; es decir, cada uno de los elementos que lo conforman debe complementarse con los demás, de acuerdo a las propiedades intrínsecas que posibilitan el carácter integrador. Si dicha integración se presenta de forma ordenada, constante o cíclica, los resultados se evidenciarán por un entorno favorable en donde los seres vivos desarrollan y conviven gracias a las posibilidades de sustento brindadas por las propias riquezas del espacio ambiental. Lamentablemente, los espacios o más específicamente determinados elementos o recursos han sufrido deterioro y dicho estado, aunque parezca contradictorio, ha resultado de la actividad de quienes por siglos se vieron 
beneficiados con las bondades brindadas por la naturaleza. En otras palabras, la actividad del ser humano que por descuido o en algunos casos, ambición, ha empleado su dominio para sustraer exageradamente elementos que difícilmente se recuperan.

A pesar de las dificultades para recuperar íntegramente el entorno, deben desarrollarse estrategias que eviten el progreso del daño ocasionado. Por tal motivo, es imprescindible el conocimiento y la inquietud por identificar aspectos nocivos para su control o mitigación.

En el presente estudio, la identificación de los aspectos dañinos señalados es considerada bajo el concepto de conciencia ambiental, en donde las alteraciones o eventos desfavorables deben ser identificados por los estudiantes en una primera instancia, determinando así aquello que es materia de preocupación para la búsqueda posterior de soluciones.

Los resultados respecto al nivel de conciencia ambiental se evidencian favorables en el grupo evaluado, siendo así capaces de analizar situaciones desfavorables, lo cual es un paso importante ya que no perciben como ajenas tales situaciones. Aminrad, Sayed, Samad \& Sakari (2013) identificaron, de forma similar, un nivel apropiado de conciencia ambiental en una población de estudiantes de nivel secundario al igual que Dicle, Isil \& Safiye (2010), quienes estudiaron dicha característica en una población de estudiantes universitarios. Es señalada, además, la preocupación por factores que de forma importante influyen sobre la conciencia ambiental. Así lo explican, Urda y Bonan (2016). El desarrollo de la conciencia ambiental pareciera ser importante para desencadenar conductas protectoras del entorno; es así que los resultados son consistentes con dicho enunciado, ya que la conducta resultante tras la medición estuvo representada por valores importantes. En concordancia a dichos resultados, Tien-Ming \& Homer (2015) señalaron un apropiado grado de conductas favorables hacia el cuidado ambiental, del mismo modo que Palavecinos, Amérigo, Ulloa y Muñoz (2016) determinaron en poblaciones de Sudamérica y Europa. En diversos estudios se toman en cuenta numerosos factores asociados a la conducta, por tal motivo resulta complejo hallar un solo parámetro que permita la orientación de la misma.

Los resultados en la presente investigación permiten establecer relación directa entre la conciencia ambiental y la conducta pro ambiental, lo cual es coherente con los resultados presentados por Palavecinos et al., (2016), quienes señalan la relación directa entre ambas variables, especificando además ciertas características de las poblaciones involucradas en su análisis. Otros elementos involucrados podrían influenciar en dichos resultados, lo cual da luces para incrementar estudios al respecto. La complejidad señalada anteriormente, respecto al estudio de la conducta se manifiesta en diversos estudios con resultados variables, difíciles de uniformizar o generalizar hacia todas las poblaciones. Tonelo y Valladares (2015) presentan también resultados que permiten establecer una relación directa e importante entre conciencia ambiental y conducta sustentable. Las creencias y diversas normas de carácter subjetivo también pueden ser consideradas como influyentes en el desarrollo de la conducta protectora hacia el ambiente (Torres, Barreto y Vásquez, 2015).

Las características propias de los diversos estudios requieren la consideración o desarrollo de investigaciones constantes incluyendo múltiples variables, ya que cada uno de los aspectos específicos servirá para incrementar el conocimiento sobre la complejidad e importancia de la conducta como consecuencia fundamental con carácter significativo modificador de las particularidades del medio o entorno ambiental.

\section{CONCLUSIONES}

Existe predominio de un nivel alto de conciencia ambiental representado por las opiniones favorables al identificar las características de deterioro ambiental y reconociendo la responsabilidad de los seres humanos. Existe predominio de una conducta pro ambiental apropiada, al identificar un nivel elevado de conductas que se orientan a la recuperación o mitigación de eventos adversos. En el presente estudio se evidencia relación directa entre la conciencia ambiental y la conducta pro ambiental, por lo que el grado de preocupación respecto al daño del ambiente se puede reflejar en las conductas protectoras del entorno. A pesar de considerar herramientas que de manera subjetiva evalúan las variables de estudio, siendo esto una posible limitante para el análisis de resultados, debe considerarse que la cuantificación aplicada proporciona parámetros de orientación para desarrollar estudios desde otros enfoques, habiendo sido algunos señalados en estudios previos. 


\section{REFERENCIAS BIBLIOGRÁFICAS}

Aminrad, Z., Sayed, S., Samad, A. \& Sakari, M. (2013). Relationship between awareness, knowledge and attitudes towards environmental education among secondary school students in Malaysia. World Applied Sciences Journal, 22(9), 1326-1333. Recuperado de https://www.research gate.net/publication/286958008_Rela tionship_between_awareness_knowl edge and attitudes towards environ mental_education_among_secondary school_students_in_Malaysia

Consuegra, N. (2009). Diccionario de psicología. Recuperado de https://ebookcentral. proquest.com

Corral, V. (2012). Sustentabilidad y psicología positiva: una visión optimista de las conductas proambientales y prosociales. Recuperado de https://ebookcentral.proquest.com

Corral, V., Frías, M. \& González, D. (2003) Percepción de riesgos, conducta proambiental y variables demográficas en una comunidad de Sonora, México. Región y sociedad, 15(26), 49-72. Recuperado de http://www.scielo.org.mx/scielo.p $\mathrm{hp}$ ? script $=$ sci arttext\&pid $=\mathrm{S} 1870$ $39252003000100002 \& \operatorname{lng}=\mathrm{es} \& \operatorname{tlng}=$

Dehaene, S. (2015). La conciencia en el cerebro: descifrando el enigma de cómo el cerebro elabora nuestros pensamientos. Recuperado de https://ebookcentral.proquest.com

Dicle, O., Isil, C. \& Safiye, K. (2010). Environmental awareness of University Students in Ankara, Turkey. African Journal of Agricultural Research, 5(19), 26292636 . R e c u p e r a d o d e https://academicjournals.org/article/a rticle1380961160_Oguz\%20et\%20al. pdf

Dunlap, R. \& Van Liere, K. (2008). The "New Environmental Paradigm", The Journal of Environmental Education, 40(1), 19-28. Recuperado de https://www.researchgate.net/publica tion/254345132_The_New_Environ mental_Paradigm

Dunlap, R., Van Liere, K., Mertig, A. \& Jones, R.
(2000). Measuring Endorsement of the New Ecological Paradigm; A revised NEP Scale. Journal of Social Issues 56(3), 425-442. Recuperado de https://web.standford.edu/kcarmel /CC_BehavChange_course/readings/ Additional\%20Resources/J\%20Soc $\% 20 I s s u e s \% 202000 /$ dunlap_2000_5 nep_a.pdf

Flannery, $\overline{\mathrm{T}}$. (2011). El clima está en nuestras manos: Historia del calentamiento global. Lima, Perú: Taurus.

Grande-García, I. (2013). Psicología: historia, teoría y procesos básicos. Recuperado dehttps://ebookcentral.proquest.com

Lanegra, I. (2017). ¿Qué es el cambio climático? Lima, Perú: Editorial Planeta Perú S.A.

Mosterín, J. (2010). Naturaleza, vida y cultura. Lima, Perú: Fondo editorial de la Universidad Inca Garcilaso de la Vega.

Palavecinos, M., Amérigo, M., Ulloa, J. y Muñoz, J. (2016). Preocupación y conducta ecológica responsable en estudiantes universitarios: estudio comparativo entre estudiantes chilenos y españoles. Psychosocial Intervention, 25(3), 143-148. Recuperado de http://scielo.isciii.es/scielo.php?script =sci arttext\&pid=S1132-

Scaramelli, A. (2011). Evolución de la conciencia: dónde estoy y hacia dónde $\begin{array}{llll}v & y\end{array}$. $\mathrm{R}$ e c u p e $\mathrm{r}$ a d o $\mathrm{d} \mathrm{e}$ https://ebookcentral.proquest.com

Tien-Ming, Ch. \& Homer, C. (2015). How do environmental knowledge, environmental sensitivity, and place attachment affect environmentally responsible behavior? An integrated approach for sustainable island tourism, Journal of Sustainable Tourism, 23(4), 557-576. Recuperado de https://www.tandfonline.com/doi/ abs/10.1080/09669582.2014.965177

Tonello, G. y Valladares, N. (2015). Conciencia ambiental y conducta sustentable relacionada con el uso de energía para iluminación. Gestión y Ambiente, 18(1),45-59. Recuperado de http://www.redalyc.org/articulo.oa?id $=169439782003$

Torres, T., Barreto, I. y Vásquez, J. (2015). Creencias y normas subjetivas como predictores de intención de 
comportamiento proambiental. Suma psicológica, 22(2), 86-92. Recuperado de https //www.science direct.com/science/article/pii/S01214 38115000235

Urda, E. \& Bonan, L. (2016). Saber no alcanza para actuar: revisión y reflexiones acerca de la relación entre el conocimiento y la adopción de conductas ambientales. Ciência \& Educação (Bauru), 23(2), 357-372.
Recuperado de http://www.scielo.br/ s c i e 1 o.p h p ? p id = S 1516 $73132017000200357 \&$ script $=$ sci_abs tract\&tlng $=\mathrm{es}$

Valderas, J. (2017). La Conciencia. México, México: RBA Editores México.

Williams, F. (2018). La dosis natural. (1 $\left.1^{\mathrm{a}} \mathrm{ed}.\right)$. Bogotá, Colombia: Editorial Planeta Colombiana S.A. 


\title{
Estudio geotécnico con fines de cimentación para tres asociaciones de vivienda en Tacna
}

\author{
Geotechnical study for foundation purposes for three housing associations in \\ Tacna
}

\author{
${ }^{1}$ Brandon Huanca Cutipa \\ ${ }^{2}$ Ruth Flores Terrazas \\ ${ }^{3}$ Wilber Mendoza Ramírez
}

\section{RESUMEN}

La presente investigación cuantitativa tuvo como objetivo principal plantear una adecuada alternativa de cimentación a partir de la realización de estudios geotécnicos mediante los ensayos de laboratorio y métodos geofísicos: refracción sísmica y MASW en las asociaciones de vivienda Los Damnificados del 23 de Junio B, Corazón de María y El Manantial, ubicados en el Distrito Coronel Gregorio Albarracín Lanchipa de la ciudad de Tacna. Con los ensayos de refracción sísmica se conoció la estratigrafía del terreno y su ripabilidad, con el ensayo de MASW se encontraron las propiedades dinámicas del suelo y su clasificación según NTE E.030, mientras que los ensayos de laboratorio determinan las propiedades físicas, químicas y mecánicas del suelo. Del ensayo de MASW se obtuvo que el tipo de suelo es $\mathrm{S} 1$ y corresponde a un suelo muy rígido, y de la exploración por calicatas se clasificó como grava pobremente graduada (GP). De los resultados se obtuvo un $\mathrm{Vs}_{30}$ (promedio) de $652.86 \mathrm{~m} / \mathrm{s}$, un Ts (promedio) de 0.18 y una capacidad de carga admisible con promedio de $2.1 \mathrm{~kg} / \mathrm{cm}^{2}$ por falla local. De este modo, se realizó una microzonificación de la zona con las velocidades de ondas de corte promedio $\mathrm{Vs}_{30}$, propiedades dinámicas del suelo y capacidad portante. Finalmente, conociendo las propiedades del suelo se diseñó una zapata aislada cuadrada de $1 \mathrm{~m}$ de ancho cimentada a una profundidad de $1.5 \mathrm{~m}$ para las tres asociaciones de vivienda.

Palabras claves: Cimentación, estudios Geotécnicos, métodos geofísicos, MASW, refracción sísmica, ripabilidad, suelos.

\section{ABSTRACT}

The main objective of this quantitative research is to propose an adequate alternative foundation based on geotechnical studies through laboratory tests and geophysical methods such as seismic refraction and MASW, which were applied in the housing associations of Los Damnificados del 23 de Junio - B, Corazón de María and El Manantial. All these three housing associations are in the district of Coronel Gregorio Albarracín Lanchipa in the city of Tacna, Peru. The stratigraphy of the terrain and its rippability were known with the help of the seismic refraction tests. With the MASW test, the dynamic properties of the soil and its classification according to NTE E.030 were found, while the laboratory tests determined the physical, chemical and soil mechanics. It was obtained from the MASW test, that the soil type is S1 which corresponds to a very rigid soil, and from the exploration of pits, it is classified as poorly graded gravel (GP). From these results, we obtained a $\mathrm{V}_{\mathrm{s} 30}$ (average) of $652.86 \mathrm{~m} / \mathrm{s}$, a Ts (average) of 0.18 and an average admissible load capacity of $2.1 \mathrm{~kg} / \mathrm{cm}^{2}$ for local failure. In this way, a microzoning of the area was carried out with the average cut wave velocities $\mathrm{V}_{\mathrm{s} 30}$, dynamic soil properties and bearing capacity. Finally, after obtaining the properties of the soil, a square shaped isolated footing of $1 \mathrm{~m}$ wide was designed and cemented to a depth of $1.5 \mathrm{~m}$ for the three housing associations.

Keywords: Foundations, geotechnical studies, geophysical methods, MASW, rippability Perú, seismic refraction, soils.

\footnotetext{
${ }^{1}$ Universidad Privada de Tacna. Tacna- Perú. E-mail: brandon10_700@hotmail.com

${ }^{2}$ Universidad Privada de Tacna. Tacna- Perú. E-mail: siiomaraaa@ $\bar{\varnothing}$ gmail.com

${ }^{3}$ Universidad Privada de Tacna. Tacna- Perú. E-mail: wimeral1601@hotmail.com
} 


\section{INTRODUCCIÓN}

La ciudad de Tacna es considerada una zona de silencio sísmico o laguna sísmica. Se espera un sismo de mayor intensidad al ocurrido el 23 de junio del 2001, que registró una intensidad de 6.9 en la escala de Richter. La población no está preparada para este fenómeno y mucho menos las infraestructuras de las viviendas, debido a que la mayoría de ellas son producto de construcciones informales, las cuales no cuentan con estudios de suelos, planos y la intervención de un profesional durante su proceso constructivo.

De este modo, después del terremoto del 2001, el Instituto Nacional de Defensa Civil (INDECI, 2004) desarrolló el mapa de peligros sísmicos en la ciudad de Tacna, el cual identificó los diferentes tipos de suelos que se ubican en la ciudad, clasificando los suelos del distrito Coronel Gregorio Albarracín Lanchipa entre gravas bien graduadas y pobremente graduadas. Debido al incremento de la población, se están poblando zonas que no fueron evaluadas detalladamente, por ejemplo, el sector denominado Viñani, ubicado en el distrito Coronel Gregorio Albarracín Lanchipa.

La presente investigación tiene como objetivo principal plantear una adecuada alternativa de cimentación a través de un estudio geotécnico, el cual beneficiará a las asociaciones de vivienda $L o s$ Damnificados del 23 de Junio B, Corazón de María y El Manantial. Los estudios geotécnicos fueron realizados mediante la exploración de calicatas, realización de ensayos básicos y especiales del suelo, y métodos geofísicos, obteniendo así las características del suelo, lo cual nos permite diseñar una adecuada cimentación.

Otros estudios se han basado en el estudio geofísico. Según Rosales (2001), los resultados explican el comportamiento dinámico del suelo y sus efectos sobre edificaciones. De igual forma, Huanacuni y Llanqui (2014) demuestran la clasificación de perfiles por medio de la velocidad de onda promedio de corte a $30 \mathrm{~m}$ y sus propiedades elásticas por la relación de velocidad de ondas Vpy Vs.

\section{MATERIALYMÉTODOS}

\section{Población o muestra de estudio}

Se consideró como población o muestra de estudio únicamente a las asociaciones de vivienda Los Damnificados del 23 de Junio B, Corazón de María y El Manantial ubicados en el distrito Coronel Gregorio Albarracín Lanchipa, Tacna.

\section{Técnicas e instrumentos para la recolección de} datos

Vara (2012) expresa que todos los instrumentos que se emplean para la recolección de datos científicos deben ser fiables y válidos. En cuanto a la recolección de datos se realizaron revisiones de informes del INDECI (Instituto Nacional de Defensa Civil), publicaciones del IGP (Instituto Geofísico del Perú), publicaciones del CISMID (Centro Peruano Japonés de Investigaciones Sísmicas y Mitigación de Desastres) e investigaciones de tesis similares que sirvieron como base para la realización de la siguiente investigación. De esta manera se realizó la visita a la zona de estudio. En la Figura 1 se observa el plano de ubicación del sector evaluado.

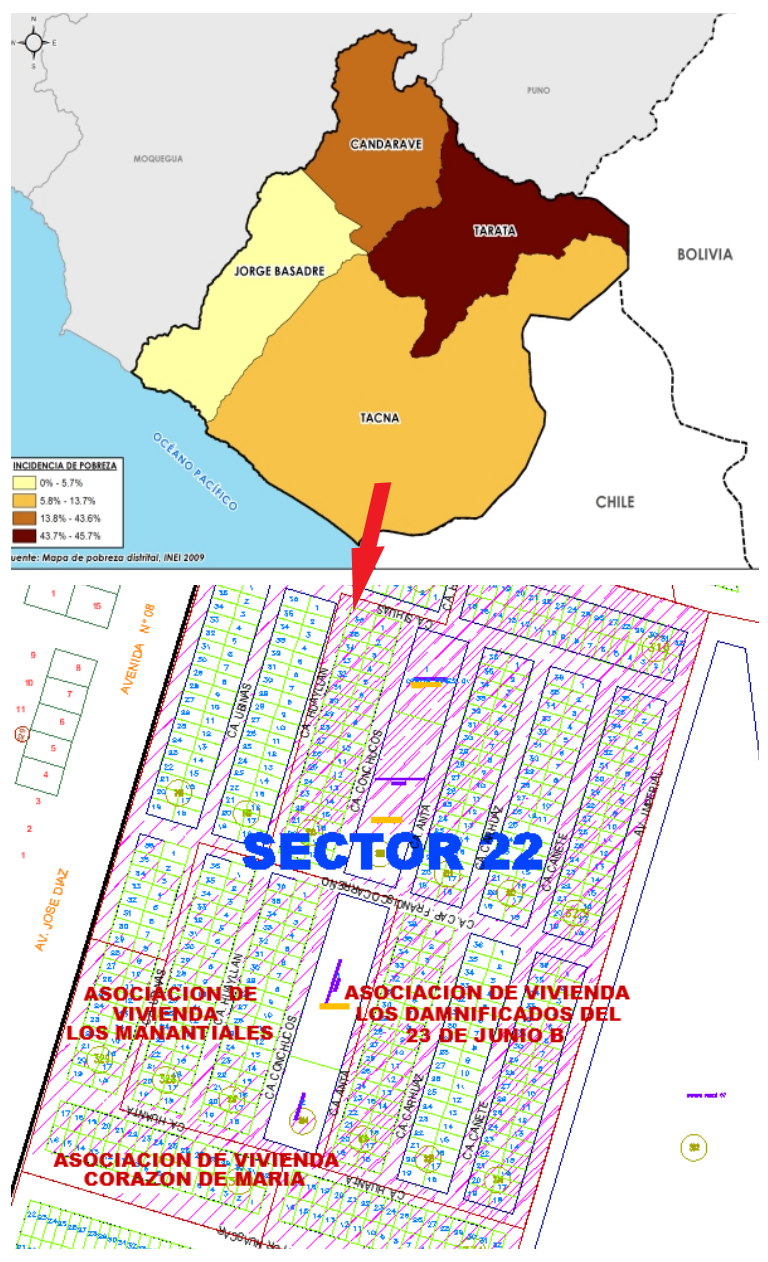

Figura 1. Plano de ubicación del sector evaluado.

De esta manera, se realizaron estudios geotécnicos mediante los ensayos de campo directos e indirectos: 


\section{Ensayos geotécnicos de campo indirectos}

En cuanto a los ensayos indirectos, se realizó la exploración geofísica mediante los métodos de Refracción Sísmica y Medición de Ondas de Corte (MASW) como se observa en la Figura 2.

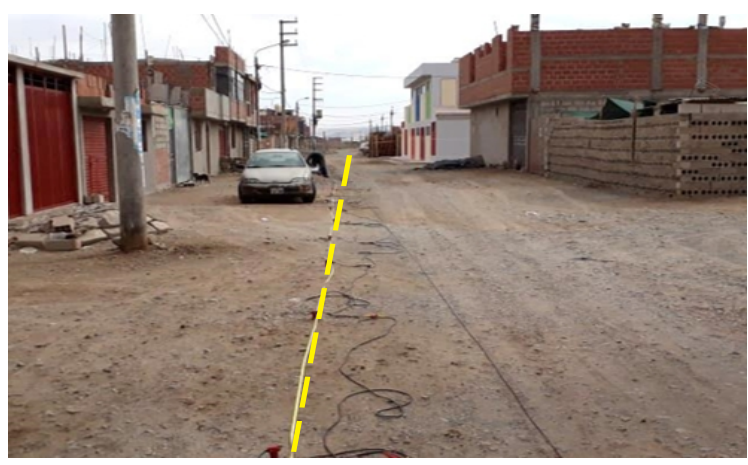

Figura 2. Línea de ensayo para el método de refracción sísmica y MASW.

El ensayo de refracción sísmica es un método de exploración geofísica que permite determinar la estratigrafía del subsuelo en forma indirecta, basándose en el cambio de las propiedades dinámicas de los materiales que lo conforman (Rivera, Piedra y Paripanca, 2016) Por otro lado, el Análisis Multicanal de Ondas Superficiales (MASW) es un método no destructivo que se usa para evaluar la velocidad de onda de corte (Vs), vinculado al mismo módulo de corte $(\mathrm{G})$. Este método analiza las propiedades de dispersión de los modos fundamentales de las ondas Rayleigh, las cuales se propagan a lo largo de la superficie desde el punto de impacto a los receptores (Park, Miller \& Xia, 1999). Esto indica que los perfiles sísmicos del terreno se precisan del método de inversión por las curvas de dispersión, por medio de las ondas Rayleight que se propagan en un medio de espacio homogéneo, consiguiendo una velocidad de fase, la cual varía entre un 90 \% y 95 $\%$ del valor de la velocidad de onda de corte (Vs) (Hayashi, 2008).

En el método de Refracción Sísmica se realizó un análisis total de $540 \mathrm{~m}$ lineales, ubicados en 7 líneas sísmicas; y se realizaron 6 ensayos de MASW, que fueron distribuidas adecuadamente en toda la zona de estudio para definir así la estratigrafía y el tipo de suelo del terreno.

Por otra parte, se realizó el levantamiento topográfico mediante fotogrametría. En la Figura 3 se observa el drone phantom 4pro v.2.0 utilizado para el levantamiento topográfico.

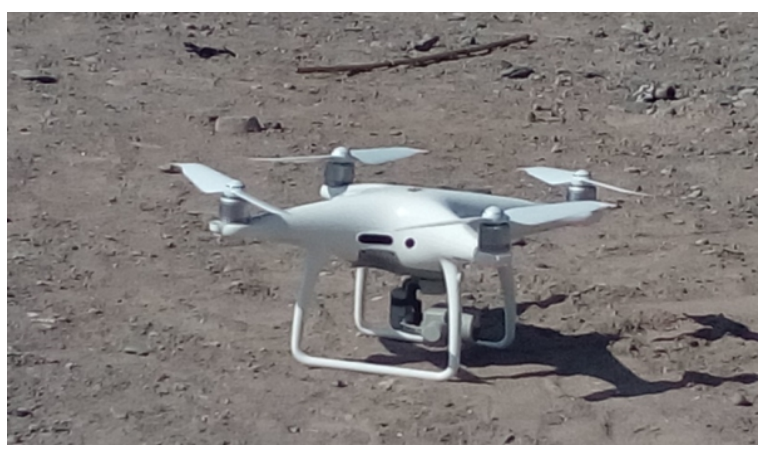

Figura 3. Drone phantom 4pro v.2.0 utilizado para el levantamiento topográfico.

\section{Ensayos geotécnicos de campo Directos}

En cuanto a los ensayos directos, se realizaron un total de 6 calicatas que fueron distribuidas en toda la zona de estudio como se observa en la Figura 4.

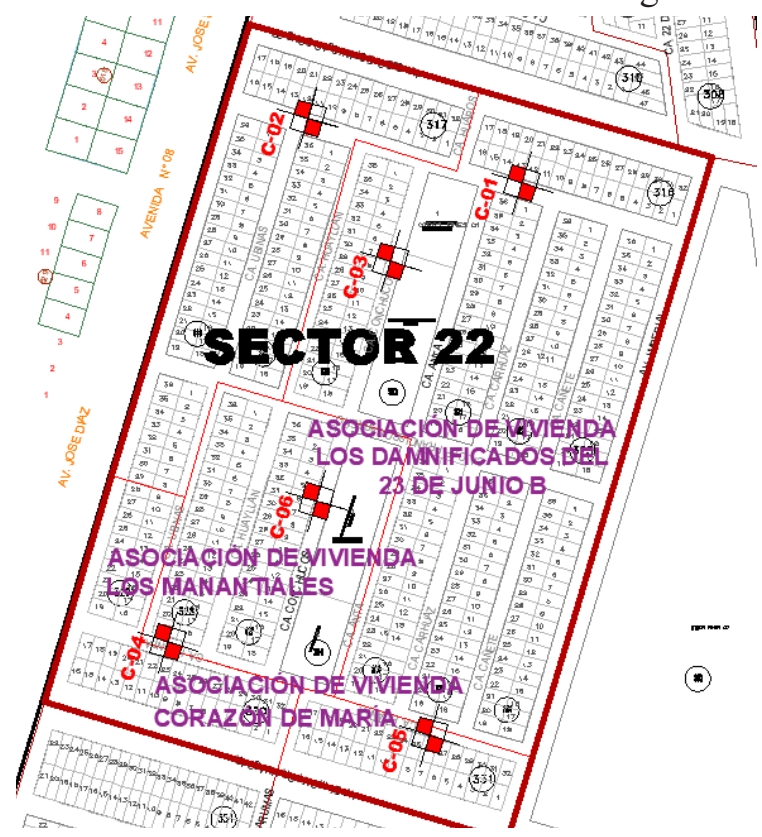

Figura 4. Ubicación de las calicatas.

Las calicatas fueron excavadas con una dimensión de $2 \mathrm{~m} * 1 \mathrm{~m}$ y con profundidades variables de 1.5 a $3 \mathrm{~m}$, cada calicata fue evaluada en campo por medio del ensayo de densidad in situ, realizado por el método del cono de arena, de acuerdo a la norma técnica peruana (NTP) 339.143 (NORMA - American Society for Testing and Materials o ASTM 1556).

De este modo, la norma técnica E.050 de Suelos y Cimentaciones nos indica las formas de obtener y transportar las muestras del terreno para la realización de los ensayos correspondientes, de las calicatas se extrajeron muestras alteradas en bolsas herméticas. 


\section{Procesamiento y análisis de datos}

El propósito principal de los ensayos geotécnicos es determinar las características de los diversos suelos presentes en la zona de estudio. E1 procesamiento y análisis de datos se ejecuta con el software SeisImager que es dispuesto por la página web Geometrics con acceso libre, en el cual se procesa la información a través de los módulos de programa según el procedimiento de (Park, Miller, Xia, \& Ivanov, 2007).
En la Tabla 1 se muestra la ubicación de las líneas geofísicas del ensayo de refracción sísmica. Este método consiste en medir el tiempo en el que la energía se propaga en forma de ondas $\mathrm{Vp}$ (ondas de compresión). El procesamiento de la información se ejecuta con el módulo de programa "PICKWIN", que determina el tiempo que tardan en propagarse las ondas sísmicas desde los puntos de tiro hasta los geófonos.

Tabla 1. Ubicación de las líneas geofísicas distribuidas en la zona de estudio. Datum: WGS84

\begin{tabular}{|c|c|c|c|c|c|c|c|c|c|}
\hline $\begin{array}{l}\text { UBICACIC } \\
\text { SÍSMICAS I }\end{array}$ & $\begin{array}{l}\text { E LAS LÍ } \\
\text { NVESTIG }\end{array}$ & 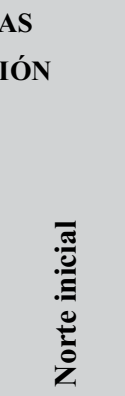 & 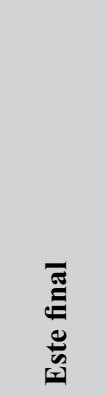 & 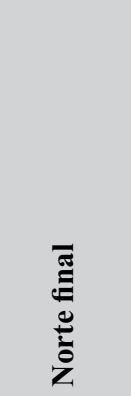 & 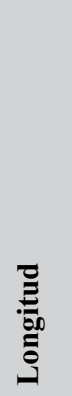 & 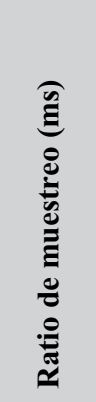 & 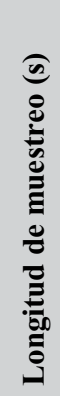 & 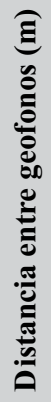 & 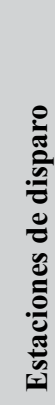 \\
\hline LS1 & 366495 & 802188 & 366566 & 8002164 & 70 & 0.125 & 0.5 & 3 & 5 \\
\hline LS2 & 366389 & 8002225 & 366461 & 8002199 & 70 & 0.125 & 0.5 & 3 & 5 \\
\hline LS3 & 366335 & 8002072 & 366407 & 8002048 & 70 & 0.125 & 0.5 & 3 & 5 \\
\hline LS4 & 366450 & 8002038 & 366523 & 8002014 & 70 & 0.125 & 0.5 & 3 & 5 \\
\hline LS5 & 366411 & 8001881 & 366483 & 8001956 & 70 & 0.125 & 0.5 & 3 & 5 \\
\hline LS6 & 366278 & 8001928 & 366351 & 8001902 & 70 & 0.125 & 0.5 & 3 & \\
\hline LS7 & 366404 & 8001984 & 366446 & 8002097 & 120 & 0.125 & 0.5 & 5 & 5 \\
\hline
\end{tabular}

En la Tabla 2 se aprecia la ubicación de los estudios MASW, este método se usa para evaluar la velocidad de onda de corte (Vs); la interpretación de los registros se realiza con el módulo de programa "SURFACE WAVE ANALYSIS", que consiste en obtener una curva de la velocidad de ondas superficiales versus la frecuencia, luego, mediante el módulo de programa "WAVE EQ" se realiza un cálculo inverso del método de inversión y a partir de la curva de dispersión se obtiene el perfil sísmico del terreno en función de Vs para cada punto de estudio.
Tabla 2. Ubicación de los estudios MASW. Datum: WGS 84

\begin{tabular}{cccccc} 
No & $\begin{array}{c}\text { ENSAYO } \\
\text { MASW }\end{array}$ & NORTE & ESTE & $\begin{array}{c}\text { UBICACIÓN } \\
\text { Ratio de } \\
\text { (ms) }\end{array}$ & $\begin{array}{c}\text { Longitud } \\
\text { de } \\
\text { muestreo } \\
\text { (s) }\end{array}$ \\
\hline 1 & MASW01 & 8002179 & 366537 & 1 & 1 \\
2 & MASW02 & 8002211 & 366423 & 1 & 1 \\
3 & MASW03 & 8002059 & 366374 & 1 & 1 \\
4 & MASW04 & 8002028 & 366490 & 1 & 1 \\
5 & MASW05 & 8001870 & 366444 & 1 & 1 \\
6 & MASW06 & 8001913 & 366319 & 1 & 1
\end{tabular}


En la Figura 5 se observa el plano con la ubicación de las 7 líneas sísmicas y 6 puntos de MASW

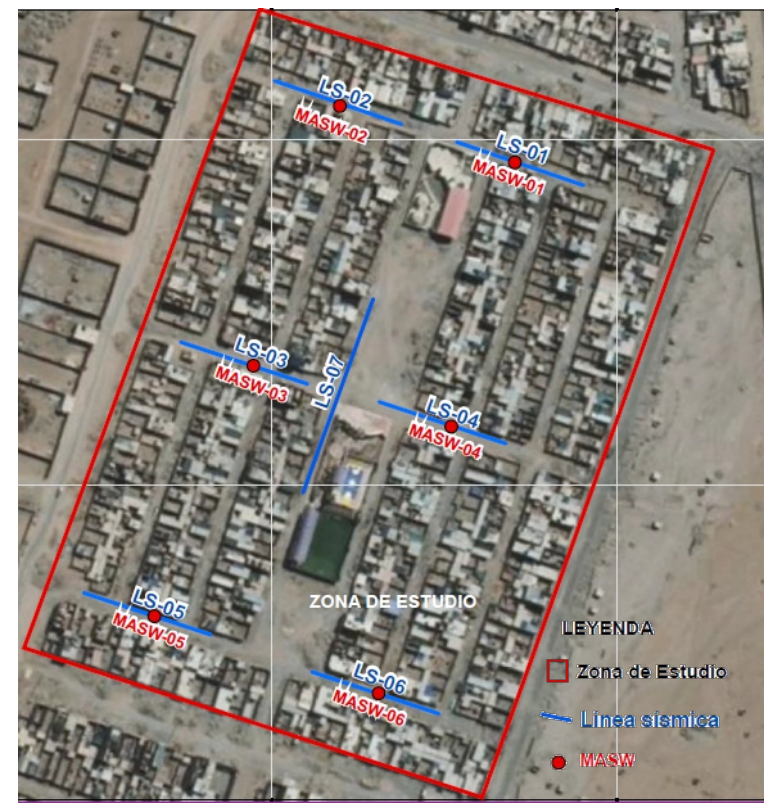

Figura 5. Plano de ubicación de las líneas sísmicas y MASW.A continuación, se señalan los ensayos de laboratorio realizados en la presente investigación.

Se realizaron los siguientes ensayos estándar: Contenido de Humedad NTP 339.127 (ASTM D2216); Análisis Granulométrico NTP 339.128
(ASTM D422); Densidad Máxima NTP 339.137 (ASTM D4253); Densidad Mínima NTP 339.138 (ASTM D4254), Densidad In situ NTP 339.143 (ASTM 1556); Ensayo de Compactación Proctor Modificado NTP 339.141 (ASTM D1557); Corrección de peso Unitario y Contenido de Humedad para partículas de sobre tamaño (ASTMD4718).

De esta forma se realizaron los siguientes ensayos especiales: Corte Directo NTP 339.171 (ASTM D3080); Compresión Triaxial no consolidado no drenado NTP 339.164 (ASTM D2850)

Asimismo se realizaron los siguientes ensayos químicos: Sulfatos NTP 400.014 (ASTM D 516); Cloruros NTP 400.014 (ASTM D 512); Contenido de Sales Solubles Totales en Suelos NTP 339.152 (BS 1377)

\section{RESULTADOS}

\section{Resultados de refracción sísmica}

En cuanto a los resultados del ensayo de refracción sísmica, se reconocieron 3 niveles de estratificación diferenciadas por sus velocidades de onda Vp. En la Tabla 3 se aprecia la descripción de los resultados obtenidos en las líneas sísmicas.

Tabla 3. Resultados obtenidos en las líneas sísmicas

\begin{tabular}{|c|c|c|c|c|c|}
\hline \multirow{3}{*}{$\begin{array}{l}\text { LÍNEA } \\
\text { SÍSMICA }\end{array}$} & \multicolumn{4}{|c|}{ POTENCIA } & \multirow[b]{3}{*}{ Material Coluvial. } \\
\hline & \multirow{2}{*}{$\begin{array}{c}\text { CAPA } \\
\text { A }\end{array}$} & \multicolumn{3}{|c|}{$\begin{array}{l}\text { PROMEDIO Vp (m/s) } \\
\quad(\mathrm{m})\end{array}$} & \\
\hline & & 2 & 300 & MATERIALES SUELTOS & \\
\hline \multirow[t]{3}{*}{-01 y LS-02 } & B & 5 & 1000 & RIPADO FACIL & Material Coluvial con saturación. \\
\hline & $\mathrm{C}$ & 18 & 2000 & RIPADO DURO - VOLADURA & Material-fluvial \\
\hline & A & $1-1.5$ & 300 & MATERIALES SUELTOS & Material Coluvial. \\
\hline \multirow[t]{3}{*}{-03 y LS-04 } & B & 4.5 & 1000 & RIPADO FACIL & Material Coluvial con saturación. \\
\hline & $\mathrm{C}$ & 14 & 2000 & RIPADO DURO - VOLADURA & Material-fluvial \\
\hline & A & $1-1.5$ & 300 & MATERIALES SUELTOS & Material Coluvial. \\
\hline \multirow[t]{3}{*}{-05 y LS-06 } & B & 4.5 & 1000 & RIPADO FACIL & Material Coluvial con saturación. \\
\hline & $\mathrm{C}$ & 14 & 2000 & RIPADO DURO - VOLADURA & Material-fluvial Coluvial \\
\hline & A & 1.5 & 300 & MATERIALES SUELTOS & Material Coluvial. \\
\hline \multirow[t]{2}{*}{ LS-07 } & B & 5 & 1000 & RIPADO FACIL & Material Coluvial con saturación. \\
\hline & $\mathrm{C}$ & 10 & 2000 & RIPADO DURO - VOLADURA & Material-fluvial \\
\hline
\end{tabular}


De acuerdo a los resultados obtenidos del ensayo de refracción sísmica, se distinguieron 3 niveles de estratificación: la capa A, B y C. Estas se determinan a continuación:

Estrato A: con velocidades de onda Vp 300 m/s; correspondiente a materiales sueltos no compactos siendo correlacionados por material suelto. Tiene una potencia menor a $5 \mathrm{~m}$.

Estrato B: con velocidades de onda Vp $1000 \mathrm{~m} / \mathrm{s}$, correspondiente a materiales semicompactos representados por conglomerados. Tiene una potencia menor a $8 \mathrm{~m}$.

Estrato C: con velocidades de onda Vp $2000 \mathrm{~m} / \mathrm{s}$, correspondientes a materiales semicompactos con mayor densidad (aumento de la Vp), representados por conglomerados. Tiene una potencia menor a $10 \mathrm{~m}$. De este modo, la velocidad sísmica de propagación de las ondas de compresión (Ondas Vp) es el parámetro más representativo para la ripabilidad del terreno. De esta manera, Caterpillar publica tablas de ripabilidad para los distintos modelos de tractores a través de la velocidad de onda Vp (Rodríguez, 2001).

Por otra parte, se realizó el procesamiento de datos. En la Figura 5 se observa el perfil de la línea sísmica LS-01.

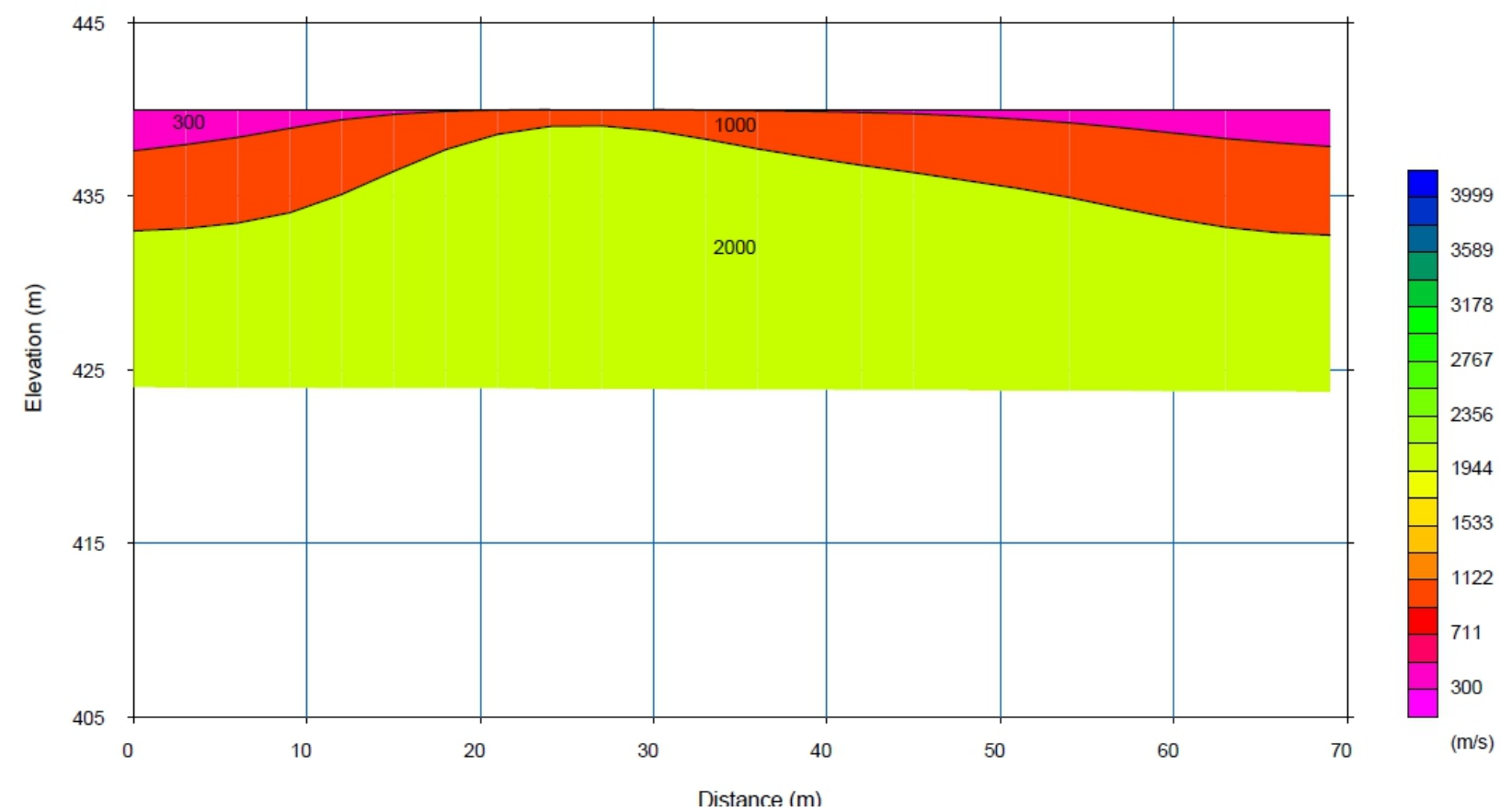

Figura 6. Perfil estratigráfico LS-02.

\section{Resultados de MASW}

De igual forma, del ensayo de MASW se determinó el perfil unidimensional de velocidades de onda S (Vs) hasta una profundidad de $30 \mathrm{~m}$. De este modo, se clasificó el tipo de suelo conforme a la NTE E.030 y se calculó el periodo fundamental de vibración del suelo Ts, tener en cuenta que este valor es referencial. Para este estudio se usó la fórmula según el código International Building Code (2012):

Donde:

$$
T s=\frac{4 H}{V s_{30}}
$$

$\mathrm{H}=\mathrm{La}$ potencia del estrato para nosotros $30 \mathrm{~m}$; $\mathrm{Vs}_{30}=$ El valor de la onda de corte Vs promedio.
En el Tabla 4 se aprecia la clasificación Vs30, con respecto a la Norma Sismorresistente (NTE) E.030 y periodo de vibración.

Tabla 4. Clasificación Sismorresistente E.030 y periodo de vibración Ts

\begin{tabular}{|c|c|c|c|c|c|c|}
\hline 离 & $\begin{array}{l}5 \\
\dot{1} \\
3 \\
3 \\
\sum\end{array}$ & 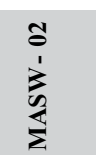 & $\begin{array}{l}0 \\
0 \\
1 \\
\vdots \\
\sum \\
\sum\end{array}$ & $\begin{array}{l} \pm \\
0 \\
1 \\
\vdots \\
\sum \\
\sum\end{array}$ & $\begin{array}{l}10 \\
0 \\
1 \\
3 \\
\frac{1}{2}\end{array}$ & $\begin{array}{l}0 \\
\vdots \\
1 \\
3 \\
5 \\
\sum\end{array}$ \\
\hline $\begin{array}{l}\text { Tipo } \\
\text { Suelo }\end{array}$ & S1 & S1 & S1 & S1 & S1 & S1 \\
\hline $\begin{array}{l}\text { Vs30 } \\
(\mathrm{m} / \mathrm{s})\end{array}$ & 658.1 & 677.4 & 639.8 & 653.9 & 645.6 & 642.1 \\
\hline Ts & $\begin{array}{l}0.18 \\
\text { ROCA }\end{array}$ & $\begin{array}{c}0.18 \\
\text { - SUEL }\end{array}$ & 0.19 & 0.18 & $\begin{array}{c}0.19 \\
\text { RO } \\
\text { SUF } \\
\text { RIG }\end{array}$ & $\begin{array}{l}0.19 \\
\text { LAO } \\
\text { LOS } \\
\text { DOS }\end{array}$ \\
\hline
\end{tabular}


De acuerdo a la Norma Técnica Peruana Sismorresistente (NTE) E.030 el tipo de suelo es S1 correspondiente a suelos muy rígidos, con una Vs30 variante desde $639.8 \mathrm{~m} / \mathrm{s}$ a $677.4 \mathrm{~m} / \mathrm{s}$ y un periodo de

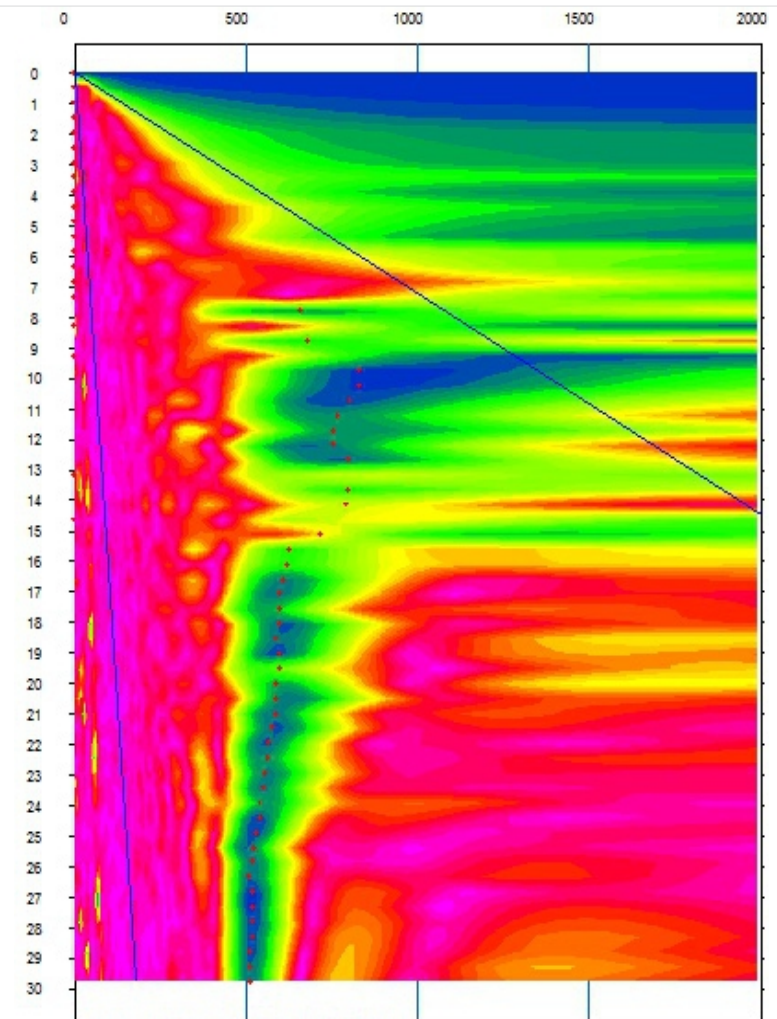

Figura 7. Procesamiento del registro sísmico MASW-02.

\section{Resultados de los ensayos de laboratorio}

Posteriormente, los ensayos de laboratorio que se realizaron a las muestras de la zona de estudio. En la Tabla 5 se aprecia el resumen de los resultados de los ensayos estándar.

Tabla 5. Resultados de los ensayos de laboratorio

\begin{tabular}{|c|c|c|c|c|c|c|c|c|}
\hline 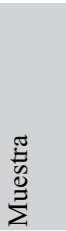 & 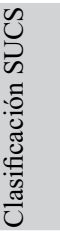 & 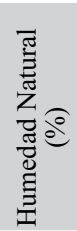 & 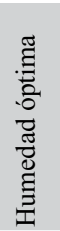 & 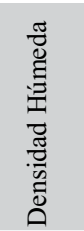 & 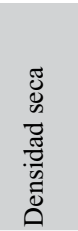 & 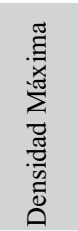 & 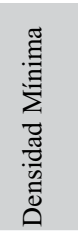 & 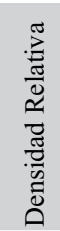 \\
\hline $\mathrm{C}-01$ & GP & 1.58 & 6.1 & 2.197 & 2.163 & 2.209 & 2.112 & 53.4 \\
\hline $\mathrm{C}-02$ & GP & 1.72 & 8.7 & 2.14 & 2.104 & 0.153 & 2.048 & 54.3 \\
\hline $\mathrm{C}-03$ & GP & 1.79 & 9.4 & 2.159 & 2.121 & 2.178 & 2.057 & 54 \\
\hline $\mathrm{C}-04$ & GP & 1.56 & 9.7 & 2.105 & 2.073 & 2.151 & 1.991 & 53.2 \\
\hline $\mathrm{G}-05$ & $\mathrm{P} P$ & 1.43 & 7.8 & 2.080 & 2.050 & 2.113 & 1.986 & 52.1 \\
\hline$=06$ & $P$ & 1.69 & 9.5 & 2.177 & 2.141 & 2.183 & 2.096 & 52.9 \\
\hline
\end{tabular}

Los ensayos de límite líquido y límite plástico no se pudieron completar, ya que el suelo no presenta las características necesarias. vibración del suelo (Ts) que va desde 0.18 a 0.19 , teniendo un promedio de Ts de 0.18 .

En la Figura 6, se muestra el análisis de la dispersión de ondas para ser invertidos en un perfil Vs de 1D.

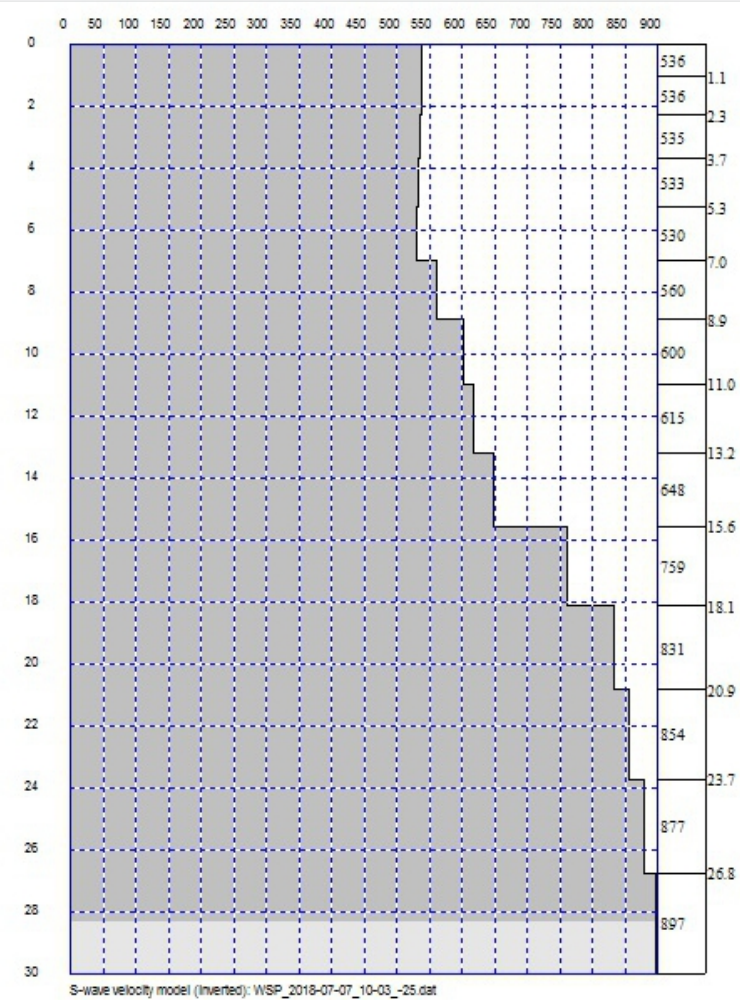

\section{Resultados de los ensayos especiales}

Los ensayos especiales, de corte directo y triaxial, fueron realizados sobre muestras alteradas, las cuales se extrajeron y se transportaron en bolsas impermeables, estos ensayos determinan el ángulo de fricción y el coeficiente de cohesión. En la Tabla 6 se muestra los resultados de los ensayos de corte directo y triaxial.

Tabla 6. Resultados de los ensayos de Corte Directo y Triaxial

\begin{tabular}{ccccc} 
Muestra & $\begin{array}{c}\text { Ensayo de Corte } \\
\text { Directo } \\
\text { Ángulo } \\
\text { de } \\
\text { fricción } \\
\left({ }^{\circ}\right)\end{array}$ & $\begin{array}{c}\text { Coeficiente } \\
\text { de } \\
\text { Cohesión } \\
\left(\mathrm{kg} / \mathrm{cm}^{2}\right)\end{array}$ & $\begin{array}{c}\text { Ensayo de } \\
\text { Compresión Triaxial } \\
\text { Ángulo } \\
\text { fricción } \\
\left({ }^{\circ}\right)\end{array}$ & $\begin{array}{c}\text { Coeficiente } \\
\text { de } \\
\text { Cohesión } \\
\left(\mathrm{kg} / \mathrm{cm}^{2}\right)\end{array}$ \\
\hline C-01 & 32.47 & 0.082 & - & - \\
C-02 & 35.66 & 0.114 & 32.47 & 0.00 \\
C-03 & 35.53 & 0.114 & 31.78 & 0.06 \\
C-04 & 37.11 & 0.130 & - & - \\
C-05 & 36.95 & 0.134 & 33.76 & 0.03 \\
C-06 & 37.80 & 0.124 & - & - \\
\hline
\end{tabular}




\section{Resultados de los ensayos químicos}

Para determinar el grado de agresividad química del suelo frente a una cimentación, se analizaron químicamente las muestras del suelo mediante los ensayos de cloruros, sulfatos y contenido de sales solubles. En la Tabla 7 se muestra los resultados de los ensayos químicos.

Tabla 7. Resultados de los ensayos químicos

\begin{tabular}{|c|c|c|c|c|c|c|}
\hline 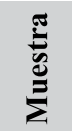 & $\frac{\mathscr{c}}{\stackrel{0}{0}}$ & $\frac{0}{\frac{0}{\pi}}$ & 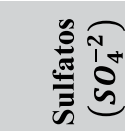 & & $\stackrel{a}{\grave{z}}$ & \\
\hline C- 01 & $0.141 \%$ & $\begin{array}{l}1408 \\
\text { ppm }\end{array}$ & $0.058 \%$ & $\begin{array}{c}577.3 \\
\mathrm{ppm}\end{array}$ & $0.072 \%$ & $\begin{array}{l}718.1 \\
\mathrm{ppm}\end{array}$ \\
\hline C- 02 & $0.669 \%$ & $\begin{array}{l}6688 \\
\mathrm{ppm}\end{array}$ & $0.274 \%$ & $\begin{array}{c}2742.1 \\
\mathrm{ppm}\end{array}$ & $0.341 \%$ & $\begin{array}{c}3410.9 \\
\text { ppm }\end{array}$ \\
\hline $\mathrm{C}-03$ & $0.046 \%$ & $\begin{array}{c}457.6 \\
\mathrm{ppm}\end{array}$ & $0.019 \%$ & $\begin{array}{c}187.6 \\
\mathrm{ppm}\end{array}$ & $0.023 \%$ & $\begin{array}{r}233.1 \\
\mathrm{ppm}\end{array}$ \\
\hline C-04 & $0.385 \%$ & $\begin{array}{c}3846.4 \\
\mathrm{ppm}\end{array}$ & $0.158 \%$ & $\begin{array}{l}1577 \\
\mathrm{ppm}\end{array}$ & $0.196 \%$ & $\begin{array}{c}1961.7 \\
\mathrm{ppm}\end{array}$ \\
\hline C- 05 & $0.121 \%$ & $\begin{array}{c}1213.4 \\
\mathrm{ppm}\end{array}$ & $0.050 \%$ & $\begin{array}{c}497.5 \\
\mathrm{ppm}\end{array}$ & $0.062 \%$ & $\begin{array}{c}618.8 \\
\mathrm{ppm}\end{array}$ \\
\hline C-06 & $0.093 \%$ & $\begin{array}{c}928.6 \\
\text { ppm }\end{array}$ & $0.038 \%$ & $\begin{array}{c}380.7 \\
\mathrm{ppm}\end{array}$ & $0.047 \%$ & $\begin{array}{r}473.6 \\
\mathrm{ppm}\end{array}$ \\
\hline
\end{tabular}

\section{Cálculo de la capacidad de carga}

El fin de este estudio se basó en la información recopilada de los ensayos de laboratorio del suelo. La capacidad portante para las 6 calicatas se calculó a través de la Teoría de capacidad de carga de Terzaghi y Peck (1967), con los factores de carga propuestos por Vesic (1973) y la expresión de Meyerhof(1963).

De esta forma, se obtuvo:

En la calicata 1, la capacidad portante para una cimentación corrida de $0.5 \mathrm{~m}$ de ancho cimentada a una profundidad de 0.8 a $1.5 \mathrm{~m}$ varía de $0.65 \mathrm{a}$ $1.08 \mathrm{~kg} / \mathrm{cm}^{2}$, para una cimentación cuadrada de 1 $\mathrm{m}$ de ancho cimentada a una profundidad de $1 \mathrm{a}$ $2.5 \mathrm{~m}$ varía de 1.07 a $2.40 \mathrm{~kg} / \mathrm{cm}^{2}$, para una cimentación rectangular de $1.2 \mathrm{~m}$ de ancho y 1.4 de largo cimentada a una profundidad de 1 a $2.5 \mathrm{~m}$ varía de 1.08 a $2.36 \mathrm{~kg} / \mathrm{cm}^{2}$.

En la calicata 2, la capacidad portante para una cimentación corrida de $0.5 \mathrm{~m}$ de ancho cimentada a una profundidad de 0.8 a $1.5 \mathrm{~m}$ varía de $0.84 \mathrm{a}$ $1.40 \mathrm{~kg} / \mathrm{cm}^{2}$, para una cimentación cuadrada de 1 $\mathrm{m}$ de ancho cimentada a una profundidad de $1 \mathrm{a}$
$2.5 \mathrm{~m}$ varía de 1.42 a $3.18 \mathrm{~kg} / \mathrm{cm}^{2}$, para una cimentación rectangular de $1.2 \mathrm{~m}$ de ancho y 1.4 de largo cimentada a una profundidad de 1 a $2.5 \mathrm{~m}$ varía de 1.44 a $3.12 \mathrm{~kg} / \mathrm{cm}^{2}$.

En la calicata 3, la capacidad portante para una cimentación corrida de $0.5 \mathrm{~m}$ de ancho cimentada a una profundidad de 0.8 a $1.5 \mathrm{~m}$ varía de 0.84 a $1.39 \mathrm{~kg} / \mathrm{cm}^{2}$, para una cimentación cuadrada de 1 $\mathrm{m}$ de ancho cimentada a una profundidad de 1 a $2.5 \mathrm{~m}$ varía de 1.41 a $3.17 \mathrm{~kg} / \mathrm{cm}^{2}$, para una cimentación rectangular de $1.2 \mathrm{~m}$ de ancho y 1.4 de largo cimentada a una profundidad de 1 a $2 \mathrm{~m}$ varía de 1.44 a $2.55 \mathrm{~kg} / \mathrm{cm}^{2}$.

En la calicata 4, la capacidad portante para una cimentación corrida de $0.5 \mathrm{~m}$ de ancho cimentada a una profundidad de 0.8 a $1.5 \mathrm{~m}$ varía de 0.95 a $1.58 \mathrm{~kg} / \mathrm{cm}^{2}$, para una cimentación cuadrada de 1 $\mathrm{m}$ de ancho cimentada a una profundidad de 1 a 2 $\mathrm{m}$ varía de 1.63 a $2.97 \mathrm{~kg} / \mathrm{cm}^{2}$, para una cimentación rectangular de $1.2 \mathrm{~m}$ de ancho y 1.4 de largo cimentada a una profundidad de 1 a $1.5 \mathrm{~m}$ varía de 1.65 a $2.29 \mathrm{~kg} / \mathrm{cm}^{2}$.

En la calicata 5, la capacidad portante para una cimentación corrida de $0.5 \mathrm{~m}$ de ancho cimentada a una profundidad de 0.8 a $1.5 \mathrm{~m}$ varía de 0.93 a $1.54 \mathrm{~kg} / \mathrm{cm}^{2}$, para una cimentación cuadrada de 1 $\mathrm{m}$ de ancho cimentada a una profundidad de 1 a 2 $\mathrm{m}$ varía de 1.58 a $2.88 \mathrm{~kg} / \mathrm{cm}^{2}$, para una cimentación rectangular de $1.2 \mathrm{~m}$ de ancho y 1.4 de largo cimentada a una profundidad de 1 a $1.5 \mathrm{~m}$ varía de $1.61 \mathrm{a} 2.23 \mathrm{~kg} / \mathrm{cm}^{2}$.

En la calicata 6, la capacidad portante para una cimentación corrida de $0.5 \mathrm{~m}$ de ancho cimentada a una profundidad de 0.8 a $1.5 \mathrm{~m}$ varía de 1.06 a $1.74 \mathrm{~kg} / \mathrm{cm}^{2}$, para una cimentación cuadrada de 1 $\mathrm{m}$ de ancho cimentada a una profundidad de $1 \mathrm{a}$ $1.5 \mathrm{~m}$ varía de 1.81 a $2.55 \mathrm{~kg} / \mathrm{cm}^{2}$, para una cimentación rectangular de $1.2 \mathrm{~m}$ de ancho y 1.4 de largo cimentada a una profundidad de 1 a $1.5 \mathrm{~m}$ varía de 1.84 a $2.54 \mathrm{~kg} / \mathrm{cm}^{2}$.

Asimismo, se halló la capacidad portante para los ángulos de fricción obtenidos por el triaxial, siendo hallados con la Teoría de Meyerhof para la falla general y localizada.

En la calicata 2, se obtuvo una capacidad portante por falla local para una cimentación cuadrada de 1 $\mathrm{m}$ de ancho cimentada a una profundidad de 1.5 $\mathrm{m}$, siendo para el ángulo obtenido por el triaxial $1.63 \mathrm{~kg} / \mathrm{cm}^{2}$ y por el corte directo $2.25 \mathrm{~kg} / \mathrm{cm}^{2}$. 
En la calicata 3, se obtuvo una capacidad portante por falla local para una cimentación cuadrada de 1 $\mathrm{m}$ de ancho cimentada a una profundidad de $1.5 \mathrm{~m}$, siendo para el ángulo obtenido por el triaxial 1.53 $\mathrm{kg} / \mathrm{cm}^{2}$ y por el corte directo $2.24 \mathrm{~kg} / \mathrm{cm}^{2}$.

En la calicata 5, se obtuvo una capacidad portante por falla local para una cimentación cuadrada de 1 $\mathrm{m}$ de ancho cimentada a una profundidad de $1.5 \mathrm{~m}$, siendo para el ángulo obtenido por el triaxial 1.80 $\mathrm{kg} / \mathrm{cm}^{2}$ y por el corte directo $2.52 \mathrm{~kg} / \mathrm{cm}^{2}$.

Para las capacidades portantes mencionadas anteriormente los asentamientos calculados, los cuales se encuentran por debajo del valor límite recomendado de $2.54 \mathrm{~cm}$ para cada una de las calicatas.

\section{DISCUSIÓN}

Los resultados de la presente investigación fueron obtenidos a través de los ensayos de laboratorio de mecánica de suelos, y los métodos geofísicos de refracción sísmica y MASW, quedando registros de este estudio por medio de fotografías, además de resultados de los ensayos de mecánicas suelo y geofísicos. Los resultados obtenidos del área de estudio nos otorgan los datos para poder dar un diseño de cimentación adecuado para esta zona.

De este modo, los resultados obtenidos solo podrán ser aplicados a esta zona, pero la metodología del estudio puede ser aplicado a otras investigaciones, debido que los ensayos geofísicos y ensayos de laboratorio pueden encontrar las verdaderas propiedades del suelo (tanto dinámicas, físicas, químicas y mecánicas). Dentro de las limitaciones que existieron en el desarrollo de esta investigación, se puede citar a tres, considerando las más importantes: Transporte de material, remoldeo del material y tiempo de ejecución de los ensayos de laboratorio.

La primera corresponde a que los ensayos básicos y especiales de laboratorio fueron analizados en la Universidad Nacional del Altiplano, situada en la ciudad de Puno, siendo transportado casi $300 \mathrm{~kg}$ de material de las 6 calicatas, realizadas en la zona de estudio ubicada en la ciudad de Tacna.

La segunda se ocasionó debido a que el suelo es conformado por grava mal graduada, de este modo la muestra no pudo ser extraída de forma inalterada, siendo remodelada en el laboratorio para la realización de los ensayos especiales.

La tercera, debido a la cantidad de material a ser analizado y cambio de personal en el laboratorio, lo que ocasionó un retraso en la entrega de resultados.

Dentro de los resultados obtenidos, es importante resaltar que la mayoría de ellos son similares a investigaciones anteriores, desarrolladas en el distrito de Gregorio Albarracín Lanchipa. Comparando los resultados con el estudio realizado por INDECI (2004), la similitud está basada en la capacidad portante que se espera que sea mayor a $3 \mathrm{~kg} / \mathrm{cm}^{2}$. Se halló en nuestro estudio una capacidad portante para la profundidad $1.2 \mathrm{y}$ una zapata cuadrada de $1 \mathrm{~m} \times 1 \mathrm{~m}$ de $4.17 \mathrm{~kg} / \mathrm{cm}^{2}$ para ser comparada con dicho estudio.

De esta manera, se obtuvo una diferencia de resultados en la exposición a los sulfatos. Según INDECI (2004) propuso un valor máximo de $0.0498 \%$, siendo éste una exposición despreciable, lo cual no coincide con los valores obtenidos en la calicata 2 y 4 , donde se muestra una exposición severa de acuerdo a la norma NTE E- 0.60 , siendo el valor más alto de $0.272421 \%$, el cual es casi 6 veces mayor que el dato otorgado por INDECI (2004).

Según la clasificación del suelo que se realizó en la zona de estudio por INDECI (2004) lo clasifico como un GW (grava bien graduada), mientras que con la presente investigación se obtuvo una clasificación de GP (grava pobremente graduada).

En los resultados de agresividad por sales, según Vargas (2017), la similitud se basa en la agresividad por sales, por ello, da recomendaciones para la protección de las viviendas ante este problema. En nuestro estudio se halla una agresividad de sulfatos muy alta de $0.272421 \%$. Comparando los resultados obtenidos de capacidad portante por el ensayo de MASW y ensayos de corte directo (Tezcan, Ozdemir, Keceli \& Erkal, 2007).

Para la calicata 1, por el ensayo de MASW se obtiene $1.19 \mathrm{~kg} / \mathrm{cm}^{2}$ y por el método tradicional se obtiene $1.24 \mathrm{~kg} / \mathrm{cm}^{2}$.

Para la calicata 2, por el ensayo de MASW se obtiene $1.29 \mathrm{~kg} / \mathrm{cm}^{2}$ y por el método tradicional se obtiene $1.67 \mathrm{~kg} / \mathrm{cm}^{2}$.

Para la calicata 3, por el ensayo de MASW se obtiene $1.26 \mathrm{~kg} / \mathrm{cm}^{2}$ y por el método tradicional se obtiene $1.66 \mathrm{~kg} / \mathrm{cm}^{2}$. 
Para la calicata 4, por el ensayo de MASW se obtiene $1.12 \mathrm{~kg} / \mathrm{cm}^{2}$ y por el método tradicional se obtiene $1.92 \mathrm{~kg} / \mathrm{cm}^{2}$.

Para la calicata 5, por el ensayo de MASW se obtiene $1.11 \mathrm{~kg} / \mathrm{cm}^{2}$ y por el método tradicional se obtiene $1.86 \mathrm{~kg} / \mathrm{cm}^{2}$.

Para la calicata 6, por el ensayo de MASW se obtiene $1.26 \mathrm{~kg} / \mathrm{cm}^{2}$ y por el método tradicional se obtiene $2.13 \mathrm{~kg} / \mathrm{cm}^{2}$.

Llegando a la conclusión que, el método geofísico es muy conservado y el método tradicional da resultados más reales. Teniendo coherencia en la conclusión con el estudio realizado en Ecuador por Aguay y Dranichnikov (2012).

De acuerdo a los resultados obtenidos de este estudio se conoce que la amplificación sísmica que tendrá el suelo es de un S1, según la NTE E.030 (2018).

\section{CONCLUSIÓN}

Los métodos geofísicos nos ayudan a conocer las propiedades dinámicas del suelo, la cual nos permite realizar un buen diseño de cimentación. De acuerdo a los resultados obtenidos del método geofísico de Refracción sísmica se puede afirmar que el área estudiada posee 3 diferentes capas de estratigrafía correspondiente a material suelto no compacto, material semicompacto representado por conglomerado y materiales semicompactos con mayor densidad. Eel terreno posee velocidades de onda $\mathrm{Vp}$ variante desde 300 a 2 $000 \mathrm{~m} / \mathrm{s}$. De la misma manera, con los resultados obtenidos del método de MASW se conoce que el tipo de suelo del área estudiada es un $\mathrm{S}_{1}$ correspondiente a suelos muy rígidos; con un $\mathrm{V}_{\mathrm{S30}}$ (promedio) de $652.86 \mathrm{~m} / \mathrm{s}$ y un $\mathrm{T}_{\mathrm{s}}$ (promedio) de 0.18 .

De acuerdo a los resultados obtenidos de la realización de los ensayos de laboratorio se confirmó que el suelo del área estudiada se clasifica como grava pobremente graduada (GP), el cual no presenta límite líquido ni límite plástico, con una densidad In situ que varía de 2.050 a 2.163 De esta manera se obtuvo el ángulo de fricción que varía de $32.47^{\circ}$ a $37.8^{\circ}$, de igual forma se halló tres ángulos de fricción mediante el Ensayo de Compresión Triaxial de las calicatas 2, 3 y 5 , siendo correspondientemente $32.47^{\circ}$, $31.78^{\circ}$ y $33.76^{\circ}$. Se reconoció también que presenta niveles altos de sulfatos que varían de 0.01876 a $0.27421 \mathrm{v} \%$.

Mediante los métodos geofísicos se determinaron las propiedades dinámicas del área evaluada conociendo así el módulo de Poison (v) que varía de 0.41 a 0.46 , el módulo de Young (E) que varía de 1364.28 a $4069.13 \mathrm{MPa}$, un módulo de Rigidez(G) que varía de 466.85 a $1438.80 \mathrm{MPa}$ y un módulo de BULK (K)que varía de 5853.71 a $7892.67 \mathrm{Mpa}$.

Mediante la realización de los ensayos se concluyó que es un buen suelo, apto para construcciones y que no fallaría rápidamente, siendo su capacidad portante para una cimentación cuadrada de $1 \mathrm{~m}$. cimentada a una profundidad de $1.5 \mathrm{~m}$. que varía de 1.51 a 2.55 $\mathrm{kg} / \mathrm{cm}^{2}$

\section{REFERENCIAS BIBLIOGRÁFICAS}

ASTM D 1556 (1996). Standard Test Method for density and unit weight of soil in place by the sand-cone method. USA: American Society for Testing and Materials.

Aguay, H. y Dranichnikov, T. (2012). Cálculo de capacidad portante basado en geofisica y método convencional: El caso del puente sobre el río Maicito. Ecuador: Universidad Politécnica Salesiana.

Hayashi, K. (2008). Development of the Surfacewave Methods and Its Application to Site Investigations (Thesis or Dissertation). Kyoto University, Japón.

Huanacuni, D. y Llanqui, G. (2014). Caracterización dinámica de los suelos de la ciudad de Tacna (tesis de pregrado). Universidad Privada de Tacna, Tacna, Perú.

IBC. (2012). International Building Code.USA: International Code Council.

INDECI. (2004). Mapa de peligros de la ciudad de Tacna: distritos de Tacna, Gregorio Albarracín, Pocollay y Complemento Alto de la Alianza y Ciudad Nueva. Volumen I-Memoria, Tacna.

Meyerhof, G. (1963). Some Recent Research on the Bearing Capacity of Foundations The ultimate bearing capacity of foundations. Canadian Geotechnical Journal, 1, 16-26.

NTP 339.143 (1999). Método de ensayo estándar 
para la densidad y peso unitario del suelo in-situ mediante el método del cono de arena. Lima, Perú:Comisión de Reglamentos Técnicos y Comerciales

NTE E.030 (2018). Diseño sismorresistente. Lima, Perú: Diario Oficial El Peruano.

NTE E.050 (2018). Suelos y Cimentaciones. Lima, Perú: Diario Oficial El Peruano.

Park, C., Miller, R., \& Xia, J. (1999). Multichannel analysis of surface waves (MASW): Geophysics, 64(3), 800-808.

Park, C., Miller, R., Xia, J., \& Ivanov, J. (2007). Multichannel analysis of surface waves (MASW)- active and passive methods: $T h e \quad L e a d i n g \quad E d g e$. Recuperado de http://www.masw.com /files/PAR-07-A.PDF

Rivera, M., Piedra, R., y Paripanca, Y. (2016). Ensayos Geofísicos de Refracción Sísmica y de Medición de Ondas de Corte (MASW y MAM) para usos de cimentación en obras de edificaciones. Civilizate-CIV. 8, 50-55 Recuperado de http://revistas.pucp.edu.pe/index.ph $\mathrm{p} /$ civilizate/article/view/18630

Rodríguez, M. (2001). Geofisica aplicada a la obra civil: Método geoeléctrico y sísmica de refracción. Recuperado de http://www.geoconsult.es

Rosales, C. (2001). Sobre el comportamiento sísmico de los depósitos de suelos del área de Cañaveralejo, Cali, Colombia (tesis de pregrado). Universidad del Valle, Santiago de Cali, Colombia.

Terzaghi, K. \& Peck, R. (1967). Soil Mechanics in Engineering Practice (Second ed.). New York: John Wiley \& Sons, Inc.

Tezcan, S., Ozdemir, Z., Keceli, A. \& Erkal, A. (octubre, 2007). A Rapid Technique to Determine Allowable Bearing Ressure.International Earthquake symposium Kocaeli. Simposio llevado a cabo en el Kocaeli Metropolitan Municipality Convention, Turquia.

Vara, A. (2017). Desde la idea a la sustentación :7 pasos para una tesis exitosa. Lima: Universidad de San Martin de Porres.

Vargas, G. (2017). Diagnóstico, prevención y reparación en viviendas de albañilería con problemas de humedad en el distrito Gregorio Albarracín Lanchipaprovincia Tacna-departamento Tacna (tesis de pregrado). Universidad Privada de Tacna, Tacna, Perú.

Vesic, A. (1973). Analysis of ultimate loads of shallow foundations. Journal of the Soil Mechanics and Foundations Division, 99, 45-73. Recuperado de https://cedb.asce.org/CEDBsearch/rec ord.jsp? dockey $=0020165$ 


\title{
ARTÍCULO INFORMATIVO
}

\section{El valor de la gestión de corrosión en la gestión de activos Un diagnóstico para el desarrollo competitivo de la Industria de Control de Corrosión}

\author{
The Value of Corrosion Management in Asset Management \\ A diagnosis for the competitive development of the Corrosion Control Industry \\ ${ }^{1}$ Abel De la Cruz Pérez
}

\section{RESUMEN}

En los últimos años, la industria de control de corrosión e integridad de activos y en particular el sector de uso y aplicación de pinturas y recubrimientos de protección (constituida por las empresas proveedoras de productos, maquinaria, equipos y servicios, así como por las empresas contratistas de aplicación técnica, empresas de asesoría y consultoría, entre otras) vienen atravesando una disminución en sus ingresos de ventas y un decrecimiento de sus niveles de rentabilidad. Por ello, se ha visto necesario realizar un análisis del comportamiento del mercado sobre la base de información, experiencias y prácticas de aplicación de la tecnología y gestión de la corrosión en la gestión de activos de los diferentes países de la región en los últimos veinte años. Esto, con la finalidad de determinar los factores causa raíz que han impedido el crecimiento y desarrollo tecnológico del Control de Corrosión en los países de nuestra región. Se han planteado las acciones matrices inmediatas y el reto que deberá asumir la nueva generación de profesionales, empresas e instituciones relacionados e involucradas en la industria. Todo ello, a fin de hacer frente al fenómeno de destrucción de materiales (lo más perjudicial de la integridad de los activos) y disminuir las grandes pérdidas económicas, cuidar del medio ambiente y proteger la vida y la salud de las personas.

Palabras Clave: Activos, corrosión, integridad, pinturas, recubrimiento.

\section{ABSTRACT}

In recent years, the industry of corrosion control and integrity of assets and in particular the sector of use and application of paints and protective coatings (constituted by the suppliers of products, machinery, equipment and services, as well as by contractors of technical application, advisory and consulting companies, among others) are going through a decrease in their sales revenues and a decrease in their levels of profitability. Therefore, it has been necessary to perform an analysis of market behavior based on information, experiences and practices of application of technology and corrosion control in the asset management of different countries in the region in the last twenty years. This, in order to determine the root cause factors that have impeded the growth and technological development of Corrosion Control in the countries of our region. The immediate matrix actions and the challenge that the new generation of professionals, companies and institutions related and involved in the industry have to face have been considered. All this, in order to deal with the phenomenon of destruction of materials (the most damaging of the integrity of assets), reduce the large economic losses, take care of the environment and protect people's life and health.

Keywords: Assets, corrosion, integrity, coatings, paints. 


\section{INTRODUCCIÓN}

El 2018 ha sido un año donde los niveles de la producción nacional, en la industria de los recubrimientos de protección, no se han podido recuperar de anteriores depresiones. Por otro lado, las empresas fabricantes de pinturas industriales han sido afectadas en sus ingresos de ventas y en sus niveles de rentabilidad. Por ello, se consideró oportuno plantear y enfocar con pensamiento crítico algunas causas raíz que puedan servir como insumo para la generación de estrategias de ventas, de mercado y tecnológicas, a corto, mediano y largo plazo. Esto, a fin de emprender el franco crecimiento de la industria del control de corrosión en general, así como el desarrollo tecnológico de la protección anticorrosiva de superficies con recubrimientos en el Perú, siendo una problemática común que enfrentan varios países de Latinoamérica.

\section{DESARROLLOTEMÁTICO}

Anualmente, las empresas observan, en sus proyecciones y presupuestos, las posibilidades de cumplir con las metas de ventas en el mercado basándose en las inversiones de obras de nueva construcción (en miles de metros cuadrados de superficie en proyectos de fabricación metálica) y en programas de gestión de mantenimiento anticorrosivo de infraestructura ya existente, dado los millones de metros cuadrados de superficie con pintura envejecida expuesta que ya ha cumplido su ciclo de vida útil, pero desafortunadamente no existe práctica de mantenimiento anticorrosivo. Efectivamente, algunas empresas se verán favorecidas con la demanda de productos y servicios y otras no, sin embargo, podemos comprobar que en cifras globales, los consumos per cápita de recubrimientos (pinturas y galvanizado) de las últimas dos décadas en la mayoría de los países de Sudamérica se mantienen constantes y en algunos han disminuido (Tabla 1), afectándose además la rentabilidad y el desarrollo tecnológico, haciéndose notoria la baja capacidad de consumo de recubrimientos en el mercado de control de corrosión en los países de la región.
Tabla 1: Estadísticas por países en Sudamérica comparativamente con Norte América

\begin{tabular}{|c|c|c|c|}
\hline \multirow{2}{*}{$\begin{array}{l}\text { País } \\
\text { Argentina }\end{array}$} & \multicolumn{2}{|c|}{$\begin{array}{l}\text { Consumo de pinturas/ } \\
\text { Habitante (Litros) }\end{array}$} & $\begin{array}{l}\text { Consumo de } \\
\text { Galvanizado/ } \\
\text { Habitante }(\mathrm{Kg})\end{array}$ \\
\hline & $5.60(25$ & $\%$ Industrial) & 1.3 \\
\hline Bolivia & $1.18(25$ & $\%$ Industrial) & ------ \\
\hline Brasil & $8.00(25$ & $\%$ Industrial) & 1.3 \\
\hline Chile & $4.50(25$ & $\%$ Industrial) & 7.7 \\
\hline Colombia & $2.21(25$ & $\%$ Industrial) & 1.2 \\
\hline Ecuador & $3.00(25$ & $\%$ Industrial) & 2.9 \\
\hline Perú & $1.82(25$ & $\%$ Industrial) & 1.1 \\
\hline Paraguay & $2.00(15$ & $\%$ Industrial) & ----- \\
\hline Uruguay & $4.50(15$ & $\%$ Industrial) & ----- \\
\hline México & $6.50(40$ & $\%$ Industrial) & 1.3 \\
\hline E EUU & $20.0(40$ & $\%$ Industrial) & 14.0 \\
\hline
\end{tabular}

Fuente: Latinpin; y James Consulting (Abrafati) (2013)

Es por demás conocido, en especial por los especialistas, que la "corrosión es una enorme carga financiera y que invertir en el control adecuado de su prevención puede ayudar a ahorrar miles de millones de dólares a largo plazo" y también que las consecuencias siguen siendo catastróficas, afectando el medioambiente y en muchos casos la vida, la salud y la seguridad de las personas.

Más aún, en el Perú conocemos hace cuatro décadas, a través estudios realizados en otros países como EEUU, que los costos directos totales ascienden a US \$276,000 millones de dólares (3.1 $\%$ de su PBI). Cifras que han sido utilizadas por los países en Latinoamérica para intentar alarmar la conciencia de las personas sobre este fenómeno.

Recientemente, el estudio IMPACT realizado por NACE international (2016) nos da a conocer que el costo global o mundial de la corrosión se estima en US \$2,505 mil millones, lo que equivale al 3.4 $\%$ del PIB mundial (2013). Además, nos añade un dato sumamente alentador, que entre el $15 \%$ y el $35 \%$ del costo de la corrosión se podría ahorrar mediante el uso de las actuales prácticas de 
control de corrosión disponibles. Es decir, lograr un ahorro entre US \$ 375 y \$ 875 mil millones a nivel mundial.

Por ello, se plantean algunas preguntas: ¿Cuánto nos ha ayudado la difusión y el conocimiento de estas cifras extranjeras a los países de nuestra región como impulsores de una lucha contra la corrosión?

¿Se ha evaluado el Impacto Económico de la corrosión en los países de nuestra región?

¿Cómo han afectado los costos por corrosión a la rentabilidad de las empresas?

¿Se evalúa y cuantifica el ahorro de costos generado en la prevención de corrosión al aplicar una nueva Tecnología o una Tecnología Optimizada?

Ignorar estas preguntas y sus respuestas, no permite a los propietarios, administradores $\mathrm{u}$ operadores de los activos de alto valor conocer el efecto catastrófico de los costos de la corrosión.

Porque el hecho que, en los países de esta región se utilice la información del exterior, no ha ayudado a sentir y tomar conciencia de los graves daños que causa en la economía. Tampoco a sentir las consecuencias negativas del impacto en nuestro entorno y los altos niveles de riesgos e inseguridad a la que estamos expuestos en nuestras propias plantas, edificaciones e instalaciones industriales, comerciales y de servicios. Ello debido a que son cifras que no han salido de nuestra realidad y esto continuará hasta que, en los países de nuestra región y por nuestros propios medios, se consigne de forma veraz la información por empresas y por sectores industriales y se cuantifique las consecuencias. Solo a partir de ello, podremos tomar la verdadera conciencia del valor que aporta la protección contra la corrosión y la conservación de la integridad de sus activos en toda su dimensión.

Tampoco es práctica común en los países de esta región, evaluar el efecto en la productividad, calidad y rentabilidad de un Proyecto de Protección Anticorrosiva con la aplicación de nuevas tecnologías, sobre la base de extender la durabilidad del sistema de protección (concepto central de calidad de los recubrimientos). Acaso ¿debemos resignarnos a asumir las pérdidas que genera la corrosión, consignándolas en nuestros presupuestos anuales como "gastos" y simplemente ejecutarlos? Tengamos en cuenta una de las reglas de la calidad: "Lo que no se puede MEDIR no se puede CONTROLAR y lo que no se puede CONTROLAR no se puede MEJORAR" (E. Deming).

¿Cómo podremos asignar una partida de inversión para la implementación de una nueva tecnología o capacitar y entrenar ingenieros en corrosión, o en la adquisición de mejores equipos o elaborar especificaciones confiables con expectativas de durabilidad o implementar un Sistema de gestión de calidad integral en lugar de hacer solo inspección de pintado?; ¿Cómo nos podemos plantear metas de reducción de gastos anuales en control de corrosión sin parámetros de referencia "de cuanto perdemos anualmente" como base de cálculo?, ¿Cómo se van a financiar proyectos de investigación y desarrollo, sino cuantificamos el impacto negativo de las pérdidas? Debemos tener en consideración que, si los proyectos de Protección Anticorrosiva son inversiones, entonces necesitamos medir los resultados alcanzados para determinar la eficiencia en el uso de los recursos y la rentabilidad del proyecto.

Como conclusión de esta primera parte del diagnóstico, la Asociación Peruana de Profesionales en Control de Corrosión (APECORR) ha planteado la participación de las entidades representativas del gobierno relacionadas a la Industria, Construcción, Energía, Transporte, Medio Ambiente, etc., junto a las instituciones profesionales como el Colegio de Ingenieros, universidades públicas y privadas, etc., empresas del sector público y privado de las diferentes ramas de la industria, proveedores de productos y servicios para el control de corrosión, para que participen en un proyecto conjunto a fin de llevar a cabo un "estudio" para la identificación y evaluación de los costos de la corrosión, como un primer gran paso para enfrentar este fenómeno mundial. Con información propia y cuantificada, por sectores industriales, el mercado reconocería el "valor que aporta la gestión del control de corrosión" (productos, servicios, M.O., tecnología, capacitación, $\mathrm{I}+\mathrm{D}+\mathrm{i}$, maquinaria, equipamiento, asesoría, consultoría, capacitación profesional, etc.), responsabilidad fundamental dentro de la gestión de integridad de activos y como resultado se iniciaría un verdadero desarrollo de una industria competitiva (con productividad, calidad y seguridad), rentable, con demanda de calidad y en vías de crecimiento sostenido en el tiempo.

En segundo término, es conocido en la industria que la tecnología de mayor uso para el control de corrosión consiste en la aplicación de 
recubrimientos de protección, puesto que el $90 \%$ del área superficial de la infraestructura metálica productiva, de servicios y comercial expuesta a la agresividad atmosférica ( $80 \%$ ) y en inmersión o enterrada (10\%) se encuentran protegidas con recubrimientos. Sin embargo, esta práctica y el voluminoso uso de las pinturas, contrasta con el bajo desarrollo y evolución de esta industria, puesto que, debido a los resultados de baja durabilidad y fallas tempranas del recubrimiento antes de cumplir su tiempo de vida en servicio para el que ha sido diseñado y formulado, no se llega a demostrar la verdadera dimensión de su calidad (capacidad de durabilidad). Con mayor razón, no lo podremos evidenciar, si no se ha planificado un monitoreo de su comportamiento en el tiempo mediante inspecciones periódicas del estado de integridad del sistema de pinturas en servicio, de tal manera que nos permita planear un oportuno programa de mantenimiento anticorrosivo preventivo.

Si bien es cierto, la ciencia química orgánica e inorgánica aplicada a la fabricación de pinturas, que evoluciona a velocidades notables nos ha permitido el extraordinario desarrollo de nuevos recubrimientos con alta resistencia al medio que lo rodea (Poli aspárticos, Novolacas Epoxi curado con aminas ciclo alifáticas, Novolacas vinil éster, poli siloxanos epoxi, etc.), esto no se ha visto reflejado en la práctica, en una buena performance o durabilidad de los recubrimientos, puesto que el desempeño de una pintura dependerá también de la eficiencia y calidad de la "tecnología de preparación de superficie y aplicación de recubrimientos".

Un segundo factor clave para elevar la competitividad de la industria es entender lo siguiente: Hoy en día, lo que debería ser un "trabajo de protección anticorrosiva" es realizado como un "trabajo de pintado", operación que es definida en los manuales (que no le hace ningún mérito al tratamiento de superficies) como: «Preparar y limpiar el substrato y transferir el material desde un recipiente primario a la superficie a ser protegida y entonces deberá formar una película cohesiva con las propiedades deseadas».

Es evidente que, una definición de "trabajo de pintado" de esta naturaleza se ha resumido y enfocado por años en tres tareas u operaciones: a) Preparación de superficie

b) Aplicación de pintura

c) Inspección de pintado

Operaciones, que durante años han sido el enfoque y la forma de estudiar la tecnología de la aplicación de pinturas, con mayor o menor grado tecnológico en una u otra de estas operaciones. Tal es el caso de la preparación de superficie que en los países de la región es la que menos ha evolucionado (en términos de calidad, productividad y seguridad) y que se realiza en escasas condiciones de trabajo y con falta de capacitación. Así lo demuestran estadísticas que repiten en conferencias, cursos, manuales de fabricantes de pinturas y proveedores de máquinas y equipos, etc. desde el año 1980 a la fecha. Actualmente, se continúa mencionando que, aproximadamente el $80 \%$ de las fallas de los recubrimientos son causadas por una deficiente preparación de superficie y aplicación de pintura. Lo que cabe preguntar, ¿cuánto se ha desarrollado, tecnológicamente, la preparación de superficie y la aplicación de pinturas en 39 años?

En este escenario, ¿tendrá sentido desarrollar y presentar al mercado nuevas formulaciones y desarrollos de pinturas, si aún no sabemos aplicar pinturas cuyas formulaciones tienen más de 2 décadas de existencia?, ¿cuánto hemos aportado los tecnólogos o especialistas en incrementar la durabilidad o desempeño de las pinturas, utilizando y aplicando la tecnología existente en la preparación de superficie y en la aplicación de las pinturas? ¿por qué nos hemos limitado a hacer mediciones o test para conocer si cumple o no con el valor estándar establecido (espesor de película, rugosidad, condiciones ambientales, medición de adhesión, etc.) a fin de dar conformidad o rechazar una superficie tratada y pasar a ser corregida, en lugar de profundizar la implementación de un Sistema de gestión de calidad en el proyecto de protección con recubrimientos? ¿por qué nos hemos enfocado en hacer test o mediciones al producto (área tratada) solo para detectar desviaciones y corregirlas o rechazarlas (QC), en lugar de evaluar, monitorear y estandarizar el proceso, para prevenir que no ocurran los defectos o desviaciones (QA)?

En consecuencia, el enfoque moderno de la gestión de corrosión con recubrimientos dentro de la gestión de integridad de activos nos lleva a plantear un cambio. En lugar de nombrar al Tratamiento Anticorrosivo de superficies como 
"planes de pintado", los que se perciben desafortunadamente con las siguientes características:

- El pintado se ve como gasto y no como inversión.

- Se cubre la superficie sin expectativa de durabilidad.

- Donde aplicar, medir y cumplir con el espesor de película seca es lo más importante.

- Donde el color, apariencia, textura se consideran factores de calidad.

- No se ve como protección anticorrosiva con expectativa de durabilidad y protección de la integridad del acero.

- Donde el área financiera la interpreta como estética y puede ser postergada.

Debemos definir al Tratamiento Tecnológico como "gestión de corrosión con recubrimientos", puesto que esta definición:

- Si responde a un buen planeamiento y organización para la conservación e integridad de sus instalaciones, lo que en términos económicos consideraremos como un buen mantenimiento de las inversiones.

- Donde el tratamiento de superficies es un proceso tecnológico en cadena, constituido por operaciones que se integran hacia el objetivo principal, que es proteger y conservar la integridad de los activos, haciendo que la inversión tanto en infraestructura como en el tratamiento anticorrosivo sea rentable.

La gestión de corrosión mediante diferentes métodos, entre ellos los recubrimientos como parte del sistema de gestión de integridad de activos, toma una nueva dimensión y hace frente a las amenazas que atacan su integridad, implementando medidas para administrar los riesgos, priorizando la seguridad de las personas, el medio ambiente e infraestructura. Generando el ahorro de costos y la disminución de las pérdidas económicas por fallas. Solo así, podemos contar con un presupuesto de inversión y no de gastos cuando se desarrolle un proyecto de protección anticorrosiva.

La gestión del control de corrosión con recubrimientos adquiere una nueva dimensión tecnológica en los proyectos de protección, conservación e integridad de activos, puesto que:

1. Se extiende la durabilidad del sistema de pinturas.
2. Incrementa años de vida en servicio (integridad) a la infraestructura productiva (activos).

3. Incrementa la seguridad operativa, la vida, la salud de las personas y el cuidado del medio ambiente.

4. Reduce drásticamente el gasto del mantenimiento futuro, puesto que alargamos el intervalo de reparación de la pintura.

La Planificación de la gestión de control de corrosión con recubrimientos en un proyecto de protección anticorrosiva se describe de la siguiente forma:

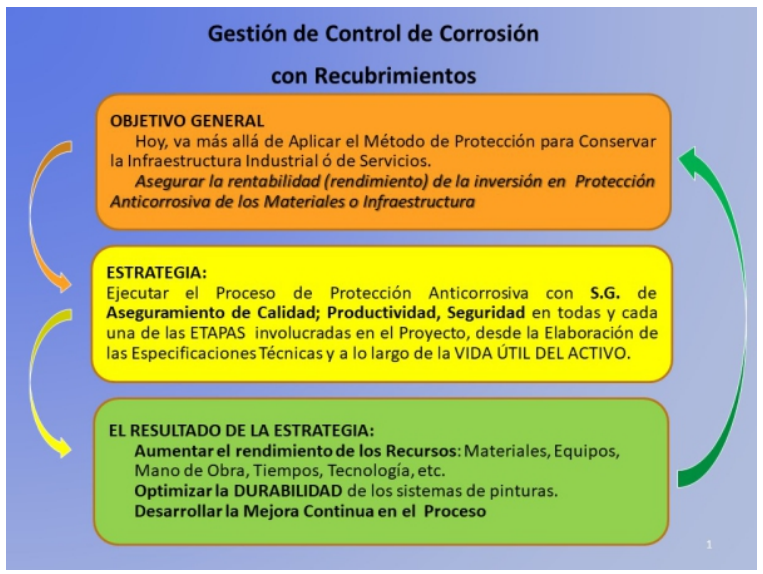

Figura 1. Planificación de la gestión de control de corrosión.

En consecuencia, con la finalidad de alcanzar los objetivos y aplicar las estrategias a lo largo de la ejecución del proyecto, transformamos el concepto de "aplicación de pinturas" en un proceso tecnológico de cinco etapas:

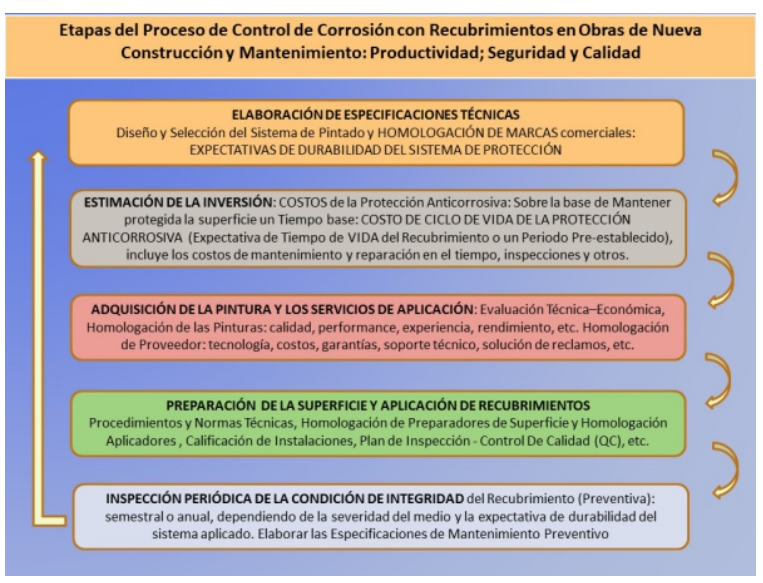

Figura 2. Etapas del proceso de control de corrosión de recubrimientos. 
Ejerciendo en todas y cada una de las etapas del proceso, la gestión de aseguramiento de la calidad, de productividad y seguridad, tal como se muestra a continuación:

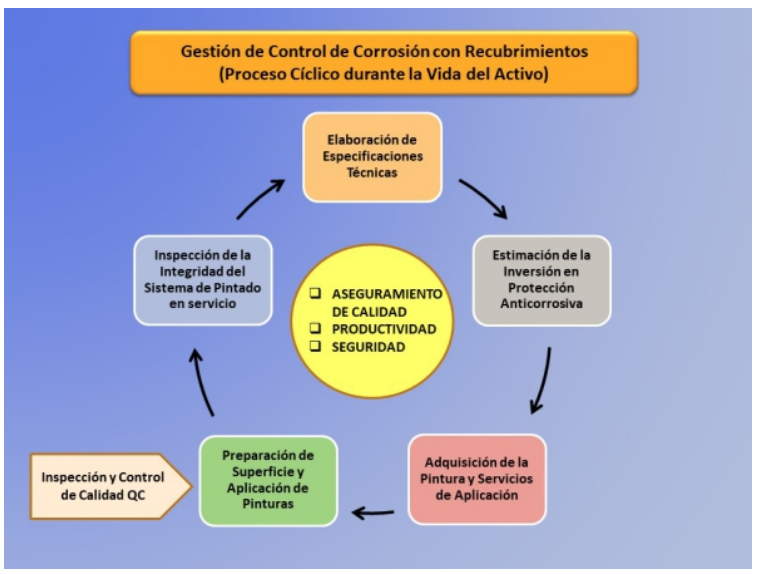

Figura 3. Proceso cíclico durante la vida del activo.

Generación de valor de la gestión de corrosión con recubrimientos dentro de la gestión de activos

El enfoque está basado en un proceso cíclico e integrado y es la forma moderna de hacer frente al tratamiento anticorrosivo de superficies, centrados en la generación de valor y satisfacción de las necesidades del cliente:

A. Valor que agrega a dueños o administradores de la infraestructura

1. Se ahorrarán costos presentes en el tratamiento y se extenderá el tiempo de vida útil del recubrimiento (durabilidad), agregando años de vida a la inversión, con lo que se ahorrarán los costos en el tratamiento anticorrosivo futuro debido a la disminución de los daños y extender los intervalos de mantenimiento o reparación del recubrimiento de protección.

2. Asimismo, los dueños de la infraestructura evitarán pérdidas económicas por el deterioro o reposición de las estructuras y/o por la falla prematura de los recubrimientos.

3. Disminuirán los tiempos de parada o interrupción de la producción o servicio de la planta.

B. Valor que agrega a constructores metalmecánicos y empresas de mantenimiento anticorrosivo

1. Procesos más eficientes y ahorro de costos a valor presente en el tratamiento, mejor oferta de precios a sus clientes.
2. Reducción de reclamos y/o litigios por fallas prematuras.

3. La implementación de un sistema de gestión de control de corrosión con recubrimientos no solo beneficia a sus clientes, sino que es una ventaja competitiva frente a sus competidores.

4. Genera confiabilidad en la calidad de la protección anticorrosiva de los activos del cliente (dueño de la infraestructura).

C. Valor que agrega a fabricantes de los recubrimientos de protección

1. Incrementar el consumo per cápita de recubrimientos de calidad.

2. Introducir al mercado un servicio de asesoría técnica con valor agregado para sus clientes, que genere diferenciación y eleve la competitividad del sector del tratamiento de superficies, que vaya más allá de ofertar "productos" de bajo precio, orientado hacia la "optimización de la productividad, la calidad y la seguridad en el tratamiento de superficies con recubrimientos".

3. El trabajo de investigación y desarrollo de nuevos productos tendrá mayor percepción de valor por los clientes.

4. Demostrar la calidad (durabilidad) de sus sistemas de pinturas.

\section{Otros beneficios generales}

1. Se fomentará el crecimiento del consumo y el desarrollo tecnológico de la industria de recubrimientos de protección

2. Se promoverá una "competencia leal" entre fabricantes de pinturas y entre contratistas de aplicación de pintura, compitiendo en base al verdadero concepto de calidad de una pintura de protección: la durabilidad del tratamiento anticorrosivo y la conservación de la integridad del activo.

3. Se promoverá la investigación y desarrollo de nuevos productos, equipos, procesos o servicios reduciendo los riesgos de seguridad, cuidado del medio ambiente y mejorando la competitividad de las empresas del sector.

4. Se incentivará y valorará la contratación y capacitación de profesionales en ingeniería de corrosión y técnicos, orientados al desarrollo de productividad, calidad y seguridad. 


\section{CONCLUSIONES}

El verdadero crecimiento y desarrollo sostenido de una industria de integridad de activos y de control de corrosión competitiva y rentable (con productividad, calidad y seguridad) requiere de un mercado consciente del valor que aportan la prevención y el control del fenómeno de la corrosión a la integridad de la infraestructura.

El primer paso para cuantificar las pérdidas económicas y reconocer la necesidad de la gestión de corrosión es llevar a cabo un estudio nacional para la identificación y evaluación de los costos de la corrosión en los diferentes sectores y actividades industriales, comerciales y de servicios.

La lucha contra el fenómeno mundial de la corrosión requiere de un proyecto conjunto $\mathrm{y}$ multidisciplinario, con la participación de las entidades representativas.

El desarrollo tecnológico de la gestión de control de corrosión requiere la formación profesional de ingenieros de corrosión a nivel de pregrado y postgrado, quienes asumirán el reto del liderazgo de nuestra industria nacional. Así como la creación de un Instituto de Materiales, Integridad y Corrosión para la promoción de la investigación tecnológica al servicio de la industria.
La gestión de control de corrosión con recubrimientos dentro de la gestión de integridad de activos agrega valor a los dueños o administradores de la infraestructura de las empresas industriales, comerciales y de servicios, a las empresas de servicios de construcción metal mecánica y de mantenimiento y a las empresas de fabricación de recubrimientos.

El profesional gestor en control de corrosión no presupuesta y ejecuta el gasto en la protección anticorrosiva, el gestor de control de corrosión optimiza e incrementa la rentabilidad de la inversión en prevención de la corrosión.

\section{REFERENCIAS BIBLIOGRÁFICAS}

Asociación Peruana de Profesionales en Control de Corrosión. Recuperado de naceperu.com/

James Consulting. (2013) Recuperado de http://henryjamesconsulting.com/

Asociación Nacional de Fabricantes de Pinturas y Tintas. México Recuperado de http://www.latinpin.com/inicio/?se $=1$

NACE International. (2016). Estudio IMPACT. Recuperado de http://impact.nace.org/ 



\section{NORMAS EDITORIALES Y GUÍA DE PRESENTACIÓN DE ARTÍCULOS CIENTÍFICOS PARA LA REVISTA CIENCIA \& DESARROLLO}

La Revista Científica Ciencia \& Desarrollo pone a consideración de la comunidad científica y académica, sus normas editoriales y guía de presentación de los artículos científicos, con la finalidad de lograr que la publicación de la revista sea un espacio abierto para la divulgación de nuevos conocimientos.

\section{CRITERIOS DE PUBLICACIÓN, CITACIÓN Y REPRODUCCIÓN}

1. La revista Ciencia \& Desarrollo es una publicación semestral de carácter científico tecnológico, orientada a promover y difundir la investigación en las áreas de ciencias agrarias, exactas, ingenierías y de materiales. Su publicación es impresa y virtual en idioma español.

Para la publicación en la revista Ciencia \& Desarrollo los artículos presentados deben ser inéditos y pueden ser: artículo científico original, artículo de revisión, carta al editor, artículo de opinión, artículo breve o de comunicación corta. Los artículos publicados en esta revista pueden ser citados en otros documentos, siempre y cuando se indique la siguiente información: Revista Científica Ciencia \& Desarrollo. Tacna (Perú): Universidad Nacional Jorge Basadre Grohmann, volumen, número de la revista, página(s) y año de publicación. ISSN 23048891.

Si la reproducción de artículos publicados en la revista es con fines académicos y sin ánimo de lucro, puede realizarse si se incluye la información establecida en el párrafo anterior.

Si su reproducción implica otros usos, debe solicitarse autorización escrita al Editor Jefe de la revista científica Ciencia \& Desarrollo.

La revista señala que la publicación de artículos no da derecho a remuneración alguna y que la responsabilidad del contenido de los artículos es de los autores, inclusive en lo relacionado con la propiedad intelectual de otros autores y/o fuentes.

La revista científica Ciencia \& Desarrollo recibe artículos de las áreas de ciencias agrarias, exactas, ingenierías y de materiales.

Los artículos deben ser redactados en español y el resumen en español e inglés, impresos en papel bond blanco de tamaño A4 (210 x 297mm), en una sola cara. La extensión del manuscrito no debe exceder doce (12) páginas, incluyendo bibliografía, escritas en una sola cara, con caracteres de 10 puntos en estilo Times New Roman.

La redacción de los artículos científicos se caracteriza básicamente por ser objetiva, categórica, impersonal, lógica, clara, breve, precisa, concisa, rigurosa y directa. El buen escrito científico no es reiterativo, monótono ni insustancial.

\section{TIPOS DE ARTÍCULOS}

2.1 Artículo científico original: La extensión del desarrollo no debe ser más de 12 páginas o caras. La redacción es en tercera persona.

Dado que la finalidad de un artículo científico es comunicar los resultados de investigaciones, ideas y debates de una manera clara, concisa y fidedigna, se tomará en cuenta los principios fundamentales de la redacción científica: precisión, claridad y brevedad.

Además los componentes del artículo científico deben cumplir con las siguientes características.

\section{Estructura}

Título: Debe contener en esencia el problema que está planteado, ser claro y preciso. Consta de 10 a 15 palabras, en caso de ser muy largo utilizar un subtítulo conciso. Su redacción es en mayúscula, respetando la redacción de las denominaciones de nombres científicos.

Title: Es el título traducido correctamente en idioma inglés.

Autor(es): Si el trabajo ha sido realizado en equipo, debe colocarse como primer autor, el que tuvo mayor responsabilidad en la realización del trabajo y el grado académico más alto.

Afiliación: Institución a la cual pertenecen los autores (especificar departamento o área por cada autor).

Resumen: Debe contener en forma escueta los objetivos, planteamiento del problema, materiales, métodos y 
resultados. El resumen y abstract se redactan en un promedio de 200 a 250 palabras. Se redacta en tiempo pasado. Debe ser escrito en un solo párrafo, separando las oraciones con punto seguido. Solo las palabras claves deben ir como punto aparte.

Palabras clave: No deben ser menores a dos ni mayores a cinco, ordenadas alfabéticamente.

Abstract: Es el resumen con una correcta traducción al inglés.

Key Word: Palabras clave correctamente traducidas al inglés.

Introducción: El autor debe procurar que todo trabajo forme una unidad desde el inicio hasta el final, coherente y relacionado. En esta parte se expone el problema, se informa lo que se conoce del mismo, se hará una revisión bibliográfica pertinente, se discute el objetivo general, fin principal y la hipótesis (si la hubiera).

Material y Métodos: Descripción de los recursos humanos, materiales físicos, financieros y técnico administrativos empleados; explicación detallada del método empleado, señalando las técnicas estadísticas, si se utilizaron.

Resultados: Se expondrá en forma clara siguiendo una secuencia lógica. Se exponen mediante figuras o tablas, donde se describe la información resumida que confirma o no la(s) hipótesis y objetivos específicos planteados en la investigación. Deben limitarse a describir los propios hallazgos encontrados, evitando adelantar interpretaciones o comparaciones. Se redacta en pasado.

Discusión: En esta parte el autor podrá comparar, discutir, argumentar sus resultados con el de otros autores. Tomar en cuenta que los resultados se exponen y no se recapitulan. De esta discusión se originarán puntos de partida para nuevas investigaciones. Se redacta en presente.

Conclusiones: Deberán ser redactadas en forma clara y precisa.

Agradecimiento: Incluirlos solamente si los hubiera, y solo se menciona a quienes contribuyeron con un apoyo muy importante (técnico) o las instituciones que han financiado la investigación (si fuera el caso).

Referencias bibliográficas: Deben aparecer solamente las referencias bibliográficas utilizadas por el autor en la realización de la investigación y que son mencionadas en la redacción del artículo científico. Serán presentadas en el orden correspondiente al estilo bibliográfico. Considerar que si en el artículo hay quince citas, también debe haber quince referencias bibliográficas.

2.2. Artículo de revisión: Debe contener: Título en español e inglés, Autor(es), Resumen, Palabras Clave, Abstract, Key Word, Introducción, Método utilizado para localizar y seleccionar los artículos relevantes sobre el tema, Análisis y comparación de los resultados encontrados, coincidencias y discrepancias, Conclusiones, Recomendaciones, Referencias bibliográficas.

2.3. Ensayo científico y Artículo informativo: La estructura es: Título en español o inglés, nombre y apellidos del autor(es), Resumen y palabras clave, Abstract y Key Words, Introducción, Desarrollo Temático, Conclusiones, Referencias bibliográficas.

2.4. Carta al editor: Debe contener: Título en español y en inglés, Autor y filiación institucional, Inicio mencionando la razón objetivo de la carta si fuera necesario, solo una tabla o una figura, Razón del planteamiento de la opinión, Discusión de resultados y/o recomendaciones, Referencias bibliográficas, no más de seis referencias bibliográficas, Correo electrónico.

\section{ESTILO DE PRESENTACIÓN}

Los artículos a ser publicados deberán cumplir los requisitos que a continuación se detallan:

DE LA PRESENTACIÓN: Se presentará un ejemplar impreso de un aproximado de 12 páginas y un CD. Los artículos deben ser preparados en formato MS Word utilizando la fuente Times New Roman de tamaño 10, a espacio sencillo. La primera página del artículo debe incluir: Título (español e inglés), nombre de autor (es), afiliaciones, abstract y palabras clave. Y utilizarán la misma fuente con distinto tamaño y estilo.

DEL TAMAÑO Y MÁRGENES: En tamaño A4 (210 x 297 cm). Los márgenes deben ser configurados de la siguiente manera: superior e izquierdo: $2.5 \mathrm{~cm}$, inferior y derecho: $2 \mathrm{~cm}$. No se permite agregar pie de página ni encabezados. Las referencias y la bibliografía se agregarán al finalizar el texto.

DEL TÍTULO: El título será escrito en español y en inglés en tamaño 16 y 14 respectivamente, Nombre (s) de autor (es) en tamaño 12, la afiliación o institución/área a la que pertenece, dirección y correo electrónico (tamaño 12). El título y autor (es) van en negrita. El título debe ir centrado y el autor justificado a la derecha. 
DEL RESUMEN: Resumen (Abstract) del artículo y palabras clave, español y en inglés. Cada artículo debe incluir un resumen de no más de 200 palabras en la primera página. Seguido por una lista de palabras clave. El resumen debe ser conciso y las palabras clave deben estar justificadas de ambos lados

DEL TEXTO: Estará escrito en dos columnas.

DE LAS REFERENCIAS Y CITAS: Utilizar el estilo de referencias bibliográficas acorde a su investigación. El formato de las citas y referencias bibliográficas que se utilizará será: en las ciencias de la salud (con excepción de Psicología) la norma Vancouver; y en las ciencias sociales, ciencias humanas, ciencias naturales y Psicología, la norma APA. Ejemplo de APA: Salas, J. (2010). El aprendizaje fundamentado a conferencia. Revista Odontología, 2(13), 26-34.

DE LAS SECCIONES: El título de una sección debe estar en fuente Times New Roman, tamaño 10 y en negrita, escrito con letras mayúsculas. Debe estar alineado a la izquierda a partir de la introducción, excepto las referencias bibliográficas.

DE LAS SUBDIVISIONES: El título de las subdivisiones debe estar alineado a la izquierda. La fuente a utilizar es Times New Roman, tamaño 10 y en negrita y solo las letras iniciales de cada palabra serán escritas en mayúscula.

DE LA FIGURAS O TABLAS: Podrá incluirse fotografías, gráficos, tablas o imágenes, etiquetándolos únicamente como figuras o tablas según convenga. Escrito en fuente Times New Roman, tamaño 9.

Las figuras serán identificadas con la etiqueta Figura, numeradas con números arábigos de manera consecutiva, la cual será ubicada al pie de la figura. Las figuras, deberán adjuntarse adicionalmente como archivo de imagen (jpg o png). Considerar la fuente.

Las tablas serán identificadas con la etiqueta Tabla, numeradas con números arábigos de manera consecutiva y ubicada en la cabecera de la tabla justificada a la izquierda.

Las figuras y tablas a utilizar deberán ser insertadas en el punto apropiado del texto, deben ser mencionadas en el texto al menos una vez y antes de su aparición. Considerar la fuente.

DEL IDIOMA, ESTILO Y CONTENIDO: Los artículos deben presentarse en español. El título y el resumen están inscritos en español e inglés. La ortografía y puntuación deben escribirse con estilo sencillo y directo. Utilice estructuras simples para las oraciones, así como vocabulario común y básico. Defina o explique el vocabulario técnico con sencillez. Explique acrónimos cuando aparezcan en el texto por primera vez. La presentación de unidades de medida y valores numéricos se realizará conforme al Sistema Internacional de Unidades, asimismo, debe utilizarse la coma para la separación decimal.

IMPORTANTE: Los autores son responsables de asegurarse que su trabajo sea conducido de una manera responsable y ética. La estructura y estilo son tan importantes como el contenido. Antes de escribir su artículo, le recomendamos que lea amplia literatura disponible para informarse respecto a cómo escribir un buen artículo técnico.

\section{PROCESO DE RECIBO, SELECCIÓNY EVALUACIÓN}

\subsection{Recepción de los artículos}

Los artículos se entregan en formato impreso en la Oficina del Fondo Editorial de la Universidad Nacional Jorge Basadre Grohmann sito en Ciudad Universitaria Av. Miraflores s/n, Tacna, Perú, o son enviados mediante correo electrónico a la cuenta: revistas@unjbg.edu.pe

Junto al artículo (construido en un procesador de textos y guardado en formato .doc o .docx) se envían las figuras presentadas en él, debidamente identificadas (en formato jpg o png con alta calidad), los datos de los autores debidamente diligenciados.

El formato impreso debe enviarse mediante carta de presentación acompañada del original impreso en papel, más un $\mathrm{CD}$ en formato de procesador de textos.

4.2 Proceso de selección

Para que un artículo sea admitido en la revista Ciencia \& Desarrollo debe cumplir con los parámetros de forma establecidos. 
Los autores que decidan retirar sus artículos del proceso de selección, no implica que pierdan la posibilidad de presentarlo para ediciones futuras.

En los artículos que a pesar de ser aceptados, se detecte algún tipo de plagio no serán admitidos para la impresión final.

Después de un tiempo prudencial, el Director de la Revista comunicará al autor sobre la aceptación de su artículo.

\subsection{Proceso de evaluación}

La primera evaluación está a cargo del comité editorial, sobre el cumplimiento de los requisitos formales y la adecuación al interés temático de la revista, de la cual se envía un mensaje a los autores donde se señala su resultado. En caso de corresponder al interés de la revista, se indica a los autores que aquellos aspectos a ajustar y la fecha límite para hacer la nueva entrega.

Comprobado el cumplimiento de los requisitos formales, el artículo es enviado a evaluación por parte de árbitros expertos, integrantes del Comité Científico de la revista. Este arbitraje se hace de forma confidencial (doble ciego; los árbitros desconocen los nombres de los autores y viceversa), mediante el diligenciamiento de un formato específico, que solicita su concepto sobre la conveniencia o no de su publicación, y las recomendaciones para mejoramiento del artículo. El resultado de la evaluación se informa a los autores oportunamente mediante correo electrónico, y en caso de requerirse, se indica la fecha para la entrega de los documentos ajustados, con el fin de que los árbitros emitan su concepto definitivo sobre la condición de publicable o no. 

Ciudad Universitaria - Av. Miraflores s/n Central telefónica: (051) (052) 583000 Anexos 2134-2115 viin@unjbg.edu.pe
foed@unjbg.edu.pe
revistas@unjbg.edu.pe

Tacna- Perú

http://www.unjbg.edu.pe 